\title{
INTERACTION OF SYNAPSIN I WITH VESICLES
}

\author{
By \\ Lucie Labelle, B.Sc
}

A thesis submitted to the Faculty of Graduate Studies and Research in partial fulfillment of the requirements for the degree of

Master of Science

\author{
Department of Biology \\ Ottawa-Carleton Institute of Biology \\ Carleton University \\ Ottawa, Ontario, Canada
}

(C) Lucie Labelle, Ottawa, Canada, 2010 


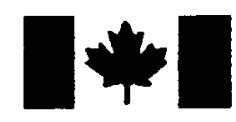

\section{Library and Archives} Canada

Published Heritage

Branch

395 Wellington Street

Ottawa ON K1A ON4

Canada
Bibliothèque et

Archives Canada

Direction du

Patrimoine de l'édition

395 , rue Wellington

Ottawa ON K1A ON4

Canada
Your file Votre référence

ISBN: 978-0-494-68618-8

Our file Notre référence

ISBN: 978-0-494-68618-8

\section{NOTICE:}

The author has granted a nonexclusive license allowing Library and Archives Canada to reproduce, publish, archive, preserve, conserve, communicate to the public by telecommunication or on the Internet, loan, distribute and sell theses worldwide, for commercial or noncommercial purposes, in microform, paper, electronic and/or any other formats.

The author retains copyright ownership and moral rights in this thesis. Neither the thesis nor substantial extracts from it may be printed or otherwise reproduced without the author's permission.
AVIS:

L'auteur a accordé une licence non exclusive permettant à la Bibliothèque et Archives Canada de reproduire, publier, archiver, sauvegarder, conserver, transmettre au public par télécommunication ou par l'Internet, prêter, distribuer et vendre des thèses partout dans le monde, à des fins commerciales ou autres, sur support microforme, papier, électronique et/ou autres formats.

L'auteur conserve la propriété du droit d'auteur et des droits moraux qui protège cette thèse. $\mathrm{Ni}$ la thèse ni des extraits substantiels de celle-ci ne doivent être imprimés ou autrement reproduits sans son autorisation.
In compliance with the Canadian Privacy Act some supporting forms may have been removed from this thesis.

While these forms may be included in the document page count, their removal does not represent any loss of content from the thesis.
Conformément à la loi canadienne sur la protection de la vie privée, quelques formulaires secondaires ont été enlevés de cette thèse.

Bien que ces formulaires aient inclus dans la pagination, il n'y aura aucun contenu manquant. 


\section{ABSTRACT}

Synapsins are the most abundant synaptic vesicle phosphoproteins found in mammalian presynaptic nerve terminals. Synapsin-vesicle interactions are mediated by both A-domain (mainly electrostatic) and C-domain (mainly hydrophobic) lipid interactions (Cheetham et al. 2000). In this thesis, we focus on the role of Serine-9 (Ser-9) phosphorylation in the modulatory action of synapsins and the binding of synapsin Ia (syn Ia) to lipid vesicles containing different charged lipids, in particular specific phosphatidylinositol (PI) and PI isomers. Pseudophosphorylated (Ser-9 $\rightarrow$ Asp) and unphosphorylatetable (Ser-9 $\rightarrow$ Ala) syn Ia mutants were generated through site directed mutagenesis to study the interactions with model synaptic vesicles consisting of dioleoylphosphatidylcholine/ dioleoylphosphatidylethanolamine/ phosphatidylinositol 3,4-biphosphate/ cholesterol. Our results indicate that the wildtype synapsin and unphosphorylatetable mutant bind charged liposomes to the same extent, while the pseudophosphorylated mutant led to reduced vesicle binding. The importance of electrostatic interactions for synapsin-vesicles binding was also highlighted, as the combined A-, B- and Cdomains of syn Ia only bind to liposomes containing anionic phospholipids. Our results of analyzing the binding of syn Ia to vesicles containing either unphosphorylated PI or phosphorylated PI isomers (phosphatidylinositol 3-phosphate, phosphatidylinositol 4-phosphate, phosphatidylinositol (3,4)-bisphosphate, phosphatidylinositol (3,5)-bisphosphate, phosphatidylinositol (4,5)-bisphosphate (PI-4,5-2P) or phosphatidylinositol (3,4,5)trisphosphate) indicate that syn Ia has highest binding affinity towards both unphosphorylated PI and monophosphorylated derivatives. In addition, atomic force microscopy and total internal reflection microscopy were used to measure synapsin binding specificity. A dissociation constant 
$\left(\mathrm{K}_{\mathrm{d}}\right)$ of $12.5 \mathrm{nM}$ for the syn Ia interaction with anionic $(10 \% \mathrm{PI}-4,5-2 \mathrm{P})$ vesicles was obtained, with electrostatic interactions accounting for $86 \%$ of the synapsin-vesicle interaction. 


\section{ACKNOWLEGEMENTS}

I would first like to thank Dr. Jim Cheetham for his supervision and guidance from the early stage of this research and for providing me extraordinary experiences during the course of my work. His ideas and his passions for science have helped me grow as a student, a researcher and a scientist, I am forever grateful.

I also gratefully acknowledge Dr. Linda Johnston for her supervision and crucial contribution to my work. Working alongside her and her research team at the NRC Steacie Institute for Molecular Sciences has nourished my intellectual maturity. I am grateful in every possible way and hope to keep up our collaboration in the future.

I convey my gratitude to Dr. Shan Zou for providing me constant encouragement and support. I thank her for our many science discussions, supervision in AFM and TIRF and for always kindly taking the time to provide me with new ideas and critical comments about my work. More than a supervisor, you became a friend, providing guidance on both a professional and personal level, thank you.

Many thanks go to all who have donated their time to help with experiments. Veronica Eurokova for help with liposome binding assays. Zhengfang Lu, Zygmunt Jakubek, Dusan Vobornik, Daniel Carter and Ryan Chan for help with TIRF measurements and data analysis. Maohui Chen and Kirk Mulligan for help with AFM procedures. I would also like to thank Mojgan Siahbazi and Ruby May A. Sullan not only for their technical assistance but for their friendship. I will always look upon the time we spent together with a smile.

I would like to thank my family and friends whose patience and understanding have made completion of this thesis possible. I will be forever grateful to my girls for all of our meaningful 
conversations and for and providing necessary comic relief in stressful times. I'm also grateful to my sister Chantal for always being there to listen and for her kind heart.

Finally, I would like to thank my parents, Monique and Gaëtan, for believing in me and allowing me to realize my potential. The support you have given me over the years is the greatest gift anyone has ever given me. If I should one day be blessed with children, I hope to be as good a parent to them as you have always been to me.

Last but not least, my husband Phil. Words can't express all the wisdom, love and support you have given me. I am so thankful to have you in my corner to push me when I feel like giving up. I am truly blessed to have had you by my side through this incredible journey, and I look forward to many more. 


\section{TABLE OF CONTENTS}

LIST OF FIGURES AND TABLES

\section{INTRODUCTION}

1.1 The SynaptiC Vesicle CyCle..................................................... 17

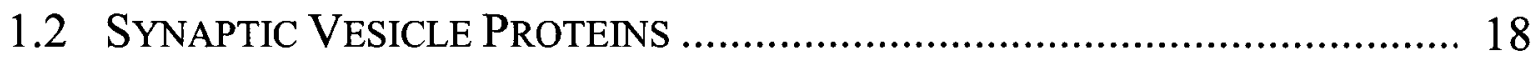

1.3 SyNAPSIN MEDIATED NEURonal ACTIVITY...................................... 18

1.4 EXPRESSION AND LOCALIZATION .................................................. 24

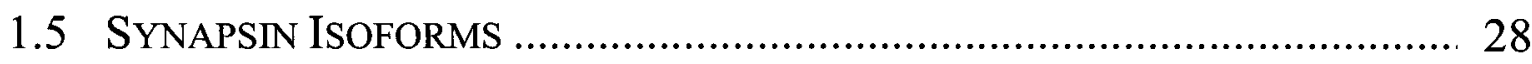

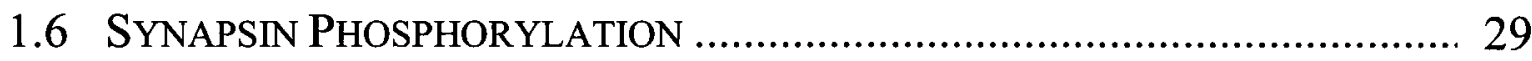

1.7 SYNAPSIN-VESICLE BINDING ..................................................... 30

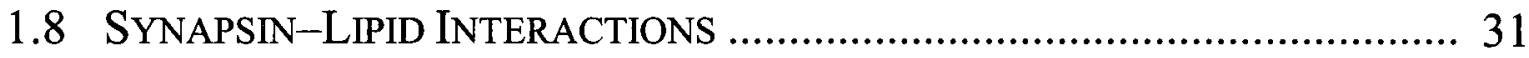

1.9 RATIONAL FOR EXPERIMENTS ...................................................... 37

\section{HYPOTHESIS I}

Synapsin IA A-Domain PhOSPhorylation AT SERINe-9 Mediates SYNAPTIC VESICLE RELEASE

2.1. MATERIALS AND METHODS............................................................ 41

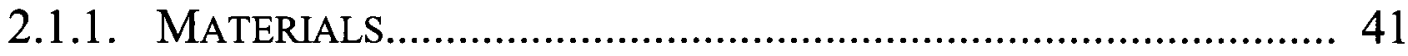

2.1.2. Transformation of SynABC in BL21 Competent Cells. 42 
2.1.3. Generation of Synapsin Ia Phosphorylation Site MUTANTS

2.1.4. RESTRICTION DIGESTION.................................................... 44

2.1.5. AGAROSE GEL ElECTROPHORESIS ...................................... 44

2.1.6. EXPREsSiOn AND Purification of Recombinant Proteins. 44

2.1.7. PREPARATION OF LUVS................................................. 45

2.1.8. PHOSPHATE ASSAY ..................................................... 45

2.1.9. LIPOSOME BINDING ASSAYS.......................................... 46

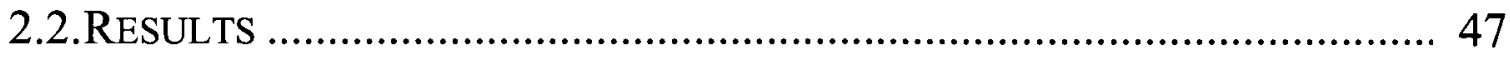

2.2.1. Creating Mutant Clones by Site Direct Mutagenesis. 47

2.2.2. EXPRESSION OF GST-SYNAPSIN IA FUSION PROTEINS ............ 50

2.2.3. PROTEIN PURIFICATION....................................................... 53

2.2.4. ProteIn-LIPOSOME BINDING ASSAYS ............................... 53

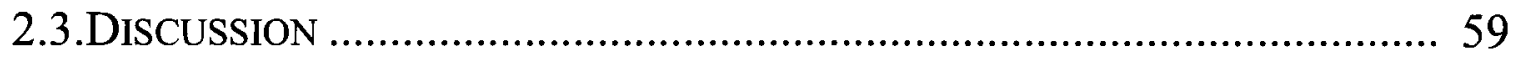

\section{HYPOTHESIS II}

MEMBRANe LIPID COMPOSITION MEDIATES SYNAPSIN IA-LIPOSOME BINDING

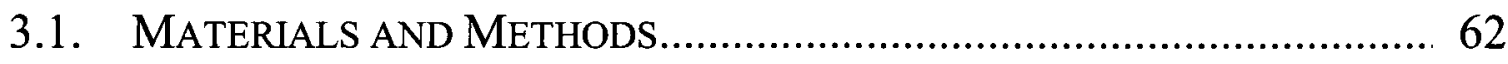

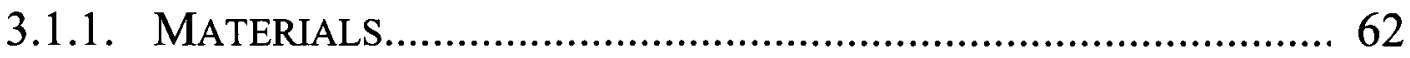

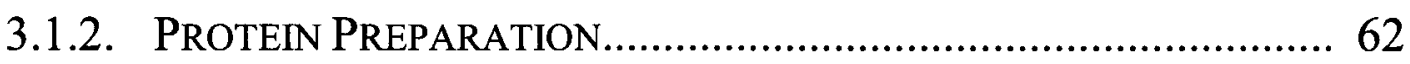

3.1.3. PREPARATION AND CHARACTERIZATION OF LUVS..................6 63 
3.1.4. LIPOSOME BINDING ASSAYS................................................... 64

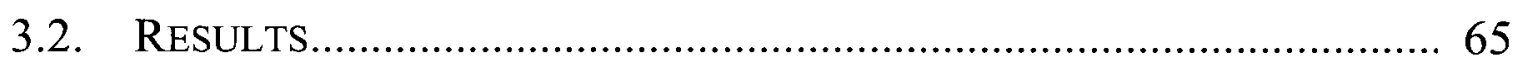

3.2.1. INCORPORATION OF PI AND PI ISOMERS IN LUVS...................... 65

3.2.2. LIPOSOME BINDING ………............................................. 74

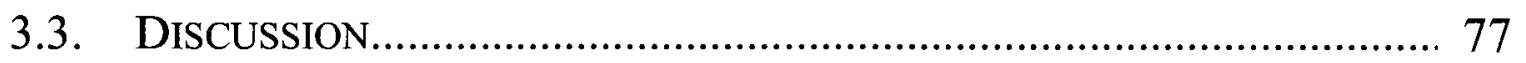

\section{HYPOTHESIS III}

QUANTIFYING SyNAPSIN IA-LUV BINDING BY ATOMIC FORCE MICROSCOPY AND TOTAL INTERNAL REFLECTION FLUORESCENCE MICROSCOPY

4.1. MATERIALS AND METHODS............................................................. 87

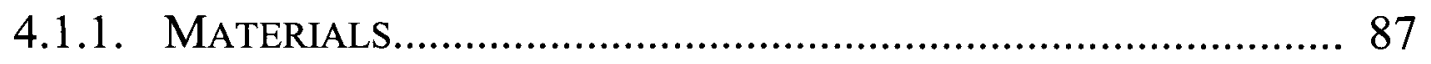

4.1.2. Protein Preparation ........................................................... 87

4.1.3. PrePARATION OF LUVS.......................................................... 88

4.1.4. SURFACE FunCTIONALIZATION............................................... 88

4.1.5. ATOMIC FORCE MICROSCOPY ……………………............... 89

4.1.6. TOTAL INTERNAL FLUORESCENCE MiCROSCOPY ........................ 89

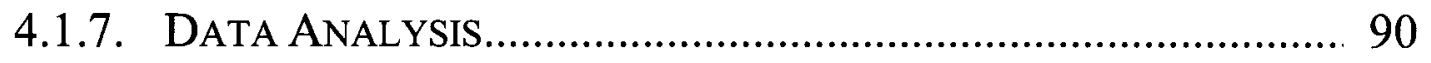

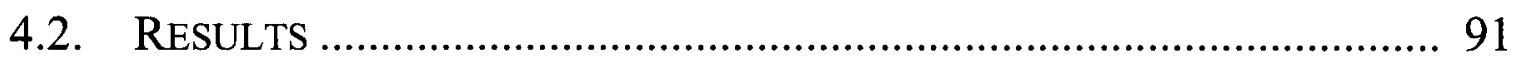

4.2.1. IMAGING OF BBSA+FITC-STREPT ………………................ 91

4.2.2. IMAGING OF ADHERENT LUVs................................................. 97 
4.2.3. INFLUENCE OF STREPTAVIDIN CONCENTRATION ON LUV

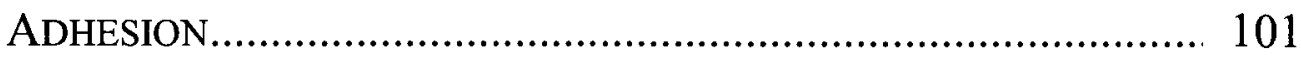

4.2.4. Two-Colour TIRF IMAging to MONITOR SPECIFIC TETHERING

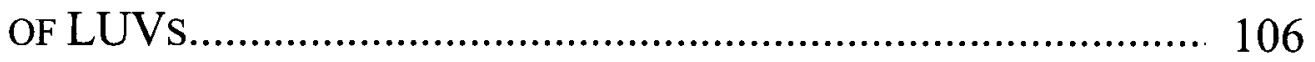

4.2.5. BINDING OF SYNAPSIN IA TO LUVS.................................... 113

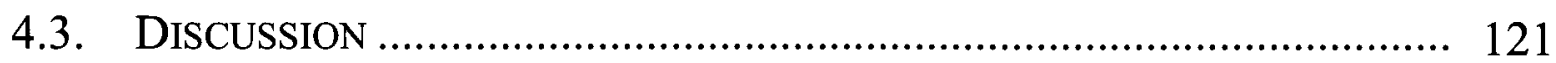

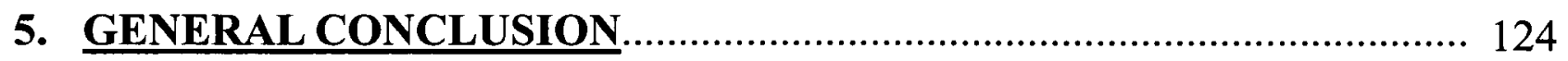

6. SIGNIFICANCE OF THIS RESEARCH …................................... 126

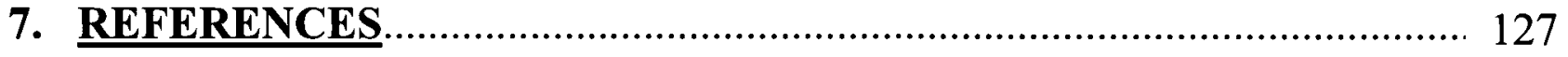




\section{LIST OF FIGURES AND TABLES}

\section{INTRODUCTION}

Figure 1.1 Illustration of a synaptic vesicle and some associated proteins.

Figure 1.2 Illustration of the involvement of synapsin in the synaptic vesicle cycle.

Figure 1.3 A-domain model for the synapsin family of proteins in humans.

Figure 1.4 Representation of phosphatidylinositol and its seven isomers.

Figure 1.5 Illustration of cycling of phosphatidylinositide residues during vesicle trafficking at the presynaptic nerve terminal.

\section{HYPOTHESIS I}

Figure 2.1 Partial Clustal W 2.0.5 of multiple sequence alignment of results obtained from sequencing of the synapsin A-domain mutant clones.

Figure 2.2 Western blotting followed by Enhanced Chemiluminescent detection of time course induction of SynABC, Syn-Ala, Syn-Asp, GST fusion proteins and pure GST with $1 \mathrm{mM}$ IPTG.

Figure 2.3 Coomassie Blue stained 10\% polyacrylamide gel of eluted purified SynABC, SynAla, Syn-Asp GST fusion proteins and pure GST.

Figure 2.4 Coomassie Blue stained 10\% polyacrylamide gel of protein-liposome binding assays. 


\section{HYPOTHESIS II}

Table 3.1 Dynamic Light Scattering data obtained for liposomes containing either 10, 20 or 30 mol\% of PI-4,5-2P extruded through 400,200 and $100 \mathrm{~nm}$ pore diameter polycarbonate membranes.

Figure 3.1 Phosphate assay results of LUVs containing 10,20 or $30 \mathrm{~mol} \%$ of PI-4,5-2P after elution through a Sephadex G-75 column.

Figure 3.2 Thin-layer chromatography on Silica gel 60 of LUVs containing 10,20 or 30 mol\% of PI-4,5-2P after elution through a Sephadex G-75 column.

Figure 3.3 Synapsin Ia selective binding with varying phosphatidylinositide residues.

\section{HYPOTHESIS III}

Figure 4.1 Illustration of a biotinylated large unilamellar vesicle specifically tethered to a streptavidin layer by biotin-streptavidin interactions.

Figure 4.2 Chemical structures of Texas Red ${ }^{\circledR}$ 1,2-dihexadecanoyl-sn-glycero-3phosphoethanolamine, triethylammonium salt (TR-DHPE) and Fluorescein (FITC).

Figure 4.3 Topographic AFM image of a clean glass coverslip, BBSA and BBSA + FITCstrept treated glass coverslip.

Figure 4.4 Topographic AFM and TIRF images of substrate-1.

Figure 4.5 Topographic AFM and TIRF images of LUVs on substrate-1.

Figure 4.6 TIRF images of a BBSA substrate treated with increasing concentrations of FITCstrept. 
Figure 4.7 TIRF images of TR-LUVs tethered to FITC-strept substrates with a series of surface coverages.

Figure 4.8 Composite TIRF images of FITC-strept and TR-LUVs.

Figure 4.9 TIRF images of substrates-1,-2,-3 and -4 before and after addition of TR-LUVs.

Figure 4.10 TIRF images of increasing concentrations of Alexa 488-syn Ia incubated on tethered LUVs.

Figure 4.11 Sum intensity signals of Alexa 488-syn Ia incubated with TR-free LUVs and plotted as a function of increasing protein concentration.

Figure 4.12 TIRF images of Alexa 488-syn Ia incubated with TR-free LUVs containing $10 \%$ PI-4,5-2P and without PI-4,5-2P. 


\section{ABBREVIATIONS}

A

aa

ADP

Alexa 488-syn Ia

AFM

ATP

BBSA

$\mathrm{BCA}$

biotin-DHPE

bp

BSA

CaMK

cAMP

chol

CMC

DAG

$\mathrm{ddH}_{2} \mathrm{O}$

DLS

DNA

DOPC

DOPE
Alanine

Amino acid

Adenosine diphosphate

Alexa 488 labeled synapsin Ia

Atomic force microscopy

Adenosine triphosphate

Biotin labeled Bovine Serum Albumin

Bicinchoninic acid

1,2-dioleoyl-sn-glycero-3-phosphoethanolamine-N-(biotinyl)

Base pairs

Bovine serum albumin

Calcium/calmodulin-dependent protein kinase

Cyclic adenosine monophosphate

cholesterol

Critical micelle concentration

Diacylglycerol

Double distilled and deionized water

Dynamic light scattering

Deoxyribonucleic acid

Dioleoylphosphatidylcholine

Dioleoylphosphatidylethanolamine 


\begin{tabular}{ll} 
DOPS & Dioleoylphosphatidylserine \\
ECl & Enhanced chemiluminescence \\
EDTA & Ethylene diamine tetra-acetic acid \\
EGTA & glycol-bis(2-aminoethylether)- $N, N, N^{\prime}, N^{\prime}$-tetraacetic acid \\
F & Phenylalanine \\
FITC & Fluorescein \\
FITC-strept & FITC labeled Streptavidin \\
GST & Glutathione S-transferase \\
HRP & Horseradish peroxidase \\
Hz & Hertz \\
IPTG & Isopropyl $\beta$-D-thiogalactopyranoside \\
kb & Kilobase \\
K & Equilibrium dissociation constant \\
KDa & Kilodaltons \\
L & Polymerase chain reaction \\
LB & Leucine \\
LUV & Luria-Bertani \\
PA & Large unilamellar vesicle \\
MAP & Methionine \\
Mean Dia & Polyacrylamide gel electrophoresis \\
PAGE & Phosphate-buffered saline \\
\hline
\end{tabular}




\author{
pGEX-SynABC pGEX vector containing an in-frame sequence encoding rat syn Ia A-, B- and \\ C-domains \\ pGEX-Syn-Ala pGEX-SynABC with Ser-9 $\rightarrow$ Ala mutation \\ pGEX-Syn-Asp $\quad$ pGEX-SynABC with Ser-9 $\rightarrow$ Asp mutation \\ PI phosphatidylinositols \\ PI-3-P Phosphatidylinositol 3-phosphate \\ PI-4-P Phosphatidylinositol 4-phosphate \\ PI-3,4-2P Phosphatidylinositol (3,4)-bisphosphate \\ PI-3,5-2P Phosphatidylinositol (3,5)-bisphosphate \\ PI-4,5-2P Phosphatidylinositol (4,5)-bisphosphate \\ PI-3,4,5-3P Phosphatidylinositol (3,4,5)-trisphosphate) \\ PI3K phosphoinositol 3-kinase \\ PKA Protein kinase A (cAMP-dependent protein kinase) \\ SDS Sodium dodecyl sulfate \\ Ser Serine \\ Ser-9 Serine at position 9 in the A-domain of synapsin \\ Std Dev $\quad$ Standard deviation \\ Substrate-1 $\quad 0.1 \mathrm{mg} / \mathrm{mL}$ FITC-strept incubated on BBSA treated substrate; \\ 98\% FITC-strept surface coverage \\ Substrate-2 $\quad 0.01 \mathrm{mg} / \mathrm{mL}$ FITC-strept incubated on BBSA treated substrate; \\ $88 \%$ FITC-strept surface coverage \\ Substrate-3 $\quad 0.001 \mathrm{mg} / \mathrm{mL}$ FITC-strept incubated on BBSA treated substrate; \\ $67 \%$ FITC-strept surface coverage \\ Substrate-4 $\quad 0.0001 \mathrm{mg} / \mathrm{mL}$ FITC-strept incubated on BBSA treated substrate; \\ $2 \%$ FITC-strept surface coverage
}




\begin{tabular}{|c|c|}
\hline SV(s) & Synaptic vesicle(s) \\
\hline syn I & Synapsin I \\
\hline syn Ia & Synapsin Ia \\
\hline syn II & Synapsin II \\
\hline syn III & Synapsin III \\
\hline SynABC & GST fusion proteins expressed from pGEX-SynABC vector \\
\hline Syn-Ala & GST fusion proteins expressed from pGEX-Syn-Ala vector \\
\hline Syn-Asp & GST fusion proteins expressed from pGEX-Syn-Asp vector \\
\hline TAE & Tris acetate/EDTA buffer \\
\hline Taq & Thermus aquaticus \\
\hline TIRF & Total internal reflection fluorescence microscopy \\
\hline TE & Tris/EOTA buffer \\
\hline TEMEO & $\mathrm{N}, \mathrm{N}, \mathrm{N}^{\prime}, \mathrm{N}^{\prime}$-tetramethylethylenediamine \\
\hline TLC & Thin layer chromatography \\
\hline TR & Texas $\operatorname{Red}{ }^{\circledR}$ \\
\hline TR-DHPE & $\begin{array}{l}\text { Texas Red } ® \text { 1,2-dihexadecanoyl-sn-glycero-3-phosphoethanolamine, } \\
\text { triethylammonium salt }\end{array}$ \\
\hline TR-vesicle & Texas Red labeled vesicles \\
\hline Tris & Tris (hydroxymethyl) aminomethane \\
\hline UV & Ultraviolet \\
\hline V & Valine \\
\hline VAMP2 & Synaptobrevin 2 \\
\hline W & Tryptophan \\
\hline
\end{tabular}




\section{INTRODUCTION}

\subsection{The SynAPTIC VeSiCle CyCLE}

Neurotransmitter release involves a specialized pathway of intracellular vesicle trafficking; the synaptic vesicle cycle. In the pre-synaptic nerve terminal, small synaptic vesicles (SVs) containing neurotransmitters are present in at least two pools: a readily-releasable pool, and a reserve pool. SVs in the reserve pool are tethered to each other and to the actin-based cytoskeleton to form clusters, while vesicles in the readily-releasable pool are docked to binding sites in the active zone. Docked SVs are primed through an ATP-dependent and rate-limiting process, which make them competent for fusion (Benfenati et al. 1992, 1993a; Greengard et al. 1993). When an action potential invades a nerve terminal, voltage gated $\mathrm{Ca}^{2+}$ channels open, allowing an influx of $\mathrm{Ca}^{2+}$ ions which triggers several biochemical events. $\mathrm{Ca}^{2+}$ ions cause fusion-competent $\mathrm{SVs}$ to fuse with the plasma membrane and release neurotransmitters into the synaptic cleft (Heuser and Reese 1973; Takei 1995; Chi et al. 2003). The fused vesicles are then recycled through clathrin-mediated endocytosis and incorporated into the reserve pool upon maturation (Rohrbough and Broadie 2005). SVs from the reserve pool may also be enlisted to participate in neurotransmitter release as $\mathrm{Ca}^{2+}$ can also signal SV release from the cytoskeleton as needed. This allows the synapse to operate over a wide range of stimulation frequencies (Rosahl et al. 1995).

The coordinated regulation of all steps of the SV cycle is of central importance for synaptic function and plasticity. Although simple with respect to its biological function, the SV cycle is complicated in that SV trafficking and exocytosis are mediated by the sequential interactions of SV proteins. 


\subsection{SYNAPTIC VeSICLE PROTEINS}

SVs are abundant organelles ranging from 40 to $50 \mathrm{~nm}$ in size as determined by electron microscopy (Valtora et al. 1992). Although small in size, SVs are not nanostructures of fixed stoichiometric composition. They are constantly modified by cytoplasmic factors making them as complex as other supramolecular structures such as spliceosomes and viruses.

A detailed description of SV composition revealed 410 different SV associated proteins (Takamori et al. 2006). The structures of most, but not all, proteins are known, and have been divided into two classes; transport proteins which execute uptake of neurotransmitters and trafficking proteins which mediate the intracellular trafficking. Synaptophysin, synaptobrevin 2 (VAMP2), synaptotagmin 1 and synapsins are among the first identified SV proteins (Figure 1.1) and turn out to be members of conserved multi-gene families involved in SV trafficking (Takamori et al. 2006).

\subsection{SYNAPSIN MEDIATED NeURONAL ACTIVITY}

Synapsins were first identified in vitro and in vivo as substrates for protein kinases found in the presynaptic nerve terminal (Czenik et al. 1987; Masubara et al. 1996; Takamori et al. 2006). Further studies revealed that these phosphoproteins are specifically targeted to the cytoplasmic surface of SVs where they represent approximately $9 \%$ of total vesicle-associated protein (Bahler and Greengard 1987; Benfenati et al. 1989a). Although experimental observations have led to numerous theories describing the relationship between vesicle-synapsin clusters and neurotransmitter release, the process is far from thoroughly understood. 
In the proposed model (Figure 1.2), before neuronal excitation, synapsins serve as a linker to tether the SV to each other and to the cytoskeleton, thus preventing them from migrating to the presynaptic membrane and releasing neurotransmitters (Benfenati et al. 1992; Benfenati et al. 1993b; Greengard et al. 1993). During an action potential, however, calcium ions trigger phosphorylation of synapsin by protein kinases. This reduces the binding affinity of synapsin to vesicles and the cytoskeleton, which disrupts the reserve pool cluster, and allows these vesicles to participate in neurotransmitter release. Physiological studies have shown that, in both vertebrates and invertebrates, injection of dephosphorylated synapsin into pre-synaptic nerve terminals led to blockage of neurotransmitter release. In fact, exogenous synapsin inhibited neurotransmission by recruiting vesicles from the releasable pool (where they await exocytosis) back into the reserve pool (where they are bound to the cytoskeleton) (Benfenati et al. 1992; Benfenati et al. 1993a and b). Thus synapsins can modulate vesicle trafficking in a phosphorylation dependant manner.

Based on this model, disruption of synapsin function would allow for higher levels of neuronal activity by increasing the number of SVs available for exocytosis. Upon injection of synapsin specific antibody into giant squid synapse, however, depletion of reserve pool SVs was observed, but the number of SVs at the plasma membrane remained unchanged. Under these conditions, action potential-evoked vesicular release under low frequencies $(0.2 \mathrm{~Hz})$ was seen to be sustained but release under higher frequencies $(18-20 \mathrm{~Hz})$ led to synaptic depression (Pieribone et al. 1995; Hilfiker et al. 1998). Maintaining a subpopulation of SVs away from the plasma membrane is therefore required for sustained neurotransmitter release during high levels of neuronal activity. Thus synapsins can regulate the release of neurotransmitters at high frequencies of stimulation by controlling the distribution of SVs. 
Figure 1.1 Illustration of a synaptic vesicle and some associated proteins. Some proteins are shown to interact with lipid membrane alone while others interact with both lipids and other membrane associated proteins. 


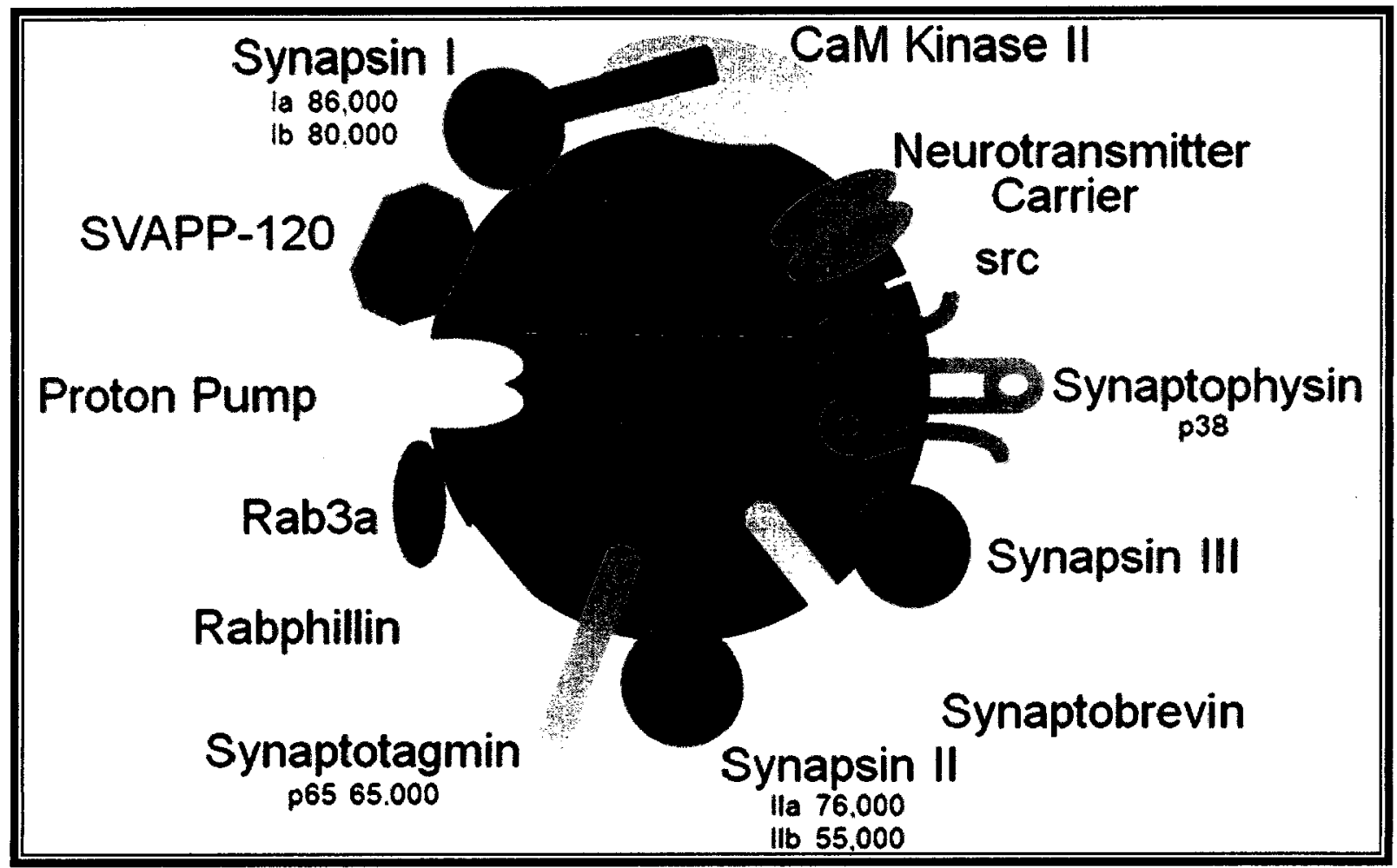


Figure 1.2 Illustration of the involvement of synapsin in the synaptic vesicle cycle. Before neuronal excitation, these proteins serve as linkers to tether the synaptic vesicle to the cytoskeleton thus preventing them from migrating to the presynaptic membrane and releasing neurotransmitters (Benfenati et al. 1992; Benfenati et al. 1993a; Greengard et al. 1993). During action potential, however, phosphorylation of these proteins by multiple protein kinases leads to a loss of protein-vesicle interactions. This action disrupts the reserve pool cluster, and allows the vesicles to migrate to the presynaptic membrane, fuse and release neurotransmitters into the synaptic cleft. 


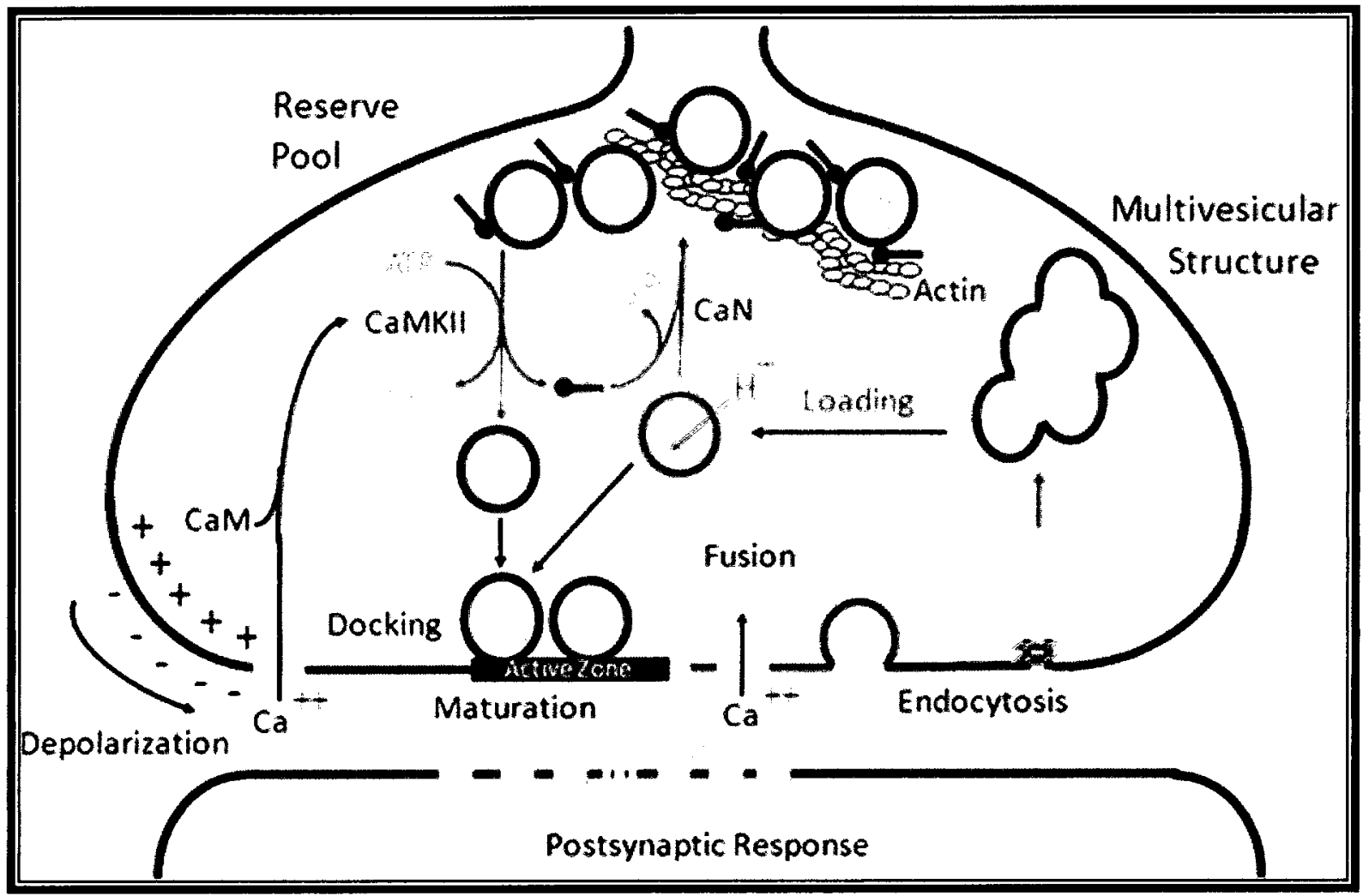




\subsection{EXPRESSION AND LOCALIZATION}

Prior to synaptogenesis, synapsins are localized in the distal axon at the growth cone (Fletcher et al. 1991). After synaptogenesis they are transported down the axon and concentrate in the presynaptic terminals, where they participate in the maintenance of SV clusters, away from the active zone by tethering them to the cytoskeletal meshwork, and to each other (Kao et al. 1998; Hosaka and Südhof 1999; Pieribone et al. 1995). This action results from the ability of synapsin binding to actin filaments and SVs. Various experimental systems support this hypothesis, as synapsins promote polymerization of actin monomers (Baines and Bennett 1986; Bahler and Greengard 1987; Benfenati et al. 1992; Valtorta et al. 1992b; Benfenati et al. 1993a; Ceccaldi et al. 1995). The affinity of synapsin-actin interaction is about 100 -fold lower $\left(\mathrm{K}_{\mathrm{d}}=1-2\right.$ $\mu \mathrm{M})$ than the affinity of synapsin to SV $\left(\mathrm{K}_{\mathrm{d}}=10 \mathrm{nM}\right)$ (Bahler et al. 1989; Benfenati et al. 1989c; Benfenati et al. 1993b).

In higher vertebrates, such as frogs and mammals, synapsins are encoded by three distinct genes, synapsin I (syn I), II (syn II) and III (syn III) (Südhof et al. 1989; Südhof 1990). Invertebrates, however, only contain one synapsin gene, implying that the branching from invertebrates to vertebrates resulted in synapsin gene duplication events. Mammalian expression of synapsin genes gives rise to 10 isoforms, composed of individual domains (A-E/F) (Figure 1.3) (Kao et al. 1999; Porton et al. 1999). Alternative RNA splicing of the syn I gene (X chromosome) gives rise to two isoforms, a and b-like. Both isoforms contain a globular terminal head region and a basic, glycine and proline rich tail region. Similarly, syn II gene ${ }^{\text {(chromosome 3) }}$ expression also gives rise to $\mathrm{a}$ and $\mathrm{b}$ isoforms while syn III gene ${ }^{\text {(chromosome } 22)}$ expression generates six transcripts, syn III a-f (Yang-Feng et al. 1986; Li et al. 1995). 
Syn III is expressed at high levels in fetal brain and at even lower levels in adult brain. Syn I and II expression levels peak during synapse formation and remain high thereafter ( $\mathrm{Lu}$ et al. 1996). Differential expression of these genes in a subset of neurons is found to contain high levels of syn I and syn II in inhibitory synapses and excitatory synapses, respectively. Knockout mice depleted of syn I and II exhibited aberrant neurite growth, retarded axon outgrowth, as well as inhibition of synapse formation and maintenance (Chin et al. 1995; Ferreira et al. 1999; Ferriera et al. 1995). Thus, both syn I and II play important roles in regulating neuronal formation and differentiation (Shaeffer et al. 1994; Ferreira et al. 1995). 
Figure 1.3 A-domain model for the synapsin family of proteins in humans. Specific domains are indicated by letters (A (A-domain), B (B-domain), C (C-domain), etc.) and organized by color. Syn Ia and Ib arise from alternative splicing of the syn I gene ${ }^{(\mathrm{X} \text { chromosome) }}$, and similarly, syn IIa and IIb arise from alternative splicing of the synapsin II gene ${ }^{\text {(chromosome 3) }}$. Syn III isoforms a-f (of which only syn IIIa is represented in this image) arise from alternative slicing of the syn III gene ${ }^{\text {(chromosome 22) }}$. All "a" isoforms share the similar E domain and all isoforms share similar Aand C-domains. Phosphorylation sites by specific enzymes are indicated by the letter "P". [Cheetham et al., unpublished] 


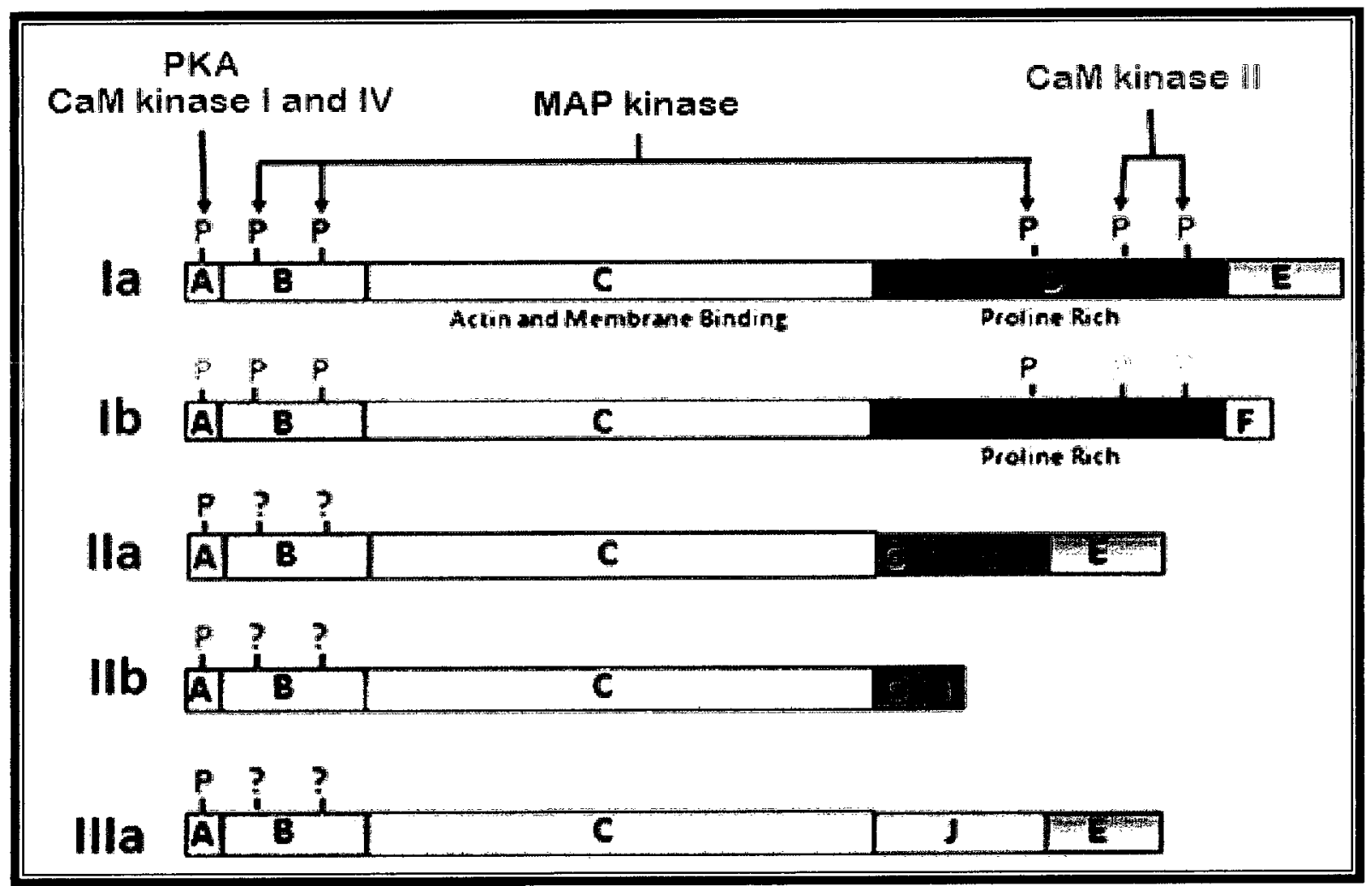




\subsection{SYNAPSIN ISOFORMS}

Structural differences between synapsin isoforms are attributed to the COOH-terminal part of the molecule while the $\mathrm{NH}_{2}$-terminal region remains highly conserved (Südhof et al. 1989; Kao et al. 1999).

Sequence alignment of the primary synapsin structure of vertebrate and invertebrate synapsins revealed that the large central C-domain is the most evolutionarily conserved. Comprised of both hydrophobic ( $39 \%$ A, F, L, M, V and W) and highly charged amino acid residues ( $27 \% \mathrm{D}, \mathrm{E}, \mathrm{K}$ and $\mathrm{R})$ (Südhof et al. 1989$)$ this large central C-domain is hypothesized to contribute to the high affinity binding of synapsins to both the SV lipid bilayer and the actin cytoskeleton (Benfenati et al. 1989c; Cheetham et al. 2000). X-ray crystallography revealed that the C-domain of syn I can dimerize in the presence of ATP (Esser et al. 1998). The crystal structure reveals that more than $80 \%$ of its $\alpha$-carbon atoms can be superimposed on those of ATP-utilising enzymes, D-alanine ligase and glutathione synthetase indicating that synapsins may represent possible phosphotransfer enzymes (Esser et al. 1998). However, further experimentation is still needed before synapsins can be classified as active ATPases.

All vertebrate synapsins also contain a short amino terminal domain (A-domain), which has a $\mathrm{Ca}^{2+}$ calmodulin dependant protein kinases I and IV (CaM Kinase I and IV) and cAMPdependent protein kinase (PKA) phosphorylation sites (Czernik et al. 1987). DNA sequencing of this domain reveals that this phosphorylation site, at Serine-9 (Ser-9), is preceded by three positively charged arginine residues that have been linked to initial SV targeting (Hosaka et al. 1999).

All "a" type isoforms share the C-terminal E-domain (Südhof et al. 1989). Injection of Edomain peptides into the presynaptic membrane leads to synaptic depression, indicating that 
synapsins may also be involved in SV fusion and release (Hilfiker et al. 1998; Kao et al. 1999). Although N-terminal B-domain and C-terminal D-, F-, G-, H- and J-domains show little primary sequence alignment, certain features are still conserved (Monaldi et al. 2009). Consensus phosphorylation sites located in the B- and D-domains are preserved among selected vertebrate and invertebrate isoforms and all proteins contain a high degree of proline, glutamine, alanine and serine amino acids. These findings support the notion that phosphorylation and amino acid sequence are important regulatory features of synapsins, as they have been evolutionarily conserved.

\subsection{SYNAPSIN PHOSPHORYLATION}

In normal physiological activity of neurons, phosphorylation of syn I occurs rapidly and to high stoichiometry. This causes conformational changes in the syn I molecule, with an increase in predicted alpha-helical content (Benfenati et al. 1993b). Changes in its biological properties cause decreased affinity to both actin and SVs, thus freeing SVs and allowing them to move from the non-releasable pool into the releasable pool (Benfenati et al. 1993b; Fuimara et al. 2004).

In vitro and in vivo studies confirmed that synapsins are substrates for multiple protein kinases such as PKA, CaM Kinase I, II and IV, and mitogen-associated protein kinase/Erk 1/2 (MAPK/Erk) (Figure 1.3). Although these kinases phosphorylate distinct sites within synapsins, the presence of these sites varies in the different isoforms and orthologues. (Greengard et al. 1993; Jovanovic et al. 2000; Sakurada et al. 2002). Syn I contains at least 7 phosphorylation sites for PKA and CaM kinase I and IV (A-domain), MAP kinases (B and D-domains) as well as Map kinase II (D-domain). The phosphorylation site at Ser-9 in the A-domains remains the only 
phosphorylation site to also be identified in both syn II and III (Hosaka and Südhof 1998; Südhof et al. 1999).

\subsection{SYNAPSIN -VESICLE BINDING}

Because phosphorylation was identified as a modulatory mechanism by which synapsins mediate vesicle release, early research suggested that synapsins bind to SVs via proteins that phosphorylate them (Benfenati et al. 1992; Benfenati et al. 1993b; Deisenhofer et al. 2004; Südhof et al. 1999). It was first hypothesized that syn I binds SVs via interaction of its variable carboxyl-terminal domains with CaM Kinase II, who phosphorylates two sites in the carboxyterminal region of the protein (Benfenati et al. 1992). Although CaM Kinase II was shown to mediate some of the association of syn I to vesicles, this modulatory interaction was unlikely to be the primary binding mechanism utilized by all synapsins (Südhof et al. 1999). Among the arguments was the fact that there is very little CaM Kinase II present on SVs, compared to synapsins which represent $9 \%$ of the total vesicle-associated proteins (Benfenati et al. 1992; Benfenati et al. 1993a; Südhof et al. 1999). Furthermore, syn II does not bind CaM kinase II but is still targeted to synaptic vesicles (Benfenati et al. 1992; Benfenati et al. 1993b; Südhof et al. 1999). Thus, although it is believed that specific targeting of synapsins to SVs involves a specific protein whose function remains to be elucidated, high affinity binding to the lipid membrane may be mediated by both protein-protein and protein-lipid interactions.

To study the binding of synapsin to lipid membranes, liposomes with similar size and lipid composition were utilized. Results revealed that binding of syn I to liposomes is reduced at higher ionic strength, which suggests that electrostatic interactions mediate part of the binding interaction (Schiebler et al. 1986). Identification of synapsin lipid-binding domains confirmed 
this hypothesis as SV recognition was shown to be initiated through electrostatic interaction between the A-domain and anionic phospholipids. This action was rapidly followed by the direct penetration of highly hydrophobic residues ( $39 \% \mathrm{~A}, \mathrm{~F}, \mathrm{~L}, \mathrm{M}, \mathrm{V}$ and $\mathrm{W}$ ) of the C-domain into the vesicle (Cheetham et al. 2000). Further analysis on the $\mathrm{N}$-terminal of the protein revealed that binding of synapsins to SVs exhibits absolute requirement of charged lipids and that only the Adomain, alone or in combination with the B- and C-domains are capable of binding to SV. The B- and C-domains, in contrast, do not bind (Hosaka and Südhof 1989).

\subsection{SYNAPSIN-LIPID INTERACTIONS}

The interaction of synapsins with membranes was shown to be initiated by electrostatic interactions between negatively-charged phospholipids, such as phosphatidylserine and phosphotidylinositol, and positively charged amino acid residues on synapsin (Benfenati et al. 1989a and b). Despite being minor constituents of neurons (Takamori et al. 2006), many charged lipids are involved in both pre- and post-synaptic functions. Of particular interest are phosphatidylinositols (PI), which play vital roles in signal transduction, and significantly, specific PI isomers are enriched at particular stages of the SV cycle (Rohrbough and Broadie 2005; Hammond and Schiavo 2006).

PIs form a unique family of phospholipids characterised by a headgroup myo-inositol ring linked to both a saturated and an unsaturated alkyl chain (Hammond and Schiavo 2006). PI isomers derive from the phosphorylation of the inositol ring at positions 3, 4 or 5 to form seven different molecules bearing one, two, or three phosphate groups (Figure 1.4). The most abundant PI isomer in eukaryotic cells is the monophosphorylated derivative phosphatidylinositol $(4,5)$ biphosphate (PI-4,5-2P) (Hammond and Schiavo 2006). A great deal of work has been dedicated 
to the understanding of the modulation of PI-4,5-2P levels in vivo. Although much still remains to be elucidated, it is becoming more and more clear that the tightly controlled cycling of PIs is essential for SV trafficking.

In the proposed model (Figure 1.5) (Hammond and Schiavo 2006), before neuronal excitations, PI-4,5-2P is clustered at the plasma membrane. Upon arrival of an action potential, vesicles released from the reserve pool are specifically targeted to the readily releasable pool via strong interactions between membrane PI-4,5-2P and SV associated synaptotagmin I and II. Once at the presynaptic membrane, proteins such as PIPKin and PI4K are recruited to prime SVs for exocytosis. In vesicles that have yet to be exocytosed, PI-4,5-2P remains in the plasma membrane and may increase as PIPKin and PI4K synthesize more PI-4,5-2P to maintain the readily releasable pool of SVs. In vesicles that are ready to undergo exocytosis PI-4,5-2P becomes a substrate for $\mathrm{Ca}^{2+}$ dependant phospholipase $\mathrm{C}$ which cleaves the phosphodiester bond between the inositol ring and the diacylglycerol (DAG) backbone. DAG serves as a signalling molecule for the active zone protein MUNC-13, which contains a DAG-activated-C1 domain. Upon activation, MUNC-13 recruits the endocytotic machinery required for exocytosis. Fused vesicles then rapidly undergo clathrin mediated endocytosis which is initiated by SV membrane synthesis of phosphatidylinositol 3-phosphate (PI-3-P) by PI3K-C2 alpha (an isoform of phosphoinositol 3-kinase (PI3K)). This model explains the hypothesis that different lipids in membranes change the activities of peripheral membrane proteins, such as synapsins. 
Figure 1.4 Representation of unphosphorylated phosphatidylinositol (PI) (A) and its seven phosphorylated isomers. Monophosphorylated derivatives (B) including phosphatidylinositol 3phosphate (PI-3-P), phosphatidylinositol 4-phosphate (PI-4-P), and phosphatidylinositol 5phosphate (PI-5-P); diphosphorylated derivatives (C) including phosphatidylinositol $(3,4)$ bisphosphate (PI-3,4-2P), phosphatidylinositol (3,5)-bisphosphate (PI-3,5-2P) and phosphatidylinositol (4,5)-bisphosphate (PI-4,5-2P); and triphosphorylated derivative (D) phosphatidylinositol (3,4,5)-trisphosphate (PI-3,4,5-3P) are listed. [Adapted from Osborne et al. 2006] 

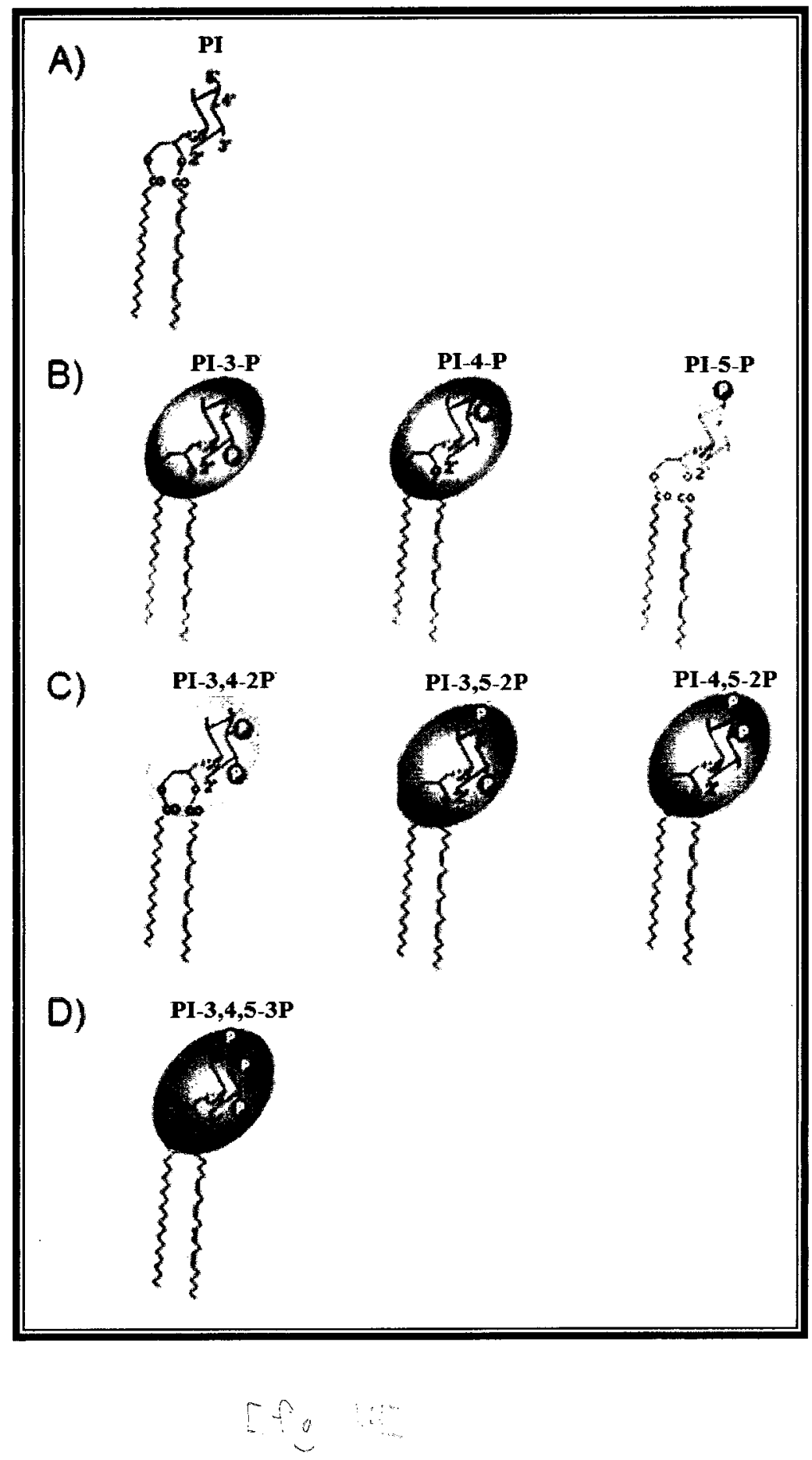
Figure 1.5 Illustration of cycling of phosphatidylinositide residues during vesicle trafficking at the presynaptic nerve terminal. PI-4,5-2P allows for specific targeting of SVs at the plasma membrane. During exocytosis, PI-4,5-2P is depleted. Clathrin mediated endocytosis is initiated by synthesis of PI-3-P in the SV membrane. Many steps within this process still need to be confirmed. [Image from Osborne et al. 2006] 


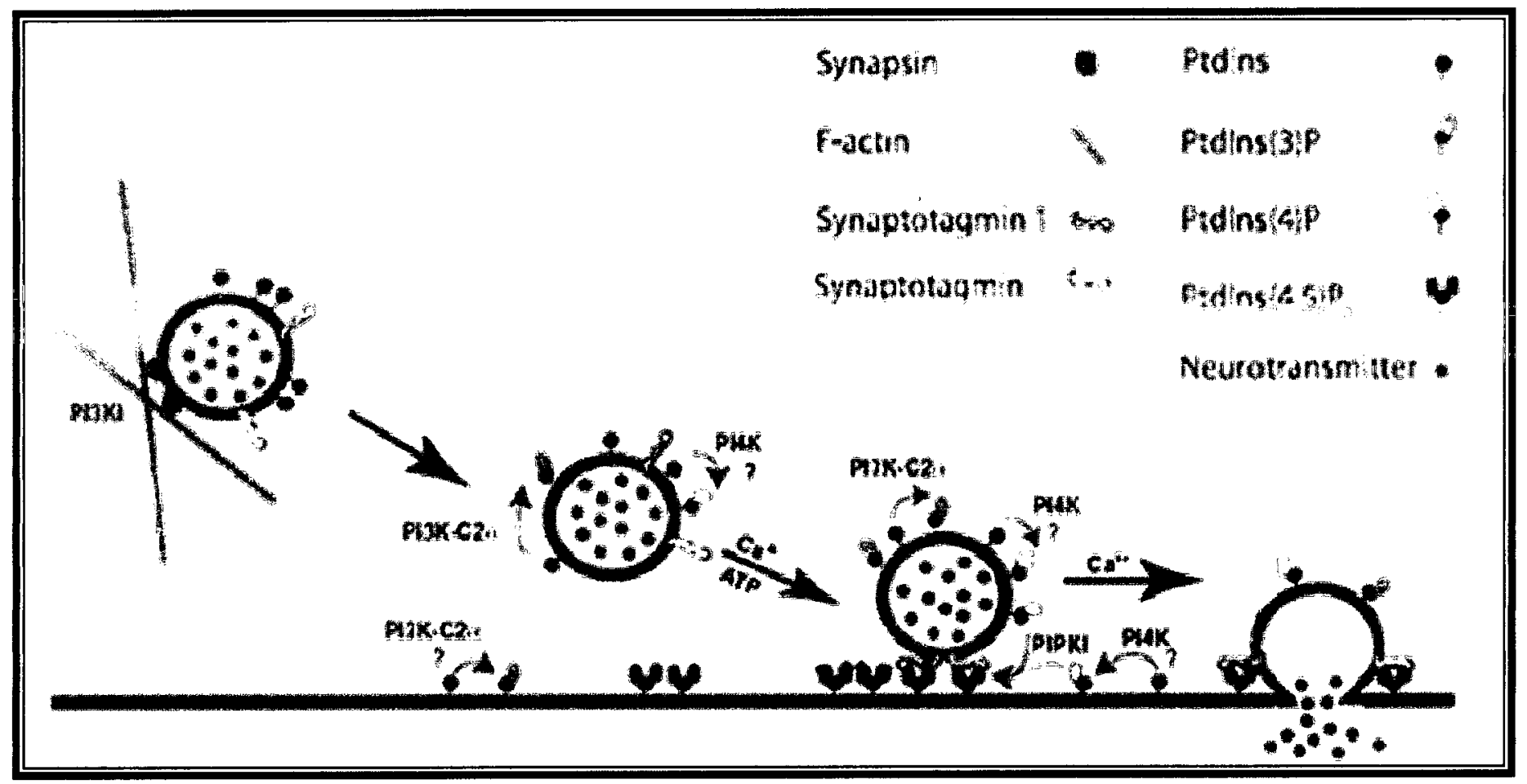

[fig: $: 5$ 


\subsection{RATIONAL FOR EXPERIMENTS}

Phosphorylation of synapsin has been shown to have a striking effect on its ability to bind SVs (Benfenati et al. 1992; Benfenati et al. 1993a; Südhof et al. 1999). Because all synapsins were suggested to be phosphorylated in an activity dependent manner, the release of SVs by synapsins was said to involve a common phosphorylation event. The prime candidate for such modulatory function was the N-terminal phosphorylation at Ser-9 in the A-domain because it is the only phosphorylation site that is present in all synapsins (Hosaka et al. 1999; Südhof et al. 1999). Recent studies have supported this hypothesis by indicating that phosphorylation of the A-domain alone can lead to vesicle liberation (Benfenati et al. 1993a; Fumira et al. 2004). The A-domain is also of great importance as it allows specific targeting of the protein to charged liposomes (Benfenati et al. 1993a). Interestingly this is the first time that the translocation of a large globular protein (704 aa) has been found to be mediated by a short lipid-binding domain that is regulated by phosphorylation. Consequently further characterization of this domain is of great interest to us.

In this thesis, we first aim to investigate the synapsin Ia-vesicle binding by:

1) determining the importance of A-domain phosphorylation in regulating lipid binding and We hypothesize that site-specific phosphorylation of Synapsin Ia at Serine 9 mediates synapsin Ia-vesicle binding

2) characterization of synapsin specificity for different anionic phospholipids.

We hypothesize that membrane lipid composition mediates synapsin Ia-liposome binding. 
General methods for measuring interaction of synapsins to SVs in vitro often involve separating membrane bound protein from unbound material by centrifugation. This technique does not however readily provide insight into electrostatic vs. non-specific interactions, protein association forces or membrane dynamics. High-resolution techniques capable of making realtime measurements of single-molecule behavior have, on the other hand, been shown to provide tremendous insight into the protein/lipid dynamics. Among these techniques, atomic force microscopy (AFM) and total internal reflection fluorescence (TIRF) microscopy have provided the opportunity to study protein interactions on a molecular level (Weerachatyanukul et al. 2007; Ira and Johnston 2007; Ira et al. 2009). This prompted us to design a method by which direct visualization and quantification of synapsin Ia-liposome complexation can be achieved.

We hypothesize that we can directly quantify the interaction of synapsin Ia with vesicles using AFM and TIRF. 


\section{HYPOTHESIS I}

\section{SYNAPSIN IA A-DOMAIN PHOSPHORYLATION AT SERINE-9 MEDiATES SyNAPTIC Vesicle RELEASE}

During neuronal excitation, multiple protein kinases phosphorylate synapsins which allows SVs to leave the reserve pool, and participate in synaptic transmission (Benfenati et al. 1992; Chi et al. 2003). Phosphorylation of the synapsin A-domain at Ser-9 is responsible for structural changes in synapsins leading to vesicle liberation from the reserve pool (Benfenati et al. 1992; Benfenati et al. 1993a). In an effort to further characterize the effect of synapsin Ia (syn Ia) A-domain phosphorylation we used pseudophosphorylated (Ser-9 $\rightarrow$ Asp) and unphosphorylatable (Ser-9 $\rightarrow$ Ala) syn Ia mutant constructs, generated through site directed mutagenesis, to investigate in vitro synapsin-liposome binding kinetics with large unilamellar vesicles (LUVs).

Biomimetic systems such as LUVs are increasingly useful in this context, as they can be designed to incorporate lipids that play important physiological roles in cellulo. Some insight into the structure and function of biological membranes can be found by studying synthetic vesicles consisting of a single type of phospholipid molecule or mixtures of phospholipids with or without proteins or peptides. Such systems are simple enough to allow systematic analysis of their properties, yet complex enough to retain the essential properties associated with biological membranes. To best mimic biological SV, synthetic LUVs were prepared by extrusion of dioleoylphosphatidylcholine (DOPC), dioleoylphosphatidylethanolamine (DOPE) / phosphatidylinositol 3,4-biphosphate (PI-3,4-2P) and cholesterol (chol) in a 2:1:1:1 ratio. Extruding a phospholipid suspension through polycarbonate filters of defined pore size allows 
one to control the size of the liposomes. Liposomes down to $50 \mathrm{~nm}$ diameter (which mimics the small SV diameter) can be prepared using this technique.

Measurements of the protein-membrane binding were based on pelleting liposomes using centrifugation to separate membrane bound proteins from free protein in solution. Our results support the important modulatory function of A-domain phosphorylation as both wildtype synapsin and the unphosphorylatable mutant bind charged liposomes to the same extent, while the pseudophosphorylated mutant showed reduced vesicle binding. Furthermore the importance of electrostatic interactions for syn Ia-vesicles binding was also highlighted, as the combined A-, B- and C-domains of syn Ia only bind to liposomes containing anionic phospholipids. 


\subsection{MATERIALS AND METHODS}

\subsubsection{MATERIALS}

Dioleoylphosphatidylcholine (DOPC), dioleoylphosphatidylethanolamine (DOPE), cholesterol (chol) and phosphatidylinositol (3,4)-bisphosphate (PI-3,4-2P) are obtained from Avanti Polar Lipids. pGEX, anti-Glutathione S-transferase (GST, $100 \mu \mathrm{g} / \mathrm{mL}$ ) antibodies and Glutathione-Sepharose 4B beads are from Amersham. Rabbit polyclonal IgG antibody (G545, affinity purified, $100 \mu \mathrm{g} / \mathrm{mL}$ ) and goat anti rabbit horseradish peroxidase (HRP, affinity purified, $100 \mu \mathrm{g} / \mathrm{mL}$ ) were from Santa Cruz Biotechnology. BamHI, EcoRI and PstI restriction enzymes and appropriate buffers were provided by Gibco BRL. Agarose and bromophenol blue were obtained from Gibco BRL. Agarose gel electrophoresis were ran in $8.5 \times 8 \mathrm{~cm}$ Owl Scientific minigel Easy-Cast systems. Ready gels of Tris- $\mathrm{HCl} \mathrm{Gel}(10 \%$ resolving gel, $4 \%$ stacking gel, $10 \%$ polyacrylamide) for SDS-PAGE were from Biorad. Protease inhibitor tablets are obtained from Boehringer Ingelheim Pharmaceuticals. Plasmid extractions were done using the Sigma GenElute Plasmid Miniprep Kit following manufacturer directions. pGEXrSynI-ABC construct containing an in-frame sequence encoding rat syn Ia A, B and C-domains was a kind gift from the Deisenhofer Laboratory (University of Texas South Western Medical Center). All DNA sequencing took place at the McGill University Genome Quebec sequencing facility and primers were designed using the Primer 3 Input (http://frodo.wi.mit.edu/). All chemicals used were analytical grade and aqueous solutions were prepared using $18.3 \mathrm{M} \Omega \cdot \mathrm{cm}$ Milli-Q water. 


\subsubsection{TRANSFORMATION OF PGEX-SYNABC IN BL21 COMPETENT CELLS}

The pGEXrSynI-ABC (pGEX-SynABC for short) construct (pGEX vector containing an in frame sequence encoding rat synapsin Ia A, B and C-domains) was generously provided by the Deisenhofer Laboratory (Deisenhofer et al. 2004; Südhof et al. 1999). Upon arrival, the plasmid was eluted from the Whatman paper using $50 \mu \mathrm{L}$ TE buffer $(10 \mathrm{mM}$ Tris- $\mathrm{HCl} \mathrm{pH} 7.5,1$ mM EDTA) and transformed into E. coli BL21 competent cells to ampicillin resistance following the manufacturer's directions for expressing sequenced constructs in BL21(DE3) Competent Cells, BL21(DE3)pLysS Competent Cells and BL21 Competent Cells (Stratagene). To confirm authenticity, the pGEX-SynABC construct was sequenced using the following primer sets:

$$
\begin{array}{ll}
\text { SynABC_1-forward } & \text { 5'-GGATGCGTTCCCAAAATTAG- 3' } \\
\text { SynABC_1-reverse } & \text { 5'-TCCGAAGAACTTCCATGTCC- 3' } \\
\text { SynABC_2-forward } & \text { 5'-CACCGACTGGGCAAAATACT- 3' } \\
\text { SynABC_2-reverse } & \text { 5'-TGGTCTTCCAGTTCCCTGAC- 3' } \\
\text { SynABC_3-forward } & \text { 5'-AGAGATGCTCAGCAGCACAA- 3' } \\
\text { SynABC_3-reverse } & \text { 5'-GGCAGATCGTCAGTCAGTCA- 3' } \\
\text { SynABC_4-forward } & \text { 5'-CTCCTCCATGCCACTCATTG- 3' } \\
\text { SynABC_4-reverse } & \text { 5'- TGCCACCTGACGTCTAAGAA- 3' }
\end{array}
$$

\subsubsection{GENERATION OF SYNAPSIN PHOSPHORYLATION Site MUTANTS}

Generation of a pseudophosphorylated Ser-9 $\rightarrow$ Asp (pGEX-Syn-Asp) mutant and a nonphosphorylatable Ser-9 $\rightarrow$ Ala (pGEX-Syn-Ala) mutant was accomplished using the QuikChange Site-Directed Mutagenesis kit from Stratagene under the manufacturer's directions for temperature cycling and transformation. Temperature cycling was accomplished using $10 \mathrm{ng}$ of 
pGEX-SynABC plasmid DNA $(5 \mu \mathrm{L})$ with 7 min extension time. The reaction ran for 16 cycles using the following mutation specific PAGE purified primers:

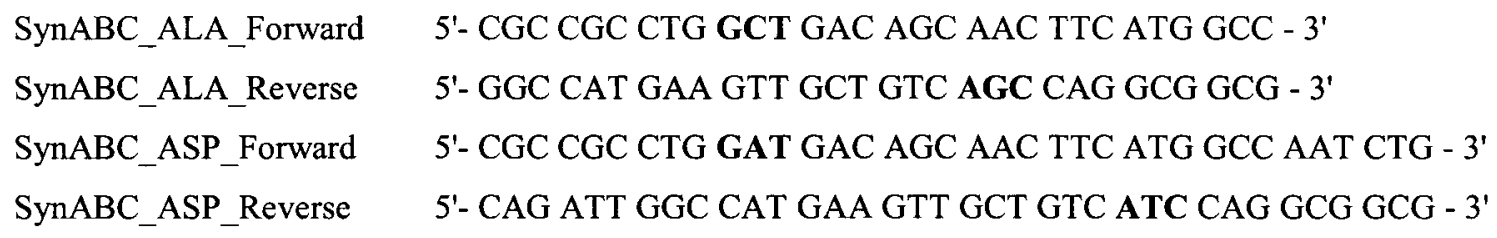

The amplified product was transformed into XL1-Blue Supercompetent Cells to ampicillin resistance (PUC18 was used as a control plasmid). Modifications made to the manufacturer's procedure included the use of SOC media instead of $\mathrm{NZY}^{+}$amine broth. The resulting expression plasmids were verified by sequencing using SynABC_1-forward and SynABC_1-reverse primers. Colony screening was attempted by directly performing a Polymerase Chain Reaction (PCR) on transformants. PCR follows the standard Taq Polymerase PCR protocol (Invitrogen) (template DNA was not extracted from the selected colonies, as they were pricked and added to the reaction mixture). The following primer sets, containing the desired mutation at the Forward primer 3' end were used for the PCR:

SynABC-ALAc_Forward SynABC-ALAc_Reverse SynABC-SERc_Forward SynABC-SERc_Reverse SynABC-ASPc_Forward SynABC-ASPc_Reverse
5'-GAT TGA TGG ACG CCG CGG CGG ACG CT- 3' 5'-ACC TTG ACC TTG CCC ATC CCA GAG TGT G- 3' 5'-GAT CTA ACT ACC TGC GGC GCC GCC TGT CG- 3' 5'-CTA CCT TGA CCT TGC CCA TCC CAG AGT GTG- 3' 5'-GGA TCT AAC TAC CTG CGG CGC CGC CTG GAT- 3' 5'-CTA CCT TGA CCT TGC CCA TCC CAG AGT GTG- 3' 


\subsubsection{RESTRICTION DIGESTION}

Restriction enzyme digests were performed by incubating double-stranded DNA with an appropriate amount of restriction enzyme, in buffers as recommended by the supplier (Gibco BRL), at the optimal temperature. BamHI, EcoRI and PstI restriction enzymes were used on pGEX-SynABC, pGEX-Syn-Ala and pGEX-Syn-Asp constructs.

\subsubsection{AGAROSE GEL ELECTROPHORESIS}

Agarose gels $(1 \%)$ were run for $1.5 \mathrm{~h}$ at 60 volts in TAE buffer $(0.4 \mathrm{M}$ Tris acetate $(\mathrm{pH} 8)$ and 0.001 M EDTA in d.d $\mathrm{H}_{2} \mathrm{O}$ ). DNA samples were diluted 1:6 in DNA sample buffer $\mathrm{V}$ $\left(0.25 \%(w / v)\right.$ bromophenol blue and $40 \%$ sucrose $(w / v)$ in d.d $\left.\mathrm{H}_{2} \mathrm{O}\right)$. Gels were stained with 0.5 $\mu \mathrm{g} / \mathrm{mL}$ ethidium bromide (in TAE buffer) and photographed under UV light (312 nm).

\subsubsection{EXPRESSION AND PURIFICATION OF RECOMBINANT PROTEINS}

Overnight cultures of BL21 pGEX-SynABC and pGEX-4T-1 (for expression of pure GST), as well as XL1-Blue pGEX-Syn-Ala and pGEX-Syn-Asp containing ampicillin (100 $\mathrm{mg} / \mathrm{mL}$ ) are used to inoculate large-scale cultures of Luria broth (ampicillin $100 \mathrm{mg} / \mathrm{mL}$ ), respectively. Cultures were grown at $37^{\circ} \mathrm{C}$ to $\log$ phase and induced with isopropyl b-Dthiogalactopyranoside (IPTG) $(100 \mathrm{mM})$ for $3 \mathrm{~h}$. Protein expression was followed after every hour of induction by analysis of $1 \mathrm{~mL}$ of extracted samples using Western Blotting with Enhanced Chemiluminescent (ECL) analysis as described by Amersham International. Cells were harvested by centrifuging (5000 RPM, $10 \mathrm{~min}$, at $4^{\circ} \mathrm{C}$ ) and resuspended in ice cold $1 \times$ PBS buffer $\left(40 \mathrm{mM} \mathrm{NaCl}, 2.7 \mathrm{mM} \mathrm{KCl}, 10 \mathrm{mM} \mathrm{Na} 2 \mathrm{HPO}_{4}, 1.8 \mathrm{mM} \mathrm{KH}_{2} \mathrm{PO}_{4}, 1 \mathrm{mM}\right.$ EDTA, $1 \mathrm{mM}$ 
EGTA), and protease inhibitors were in one tablet/ $50 \mathrm{~mL}$ of buffer. Bacterial cells were lysed by sonication (Virsonic 60, 5 times 10-15 sec, on ice). Insoluble fragments were pelleted, and GST fusion proteins (SynABC, Syn-Ala, Syn-Asp) were purified by affinity chromatography on glutathione-Sepharose under non-denaturing conditions. Twenty $\mu \mathrm{L}$ of eluted fraction was analyzed by SDS-PAGE (10\% polyacrylamide gels and stained with Coomassie Brilliant Blue) and the rest of the proteins were dialyzed against a buffer $(50 \mathrm{mM} \mathrm{KCl}, 20 \mathrm{mM}$ HEPES, $1 \mathrm{mM}$ EDTA, $0,05 \%$ Tween-20, $\mathrm{pH}$ 7.4) for 12-17 h. Protein purity was further analyzed by SDSPAGE on $10 \%$ polyacrylamide gels (stained with Coomassie Brilliant Blue) and protein concentration was determined using a standard curve prepared from BSA (Pierce albumin standard $1 \mathrm{mg} / \mathrm{mL}$ in d.d $\mathrm{H}_{2} \mathrm{O}$ ) following instructions from the BCA Protein Assay kit (Pierce).

\subsubsection{PREPARATION OF LUVS}

DOPC, DOPE, PI-3,4-2P and chol were dissolved in chloroform/methanol $(2: 1, \mathrm{v} / \mathrm{v})$. Lipid films of DOPC alone and mixtures (2:1:1:1 mol\%) obtained after drying the solvent, were hydrated and vortexed in a sucrose solution ( $91 \mathrm{mM}$ sucrose, $10 \mathrm{mM}$ HEPES, $1 \mathrm{mM}$ EDTA, pH 7.4) to obtain multilamellar vesicles. The samples were then extruded 9 times through two polycarbonate membranes ( $100 \mathrm{~nm}$ pore diameter, Avestin) to clarity to form LUVs. Final lipid concentration was determined by Phosphate assay (Cheetham lab manual). Vesicles were either used immediately or stored at $4{ }^{\circ} \mathrm{C}$ for up to a week prior to use.

\subsubsection{PHOSPHATE ASSAY}

A series of standards were made ranging from 0 to $100 \mathrm{mM}$ from a $1 \mathrm{mM}$ potassium phosphate $\left(\mathrm{KH}_{2} \mathrm{PO}_{4}\right)$ solution (final volume of $100 \mu \mathrm{L}$ was completed with Milli-Q water). Five 
$\mu \mathrm{L}$ of liposome samples and standards were used and final volumes were made up to $100 \mu \mathrm{L}$ with Milli-Q water. Thirty $\mu \mathrm{L}$ of $10 \%$ magnesium nitrate $\left[\mathrm{Mg}\left(\mathrm{NO}_{3}\right)_{2} \cdot 6 \mathrm{H}_{2} \mathrm{O}\right.$ in $95 \%$ ethanol] was added and the tubes were heated over a Bunsen burner with gentle shaking until all the fumes had disappeared. After cooling to room temperature, $0.3 \mathrm{~mL}$ of $0.5 \mathrm{M} \mathrm{HCl}$ was added to each tubes and vortexed. Tubes were then capped with marbles, boiled for 10 minutes, and cooled to RT. Then $0.7 \mathrm{~mL}$ of a working solution [ $5 \mathrm{~mL}$ of solution $\mathrm{A}\left(10 \% \mathrm{w} / \mathrm{v}\right.$ ascorbic acid in $\left.\mathrm{d} \cdot \mathrm{d} \mathrm{H}_{2} \mathrm{O}\right)$ $+30 \mathrm{~mL}$ of solution $\mathrm{B}\left(42 \% \mathrm{w} / \mathrm{v}\right.$ ammonium molybdate $4 \mathrm{H}_{2} \mathrm{O}$ in $\left.\left.1 \mathrm{~N} \mathrm{H}_{2} \mathrm{SO}_{4}\right)\right]$ was added, vortexed, and incubated for $20 \mathrm{~min}$ at $45^{\circ} \mathrm{C}$. Absorbance at $820 \mathrm{~nm}$ was measured using a Beckman UV/Vis spectrophotometer against $d \cdot d \mathrm{H}_{2} \mathrm{O}$ and the phosphate concentrations were calculated using a linear regression of the standards.

\subsubsection{LIPOSOME BINDING ASSAYS}

Volumes of buffers, LUV and protein solutions were calculated and the final volume was adjusted to $50 \mu \mathrm{L}$. The appropriate volume of liposomes and proteins were added to the binding buffer A (50 mM KCl, $20 \mathrm{mM}$ HEPES, $1 \mathrm{mM}$ EDTA, pH 7.4) to final volume of $60 \mu \mathrm{L}$ and allowed sufficient time to bind (usually $30 \mathrm{~min})$. The mixtures were spun $(1000 \times \mathrm{g}$ for $1 \mathrm{~h}$ at $\left.4^{\circ} \mathrm{C}\right)$. Supernatants were separated, and the pellets $(10 \mu \mathrm{L})$ were suspended in $50 \mu \mathrm{L}$ of binding buffer A. To determine bound proteins, both supernatant and pellet were resolved by SDS-PAGE on $10 \%$ polyacrylamide gels and stained with Coomassie Brilliant Blue. GST alone was used as a negative control. Also used were incubations of SynABC, Syn-Ala and Syn-Asp without liposomes. 


\subsection{RESULTS}

\subsubsection{Creating Mutant Clones by Site Direct Mutagenesis}

Stratagene's Site Directed Mutagenesis Kit is a simplified method to perform point mutations in double stranded vector templates. In this study, the desired mutations, Ser-9 $\rightarrow$ Ala and Ser-9 $\rightarrow$ Asp, were incorporated into specific oligonucleotide primers that cover the area where the mutation is to be made in the pGEX-SynABC vector template, and were used for temperature cycling. The resulting PCR products were then incubated with DpnI restriction enzyme to digest the parental methylated and hemi-methylated plasmid DNA. After transformation, bacterial colonies were screened to identify positive mutants. A second round of PCR reactions were performed using forward primers designed to contain either the wildtype serine, alanine, or aspartic acid mutations at their 3' ends, respectively. Primer pairs should consequently only work if the correct mutation is present. Results indicated that all 3 sets of primers (3' Ser, Ala, and Asp) bound to all transformants, as well as wildtype pGEX-SynABC, and would therefore need further optimization to allow for better primer selectivity. Three rounds of temperature gradient PCRs were performed at varying annealing temperature (from 50.1 to $79.0^{\circ} \mathrm{C}$ ) to eliminate non-specific products. But primer selectivity was not achieved because all three sets of primers still bound the un-mutated pGEX-SynABC (data not shown).

Transformants containing a plasmid of $6199 \mathrm{bp}$ (molecular weight of the pGEX-SynABC construct) were selected and sequenced. Sequencing, using A-domain specific primers, revealed that of the 4 clones ( 2 Syn-Asp and 2 Syn-Ala), 3 of them possessed the induced Ser- 9 mutations (Figure 2.1). 
Figure 2.1 Partial Clustal W 2.0.5 multiple sequence alignment of results obtained from sequencing of the synapsin A-domain of two potential clones containing the Ser-9 $\rightarrow$ Ala mutation (Syn-Alal and 2) and two potential clones containing the Ser-9 $\rightarrow$ Asp mutation (SynAsp 1 and 2). Wildtype pGEX-Syn was also sequenced and aligned as a control. The pink box represents the second codon of the syn Ia A-domain (first codon was omitted during initial cloning). The blue represents areas of discrepancy in the alignment at position 9 of the A-domain as a direct result of site direct mutagenesis of the pGEX-SynABC construct. One out of the two presumed pGEX-Syn-Ala constructs did in fact possess the Ser-9 $\rightarrow$ Ala mutation while both of the suspected pGEX-Syn-Asp constructs possess the Ser-9 $\rightarrow$ Asp mutation. 
5ranse: EMtast 4⿻一𠃋十 Stren:a: $5+30: 52$

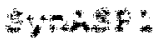
Satristo 5ituse

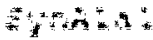
$5+2 \times 2 x^{2}$

guxiser:

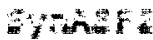
zande gyints: stimists

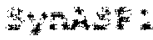
Sy+tons gyone Gintala syind:

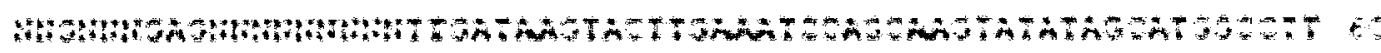

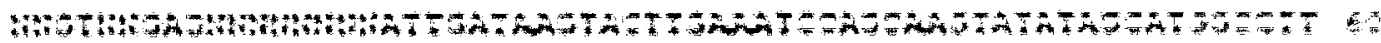

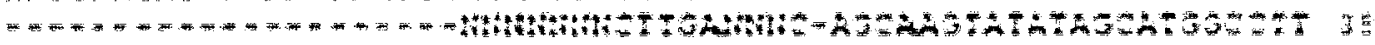

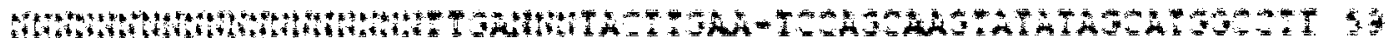

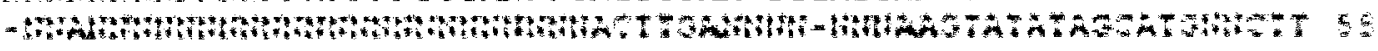

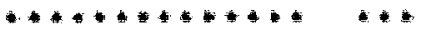

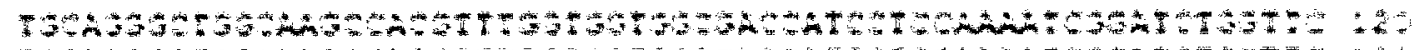

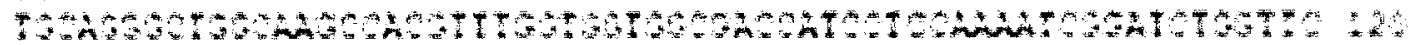

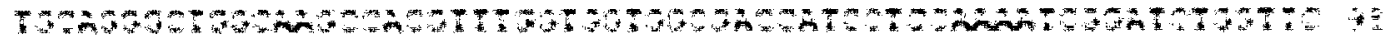

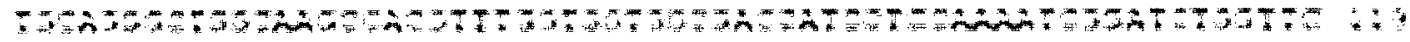

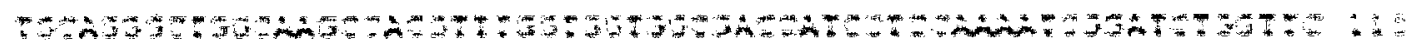

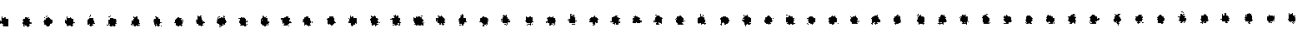

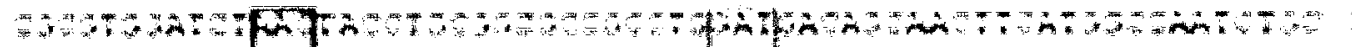

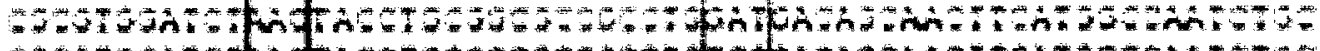

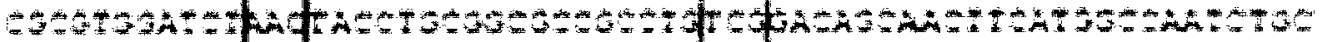

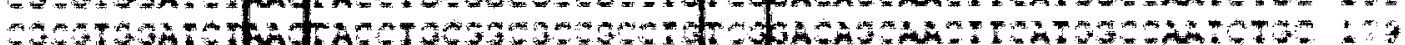

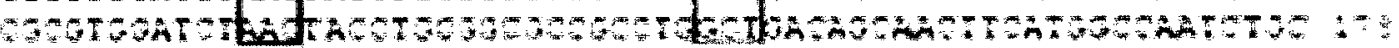

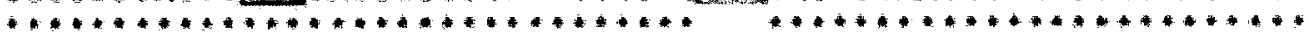

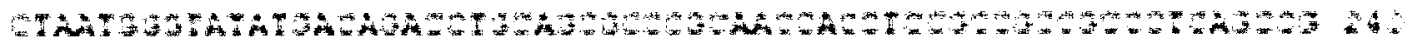

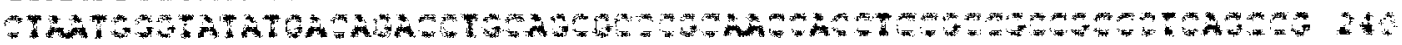

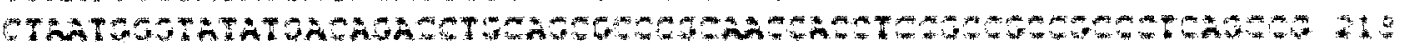

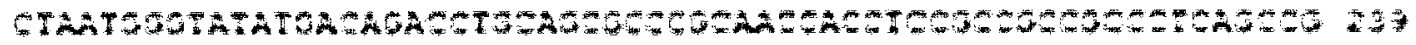

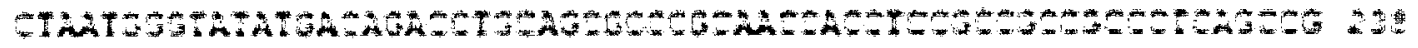
$\ldots \ldots \ldots \ldots \ldots \ldots \ldots \ldots \ldots \ldots \ldots \ldots \ldots \ldots \ldots \ldots \ldots \ldots \ldots \ldots \ldots \ldots \ldots \ldots \ldots \ldots \ldots \ldots \ldots \ldots \ldots \ldots$ 
Further characterization of the mutant constructs was accomplished through BamHI, EcoRI, and PstI restriction enzyme single digestions. Wildtype pGEX-SynABC construct was used as a control. For all constructs, digestion revealed the presence of 2 bands when digested

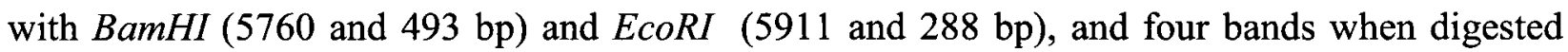
with PstI (4051, 1608, 344 and $196 \mathrm{bp)} \mathrm{(data} \mathrm{not} \mathrm{shown).} \mathrm{These} \mathrm{findings} \mathrm{indicate} \mathrm{that} \mathrm{the}$ integrity of the $6199 \mathrm{bp}$ vector template (pGEX-SynABC) was maintained during replication as a result of using the Stratagene's QuickChange Site Directed Mutagenesis Kit.

\subsubsection{EXPRESSION OF GST-SYNAPSIN FUSION PROTEINS}

Expressed GST fusion proteins are soluble in aqueous solutions and can be purified from crude bacterial lysates by affinity chromatography on immobilized glutathione. Here, E. coli BL21 cells containing pGEX-SynABC, pGEX-Syn-Ala or pGEX-Syn-Asp constructs were respectively grown overnight and induced with $1 \mathrm{mM}$ IPTG (a lactose analogue) to allow dissociation of the lac repressor (product of the lac I gene) from the $\mathrm{P}_{\text {tac }}$ promoter to promote GST fusion protein expression. Time course inductions of the GST-fusions (SynABC, Syn-Ala and Syn-Asp) were performed to optimize induction time (Figure 2.2 A, B and C). For all three fusion proteins, a three-hour induction was used. E. coli BL21 cells containing the empty pGEX-4T-1 vector were used to express pure GST (Figure 2.2 D), and the polypeptide will be used as a control in subsequent binding experiments (a three-hour induction time was also deemed optimal). The molecular weight of $26 \mathrm{kDa}$ (Margret $\mathrm{B}$ et al. 2007) was assigned to pure GST while a molecular weight of $66 \mathrm{kDa}$ (GST $26 \mathrm{kDa}$, synapsin A, B and C-domains, 40-43 $\mathrm{kDa}$ (Deisenhofer et al. 2004) was attributed to all GST-Syn fusion proteins. 
Figure 2.2 Western blotting followed by Enhanced Chemiluminescent detection of time course induction of SynABC (A), Syn-Ala (B), Syn-Asp (C) GST fusion proteins, and pure GST (D) with $1 \mathrm{mM}$ IPTG. In (A), (B) and (C), lane 1 represents protein ladder (Kaleidoscope Prestained Standard) and lanes 2, 3 and 4 are samples analyzed after 1,2 and 3 hours of induction. Lanes found in (D) are in the opposite arrangement. Arrows indicate the molecular weight of the desired induced fusion proteins ( $26 \mathrm{kDa}$ for pure GST and $66 \mathrm{kDa}$ for GST fusion proteins). 


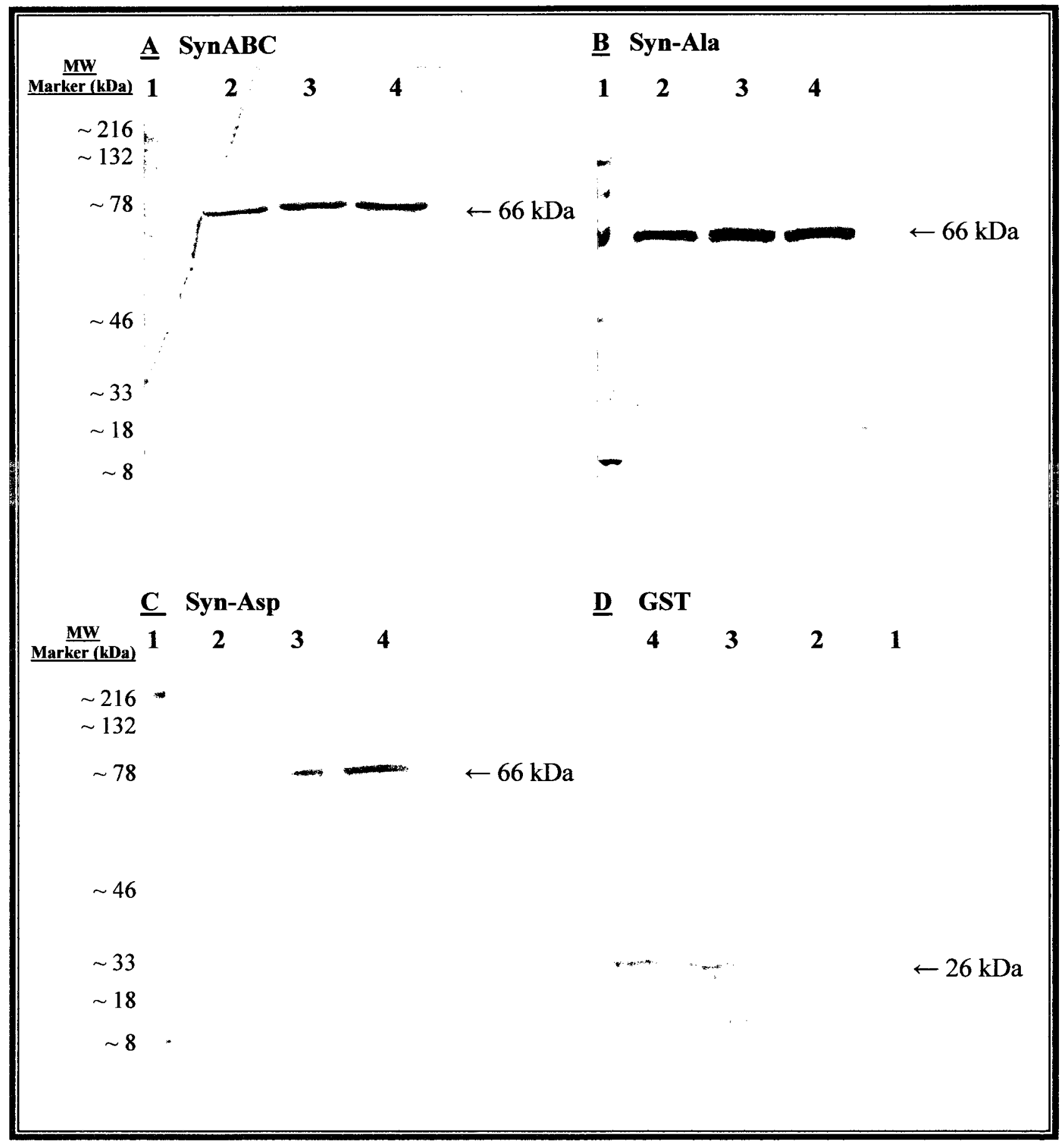

[fis 22$]$ 


\subsubsection{ProteIN PURIFICATION}

GST, SynABC, Syn-Ala and Syn-Asp proteins were purified by incubating the soluble material from lysed cells with glutathione agarose beads, followed by elution from washed beads due to competition with free glutathione. Each elution fraction was screened for the presence of the expressed fusion protein by using SDS-PAGE on $10 \%$ polyacrylamide gels followed by Coomassie Blue staining (Figure 2.3). Upon further analysis of Figure 2.3 A, B and C one can note a significant level of protein degradation (as indicated by the presence of bands ranging from about 45 to $26 \mathrm{kDa}$. Initial attempts to reduce protein degradation were made by reducing sonication times, but results indicate that further optimization is necessary. No further attempts to eliminate protein degradation were undertaken primarily because pure GST would be used as a control in protein-liposome binding experiments.

Using the standard BCA Protein Assay Kit (Pierce), protein yield was evaluated to be $1.93 \mathrm{mg} / \mathrm{mL}, 1.63 \mathrm{mg} / \mathrm{mL}, 1.18 \mathrm{mg} / \mathrm{mL}$ and $0.96 \mathrm{mg} / \mathrm{mL}$ for GST, SynABC, Syn-Ala and SynAsp, respectively.

\subsubsection{PROTEIN-LIPOSOME BINDING ASSAYS}

Lipid mixtures comprised of DOPC, DOPE, chol, PI and/or PI isomers have often been used to mimic SV composition (Südhof et al. 1989; Deinsenhofer et al. 2004). Here, SynABC, Syn-Ala and Syn-ASP proteins were incubated with either $100 \%$ DOPC or DOPC, DOPE, chol, PI-3,4-2P (2:1:1:1 mol\%) multicomponent LUVs at a 1/305 (mol/mol) ratio.

Following incubation, liposomes were pelleted, the supernatant was removed and pellets were resuspended in the appropriate volume of assay buffer. Analysis of SynABC-liposome 
binding indicated that the combined A-, B- and C-domains do not bind to liposomes made of pure DOPC, almost all protein was in the supernatant. Similar supernatant protein levels were observed in the protein control where SynABC was incubated without liposomes. SynABC did bind to liposomes containing the anionic phospholipids (PI-3,4-2P), as indicated by its presence in the pellet (Figure 2.4 A). Similar results were observed for the non-phosphorylatable Syn-Ala (Figure 2.4 B) but varied slightly for the pseudophosphorylated Syn-Asp (Figure 2.4 C). Although Syn-Asp did bind charged liposomes, it did not do so to the same extent of that of the other two fusion proteins. Only a small amount of Syn-Asp was seen to be sedimented into the pellet. Pure GST was used as a negative control and did not bind to liposomes regardless of the phospholipid charge (Figure 2.4 D). The binding results were not quantified. 
Figure 2.3 Coomassie Blue stained 10\% polyacrylamide gel of eluted purified SynABC (A), Syn-Ala (B), Syn-Asp (C) GST fusion proteins and pure GST (D). In all cases, lane 1 represents the protein molecular ladder (Kaleidoscope Prestained Standard), lanes 2-10 represent eluted fractions 1 to 9 . Arrows indicate the molecular weight of the desired purified proteins ( $26 \mathrm{kDa}$ for pure GST and $66 \mathrm{kDa}$ for GST fusion proteins). Protein degradation can be seen in $\mathbf{A}, \mathbf{B}$ and C, as indicated by the presence of bands of lesser molecular weight than that of the desired protein. 


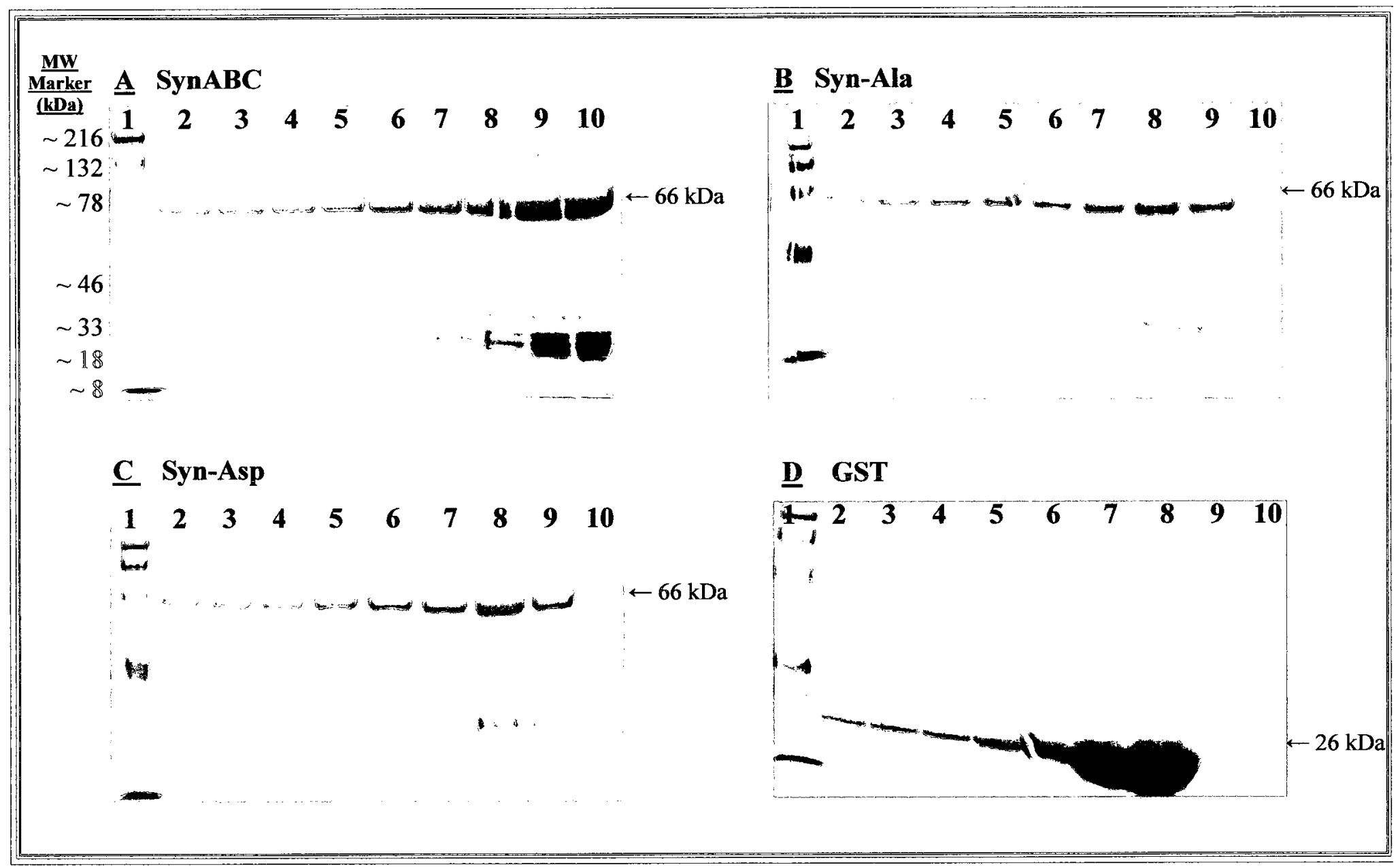

[fig 2.3 
Figure 2.4 Coomassie Blue stained 10\% polyacrylamide gel of protein-liposome binding assays. In the case of SynABC (A), Syn-Ala (B) and Syn-Asp (C) lanes 1 and 2 represent pellet and supernatant after incubation with 100\% DOPC liposomes. Lanes 3 and 4 represent pellet and supernatant, respectively, after incubation with DOPC, DOPE, chol, PI-3,4-2P (2:1:1:1 mol\%) liposomes. Lanes 5-6 and 7-8 are control incubations. Lanes 5 and 6 are pellet and supernatant after incubation of GST with charged liposomes (no binding should be evident) and lanes 7-8 are pellet and supernatant of the respective fusion protein without any liposomes. Lane 9 represents the protein molecular ladder (Kaleidoscope Prestained Standard). Note that in all cases, lanes 1 and 2 show the similar protein levels in pellet and supernatant as the 7 and 8 control lanes indicating that it was not possible to eliminate all proteins by extraction of the supernatant. Similar levels of proteins are seen in lanes 3 and 4 for SynABC (A) and Syn-Ala (B) after incubation with charged lipids, but more proteins seem to be present in lane 4 for Syn-Asp (C) indicating less binding to the supernatant. Pure GST (D) was incubated with $100 \%$ DOPC liposomes lanes 1 and 2, charged liposomes lanes 3 and 4 and no liposomes in lanes 5 and 6 . Lane 7 represents the protein molecular ladder. 


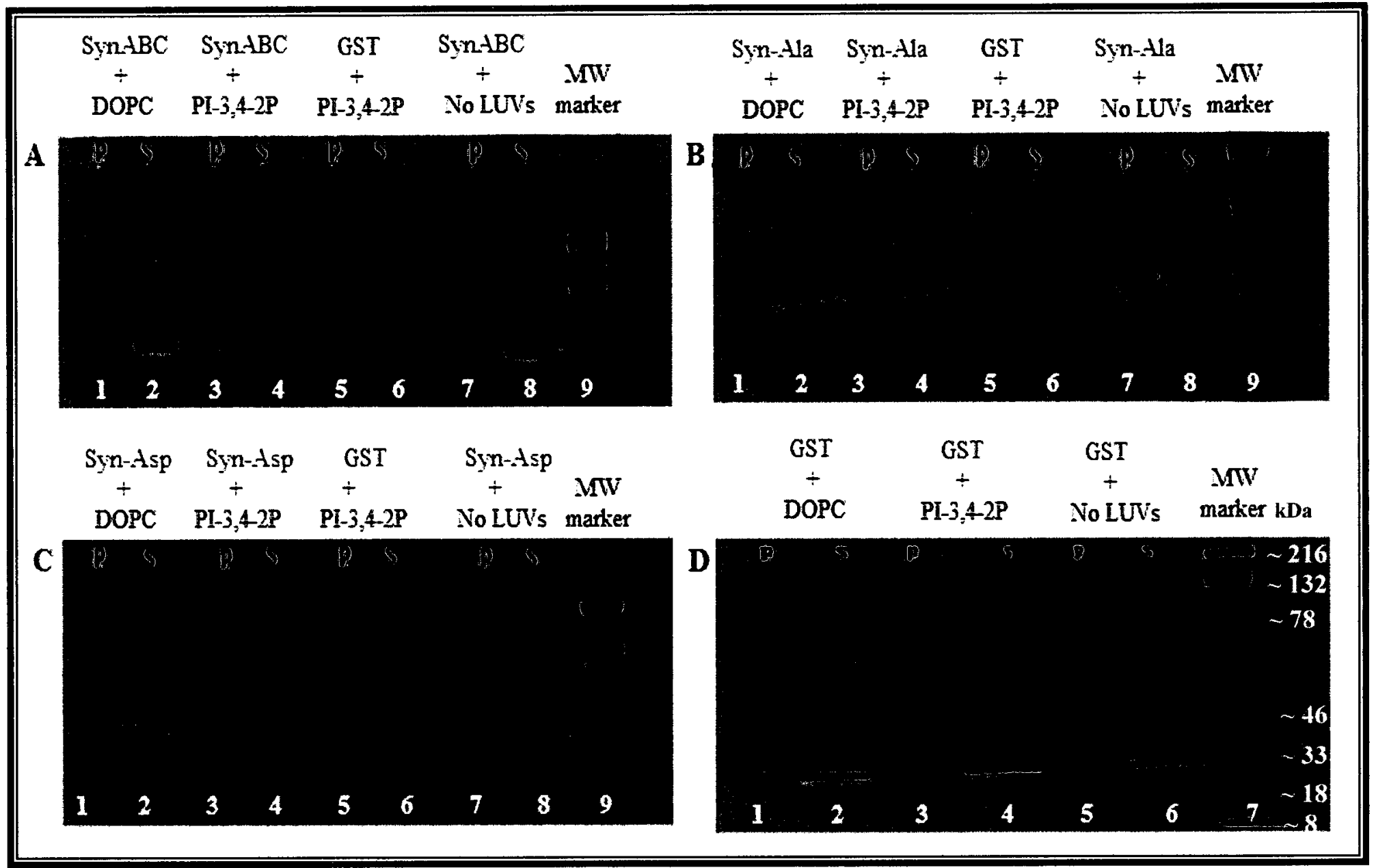

$[f i[2.4]$ 


\subsection{DISCUSSION}

Synapsins are the most abundant phosphoproteins found in the presynaptic nerve terminal (Benfenati et al. 1993a). The average concentration of syn Ia is approximately $10-30 \mu \mathrm{M}$, and it has been estimated that 10-20 synapsin molecules are present on a single SV (Scheibler et al. 1986; Benfenati et al. 1989c; De Camilli et al. 1990). Because synapsins are the most abundant SV protein, it has been suggested that their binding to vesicles is mediated by lipid-protein interactions rather than more specific protein-protein interactions. This hypothesis was supported by the discovery that binding of synapsins to SVs was initiated by electrostatic attraction between the A-domain and negatively charged head groups on the surface of the membrane (Cheetham et al. 2001). In this study, the combined A, B and C-domains of syn Ia was found to bind preferentially to charged liposomes rather than neutral liposomes thus further highlighting synapsin's preference for anionic phospholipids. Similar results have been obtained in previous studies where increasing the percentage of anionic lipids in liposomes from $20 \%$ phosphatidylserine (PS) to $50 \%$ PS, increased the labeling of synapsin by $\left[{ }^{125} \mathrm{I}\right]$ TID (syn Ia was not labeled in pure DOPC or DOPE due to the lack of anionic phospholipids) (Benfenati et al. 1992; Benfenati et al. 1993a; Cheetham et al. 2001).

Phosphorylation of synapsin causes conformational changes of the protein molecule, and is associated with major changes in its biological properties (Benfenati et al. 1993a). Thus the prime candidate for such modulatory function is the N-terminal phosphorylation site 1 in the Adomain as it is the only phosphorylation site that is present in all synapsins (Südhof et al. 1999). In this study, site directed mutagenesis was successfully used to create two mutant proteins that mimic the phosphorylated and de-phosphorylated states of syn la in order to further study synapsin-lipid binding kinetics. Our results indicate that pseudophosphorylation (Ser-9 $\rightarrow$ Asp) of 
phosphorylation site 1 in the A-domain reduces binding to anionic liposomes but does not completely inhibit all interactions. These results are somewhat contradictory to results obtained by Südhof et a.,1999, in which complete, not partial, loss of protein-liposome interactions occurred when pseudophosphorylated (Ser-9 $\rightarrow$ Asp) mutants were used in binding assays. So why do our results differ? We hypothesize that the highly conserved synapsin C-domain might have a greater impact on synapsin-liposome interactions. The crystal structure of the C-domain of syn Ia revealed that it is structurally similar to ATP-dependent synthetases suggesting an enzymatic activity for synapsins (Esser et al. 1998). In addition synapsins have been shown to bind to ATP with high affinity and to ADP with lower affinity (Hosaka and Südhof 1998), indicating that synapsins may represent phosphotransfer enzymes. Since PI and PI isomer head groups share similar structural properties to that of ATP, phosphoinositol-C-domain complexes might function as another biological mechanism by which synapsins tether SVs. The modulatory action of phospholipid-C-domain complexes are however unlikely to regulate vesicle release to the same extent as phospholipid-A-domain complexes, because no phosphorylation site has been linked to the C-domain. Our data further supports the important modulatory functions of Adomain as we demonstrate that the combined A, B and C-domains of syn Ia only bind to liposomes containing anionic phospholipids, and that interaction is greatly reduced upon Adomain phosphorylation. Further directions for this study would be to compare binding kinetics of the pseudophosphorylated A-domain with liposomes containing different PI isomers or another anionic phospholipid such as phosphatidylserine. 


\section{HYPOTHESIS II}

\section{MEMBRANE LIPID COMPOSITION MEDIATES SYNAPSIN IA-LIPOSOME BINDING}

Binding of syn Ia to liposomes has been shown to induce reorganization of membrane lipids as shown by phosphorous NMR and differential scanning calorimetry studies. This reorganization stabilizes the phospholipid bilayer and consequently, maintains SV integrity and size uniformity by preventing random fusion events. Here, we investigate if synapsin binding is regulated by the chemical composition of the lipid membrane. Interestingly, although the binding of syn Ia to anionic vesicles has been well studied (Benfenati et al. 1989b; Benfenati et al. 1993a; Cheetham et al. 2001), as of yet, the precise dependence of the class of charged lipids, in particular specific PIs, is not known. To this aim, full-length Alexa 488-labeled dephosphorylated syn Ia, was used to observe the protein's binding affinity to LUVs respectively containing specific PI or PI isomers. High speed centrifugation was used to separate LUV bound protein from unbound material. Direct determination of protein binding affinity was achieved by measuring fluorescence emission of Alexa 488. Prior to binding assays however, vesicle composition was verified to ensure that our LUVs did effectively incorporate phosphatidylinositides as these lipids are known to form micelles. Our results indicate that we were able to effectively incorporate PI and PI isomers into LUVs and that syn Ia has highest binding affinity towards both unphosphorylated PI and monophosphorylated derivatives. 


\subsection{MATERIALS AND METHODS}

\subsubsection{MATERIALS}

Dioleoylphosphatidylcholine (DOPC), dioleoylphosphatidylethanolamine (DOPE), cholesterol (chol), 1,2-dioleoyl-sn-glycero-3-phosphoethanolamine-N-(biotinyl) (Biotin-DHPE) and phosphatidylinositol (PI) and PI isomers (Phosphatidylinositol 3-phosphate (PI-3-P), Phosphatidylinositol 4-phosphate (PI-4-P), Phosphatidylinositol 5-phosphate (PI-5-P), Phosphatidylinositol (3,4)-bisphosphate (PI-3,4-2P), Phosphatidylinositol (4,5)-bisphosphate (PI4,5-2P) and Phosphatidylinositol (3,4,5)-trisphosphate (PI-3,4,5-3P)) are obtained from Avanti

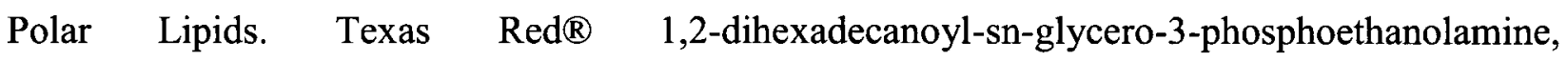
triethylammonium salt (TR-DHPE) was from Invitrogen. Alexa 488 protein labeling kit was from Molecular Probes and the BCA Protein Assay kit was from Pierce. All chemicals were of analytical grade and aqueous solutions were prepared using 18.3 M $\Omega \cdot \mathrm{cm}$ Milli-Q water.

\subsubsection{Protein Preparation}

Syn Ia was previously purified from bovine brain under non denaturing conditions (Murray et al. 2003). Proper protein folding was confirmed using circular dichroism and actin polymerization assays (Cheetham et al., unpublished). Purity was checked by SDS-PAGE (data not shown) and the protein was stored in buffer $(100 \mathrm{mM} \mathrm{NaCl}, 25 \mathrm{mM}$ Tris- $\mathrm{HCl}, \mathrm{pH} 7.4)$ at $80^{\circ} \mathrm{C}$.

The protein was labeled with Alexa 488 by using a protein labeling kit following manufacturer's directions. It was estimated that one dye can be found per protein molecule as 
estimated by absorbance at 280 and $494 \mathrm{~nm}$. Protein concentration was determined using the BCA Protein Assay kit.

\subsubsection{PREPARATION AND CHARACTERIZATION OF LUVS}

DOPC, DOPE, chol, Biotin-DHPE, TR-DHPE and selected PI or PI isomers were dissolved in chloroform/methanol $(2: 1, \mathrm{v} / \mathrm{v})$. Lipid films DOPC, DOPE, chol $(84: 1: 15 \mathrm{~mol} \%)$ and DOPC, biotin-DOPE, chol, and PI or PI isomer (74:1:15:10 mol\%) obtained after evaporating the solvent were hydrated in water to obtain multilamellar vesicles. Each sample was then extruded 9 times through two $400 \mathrm{~nm}, 200 \mathrm{~nm}$ and $100 \mathrm{~nm}$ pore diameter polycarbonate membranes respectively, to clarity to form large unilamellar vesicles (LUVs). The size of the vesicles was confirmed by Dynamic Light Scattering (DLS) using the Nicomp Nanoparticle Analyzer (Courtesy of Dr. Dennis Sprott, NRC). Vesicles were either used immediately or stored at $4{ }^{\circ} \mathrm{C}$ for up to a week prior to use.

To characterize effective phosphoinositol incorporation, LUVs were prepared from a mixture of DOPC, DOPE, chol and either $10 \%, 20 \%$ or $30 \%$ PI-4,5-2P using the above mentioned protocol. Lipid solutions were ran through a Sephadex G75 superfine column and eluted with water. A phosphate assay was performed on all eluted fractions, and fractions were further characterized by thin layer chromatography (TLC). TLC plates (Silica gel 60) were first incubated in a $5 \%$ solution of potassium oxalate in methanol:water $(2: 3, \mathrm{v} / \mathrm{v})$ for $1 \mathrm{~h}$ then activated at $110^{\circ} \mathrm{C}$ for $20 \mathrm{~min}$. Samples were applied in amounts ranging from 3 to $6 \mu \mathrm{g}$ total phosphorous in chloroform/methanol $(2: 1, \mathrm{v} / \mathrm{v})$. Plates were developed upward using chloroform/methanol/4 $\mathrm{N}$ ammonium hydroxide $(17: 7: 1, \mathrm{v} / \mathrm{v})$ and spots were revealed by exposure to iodine vapor. 


\subsubsection{LIPOSOME BINDING ASSAYS}

The appropriate volume of liposomes and proteins were added to the binding buffer A $(50 \mathrm{mM} \mathrm{KCl}, 20 \mathrm{mM}$ HEPES, $1 \mathrm{mM}$ EDTA, $\mathrm{pH}$ 7.4) to final volume of $60 \mu \mathrm{L}$ and incubated for $30 \mathrm{~min}$. The mixtures were spun $\left(1000 \times \mathrm{g}\right.$ for 1 hour at $\left.4^{\circ} \mathrm{C}\right)$. Supernatants were separated, and the pellets $(10 \mu \mathrm{L})$ were suspended in $50 \mu \mathrm{L}$ of binding buffer $\mathrm{A}$. To determine bound proteins, fluorescence spectroscopy was used (Viktor 2 Fluorometer) to quantify fluorescence of pellet and supernatant respectively. 


\subsection{RESULTS}

\subsubsection{INCORPORATION OF PI AND PI ISOMERS IN LUVS}

Surfactant molecules such as phosphoinositols tend to form micelles in solution. Their large polar headgroups aggregate and sequester their short hydrophobic chains from the surrounding solvent to form stable structures with low entropy. In order to confirm that PI monomers were being incorporated into the LUVs and not aggregating to form micelles, lipid films were prepared with 10,20 and $30 \mathrm{~mol} \%$ of PI-4,5-2P, respectively. PI-4,5-2P was used as our standard for all PIs as it was readily available.

DLS was performed to determine the size distribution of the vesicles. Table 3.1 shows DLS results of vesicles containing 10,20 or $30 \%$ PI-4,5-2P extruded with filter membranes of different $\mathrm{nm}$ pore sizes. In all three instances, vesicle mean diameter decreased upon lowering pore size. Vesicles containing $30 \%$ PI-4,5-2P have a wider distribution as indicated by high standard deviation values. The size distribution is representative of the vesicle population(s) present in the solution. If more than one population is present and they are close in size, the standard deviation (Std Dev) will be lower giving a narrower distribution and vice versa. In our case, because the mean diameter decreases and the Std Dev increases with the increasing PI-4,5$2 \mathrm{P}$ content, the wider distribution is attributed to the presence of a second population of smaller rather than larger liposomes. With micelles being between $10-20 \mathrm{~nm}$ in size, we hypothesize that the smaller population are in fact micelles. 
Table 3.1 DLS data obtained for liposomes containing either 10,20 or 30 mol\% PI-4,5-2P extruded through 400, 200 and $100 \mathrm{~nm}$ pore diameter polycarbonate membranes. Mean diameter (Mean Dia) and standard deviation (Std Dev) values were obtained for all samples extruded with all three membrane sets. Mean diameter reflects the average diameter $(\mathrm{nm})$ of the vesicle population (s) while Std Dev reflects on the width of the distribution, the higher the value, the wider the distribution. Number of samples for each lipid composition is 3 . 


\begin{tabular}{|llccc||}
\hline & & & & \\
\cline { 3 - 4 } & & \multicolumn{2}{c|}{ Polycarbonate membranes pore diameter (nm) } \\
\cline { 3 - 4 } $\mathbf{1 0 \%}$ PI-4,5-2P & & $\underline{\mathbf{4 0 0}}$ & $\underline{\mathbf{2 0 0}}$ & $\underline{\mathbf{1 0 0}}$ \\
& & 187 & 165.6 & 115.2 \\
& Mean Dia (nm) & 52.2 & 35.7 & 25.6 \\
& Std Dev (nm) & & & 108.4 \\
$\mathbf{2 0 \%}$ PI-4,5-2P & & 177.4 & 145.9 & 52.2 \\
& Mean Dia (nm) & 74.9 & 63.2 & 80.5 \\
& Std Dev (nm) & & & 45.1 \\
& & 157.3 & 123.1 & 67.4 \\
\hline
\end{tabular}

[Table $3:$ 
To test this hypothesis, all 3 vesicle types were filtered through a Sephadex G-75 column, respectively, on the basis that small micelles could easily be separated from the larger liposomes. A phosphate assay was then performed on all eluted fractions. Figure $3.1 \mathrm{~A}, \mathrm{~B}$, and C represent the total amount of phosphate per eluted fraction for vesicle solutions containing 10,20 and $30 \%$ PI-4,5-2P, respectively. In all three cases, two distinct lipid populations were obtained. For $10 \%$ PI-4,5-2P the first population eluted between fractions 2 and 8 represented $46.2 \mu \mathrm{g}$ of phosphate. The second population is represented by a small peak in fraction 10 which contains $1 \mu \mathrm{g}$ of phosphate. For the sample containing 20\% PI-4,5-2P, the first peak eluted between fractions 3 and $9(40.5 \mu \mathrm{g}$ phosphate) and the second between fractions 11 and 15 (5.4 $\mu \mathrm{g}$ phosphate). In vesicles containing 30\% PI-4,5-2P, the first peak eluted between fractions 3 and $8(47.4 \mu \mathrm{g}$ phosphate) followed by 2 smaller peaks from fractions 9 to 15 with a combined phosphate weight of $12.8 \mu \mathrm{g}$. Interestingly, the intensity of the second peak increases with the increasing PI-4,5-2P concentration (Figure 3.1). This leads us to believe that this peak corresponds to PI4,5-2P micelles.

To confirm this hypothesis, fractions corresponding to each peak were combined. Thus 2 samples, representing the two different eluted populations, were obtained for each vesicle composition and ran upwards on a TLC plate. Results indicate that the second peak does in fact correspond to PI-4,5-2P micelles as PIs are the only identifiable lipid in these samples (Figure 3.2 B). Samples pertaining to the first eluted peak (Figure $3.2 \mathrm{~A}$ ) however not only contain all other lipids but also contain a fraction of PI-4,5-2P lipids. Theoretically, at low PI-4,5-2P concentration, only phospholipid monomers are found in solution, and are free to incorporate into lipid mixtures. As the PI-4,5-2P concentration increases however, unfavourable entropy from the hydrophobic headgroups begins to dominate causing the molecules to form micelles by 
sequester their hydrophobic chains to reduce surface energy. The critical micelle concentration (CMC) is the concentration of the surfactant at which micelles are spontaneously formed. In our study, we can confirm that the CMC of PI-4,5-2P has already been reached because a small but significant PI-4,5-2P micelle population was found with the lowest PI-4,5-2P concentration tested. In all three of our samples $6.3 \mathrm{~mol} \%$ was calculated to be incorporated into our vesicles. This result is however not accurate as only $71 \%$ of total phosphate was recovered after elution, making it difficult to determine the amount of phosphate lost versus incorporated phosphate.

In an attempt to accurately quantify the PI-4,5-2P fraction that is being incorporated into our vesicle, all samples pertaining to the first and second eluted fractions were sent to the Lipid and Lipid Metabolite Analysis Core Facility (University of Alberta) for analysis by HPLC. Results were inconclusive. A quick literature search revealed that PI-4,5-2P incorporation may be largely dependent on cholesterol content. At $15 \mathrm{~mol} \%$ cholesterol, PI membrane incorporation is saturated at $8 \mathrm{~mol} \%$. In our experiment, the lipid mixture also contains $15 \mathrm{~mol} \%$ cholesterol, the above results seem to be in line with these earlier findings. 
Figure 3.1 Determination of PI-4,5-2P vesicle incorporation. Vesicle solutions containing 10 (A), 20 (B) and 30 mol\% (C) PI-4,5-2P were eluted on Sephadex G-75 columns and a phosphate assay was performed on all collected fractions. In all cases, fractions are arranged from left to right in increasing order of retention time. Fractions pertaining to the first and second eluted populations were combined for each of the PI-4,5-2P concentrations assayed, respectively, and lipid composition was determine by thin-layer chromatography (Figure 3.2). 

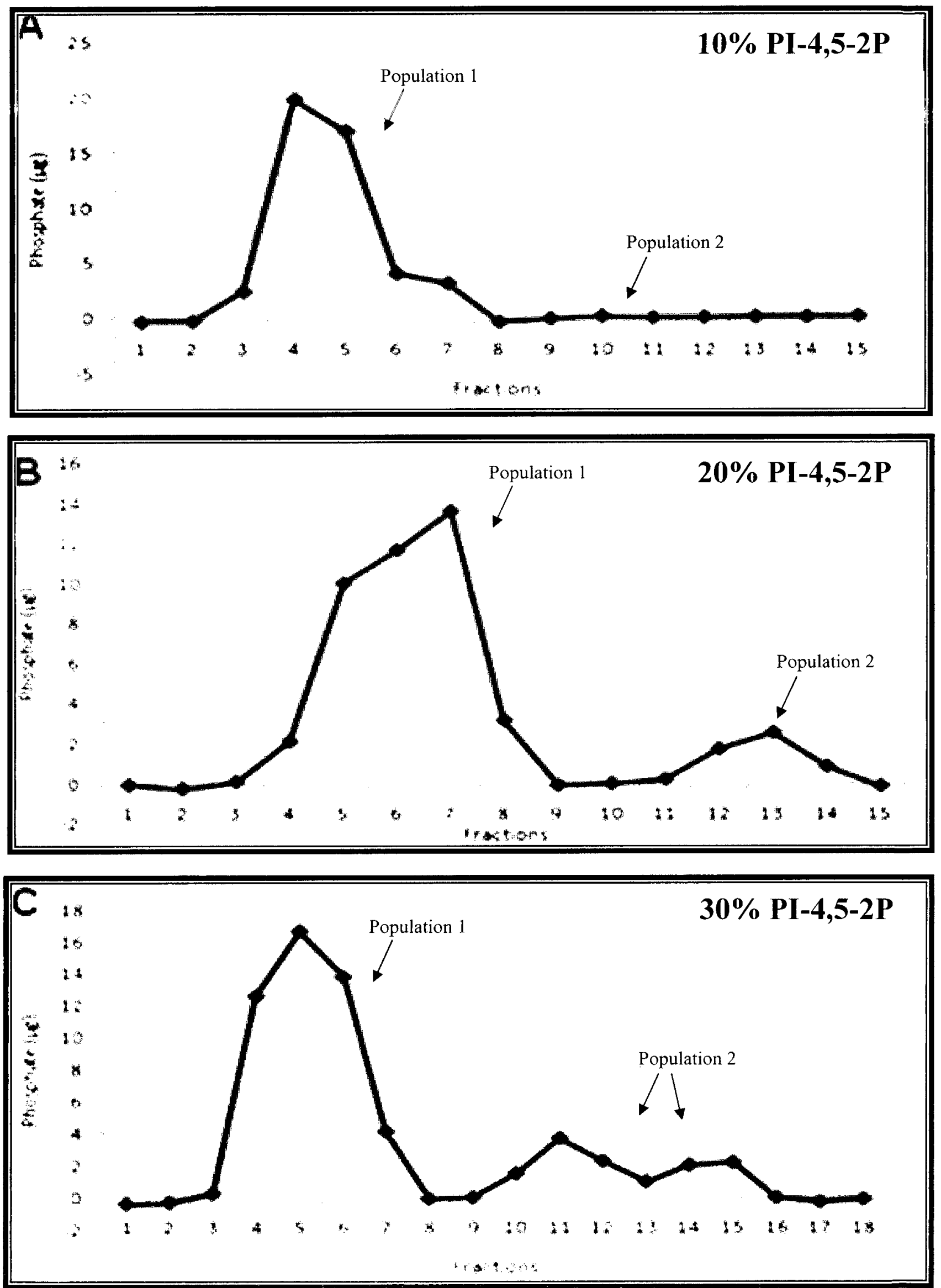
Figure 3.2 TLC on Silica gel 60 of LUVs containing same initial lipid mixture (DOPC/BiotinDHPE/chol/PI-4,5-2P/TR-DHPE) with various amounts of PI-4,5-2P. Prior to TLC, vesicle solutions were eluted on Sephadex G-75 gel and fractions pertaining to the first and second eluted populations (Figure 3.1) were respectively combined for all PI-4,5-2P concentrations tested. (A) represents TLC of the first eluted populations. Combined fractions for 10, 20 and $30 \%$ PI-4,5-2P are in lanes 6, 7 and 8, respectively. DOPC, Biotin-DHPE, chol, PI-4,5-2P and TR-DHPE were used as lipid standards and can be found in lanes 1, 2, 3, 4 and 5 respectively. The second eluted populations are represented in (B) where 10, 20 and 30\% PI-4,5-2P solution are found in lanes 1, 2 and 3. PI-4,5-2P was used as a standard and can be found in lane 4. (C) represents the total phosphate $(\mu \mathrm{g})$ of the combined eluted fractions pertaining to the second eluted population for 10,20 and $30 \%$ respectively. 

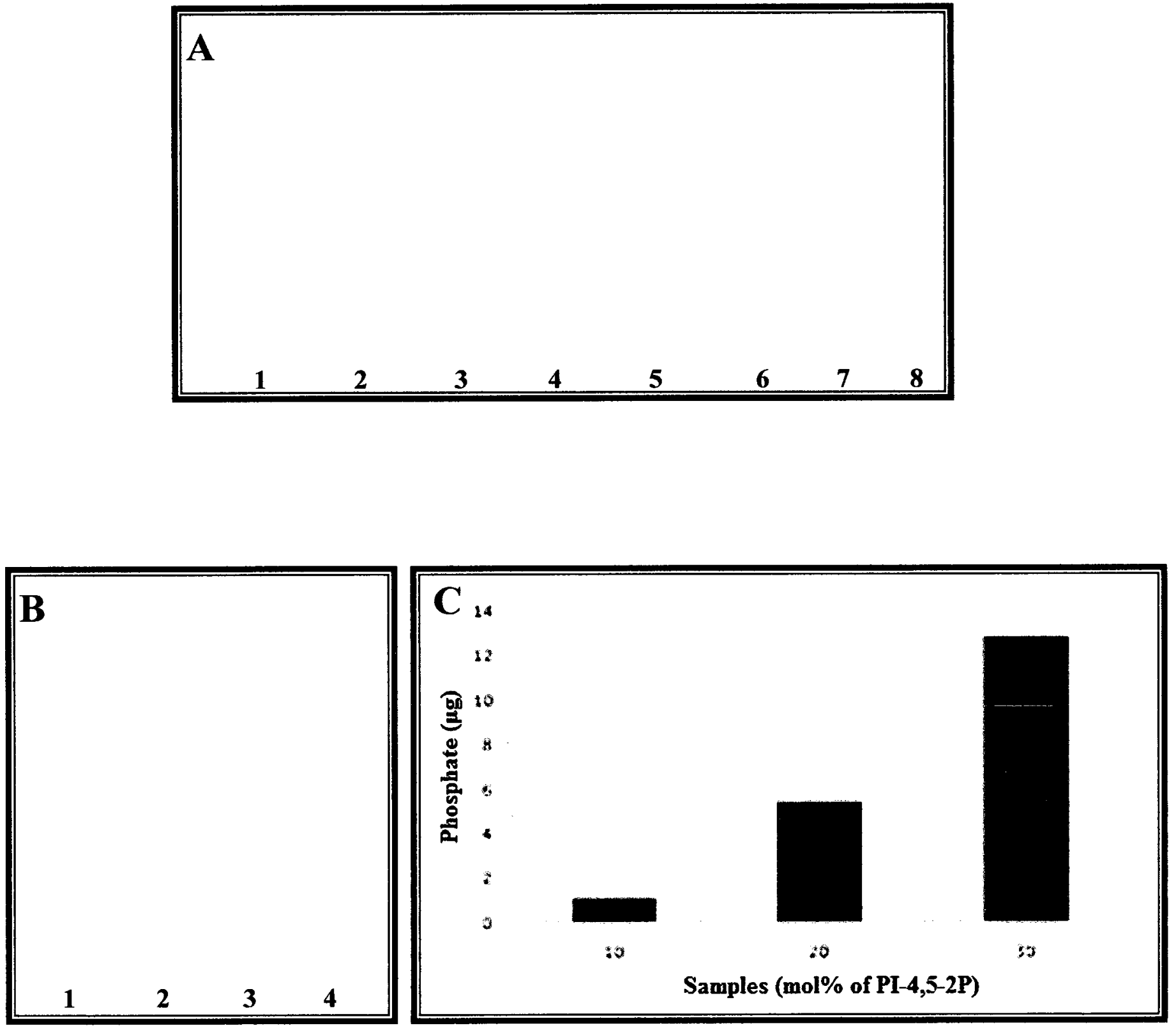

$\left[\right.$ rig. $3.2^{-1}$ 


\subsubsection{LIPOSOME BINDING}

In order to determine syn Ia binding affinity to different phosphoinositols, vesicles containing $10 \%$ of PI or PI isomers were hydrated in sucrose buffer and incubated with the protein in a $1 / 300(\mathrm{~mol} / \mathrm{mol})$ ratio. Following incubation, pellet and supernatant were separated and binding was detected and measured by fluorescence spectrophotometry.

Figure 3.3 shows percent fluorescence in both pellet and supernatant of PI and PI isomers tested. Protein alone was used as a control to indicate that all protein is found in the supernatant if no binding occurs. Our results indicate that syn Ia displays highest binding affinity towards both monophosphorylated derivatives (PI-3-P, PI-4-P, PI-5-P) and unphosphorylated PI as indicated by high levels of protein in the pellet. Synapsin exhibited moderate binding affinity towards triphosphorylated derivatives PI-2,4,5-3P and lowest binding affinity for diphosphorylated derivatives (PI-3,4-2P and PI-4,5-2P). DOPC only vesicles, used as a negative control, also demonstrated significant protein binding. 
Figure 3.3 Syn Ia selective binding with varying phosphatidylinositide residues. Syn Ia displays highest binding affinity towards PI-3-P, PI-4-P, PI-5-P and phosphatidylinositol, moderate binding affinity towards PI-2,4,5-3P and lowest binding affinity with PI-3,4-2P and PI-4,5-2P. 


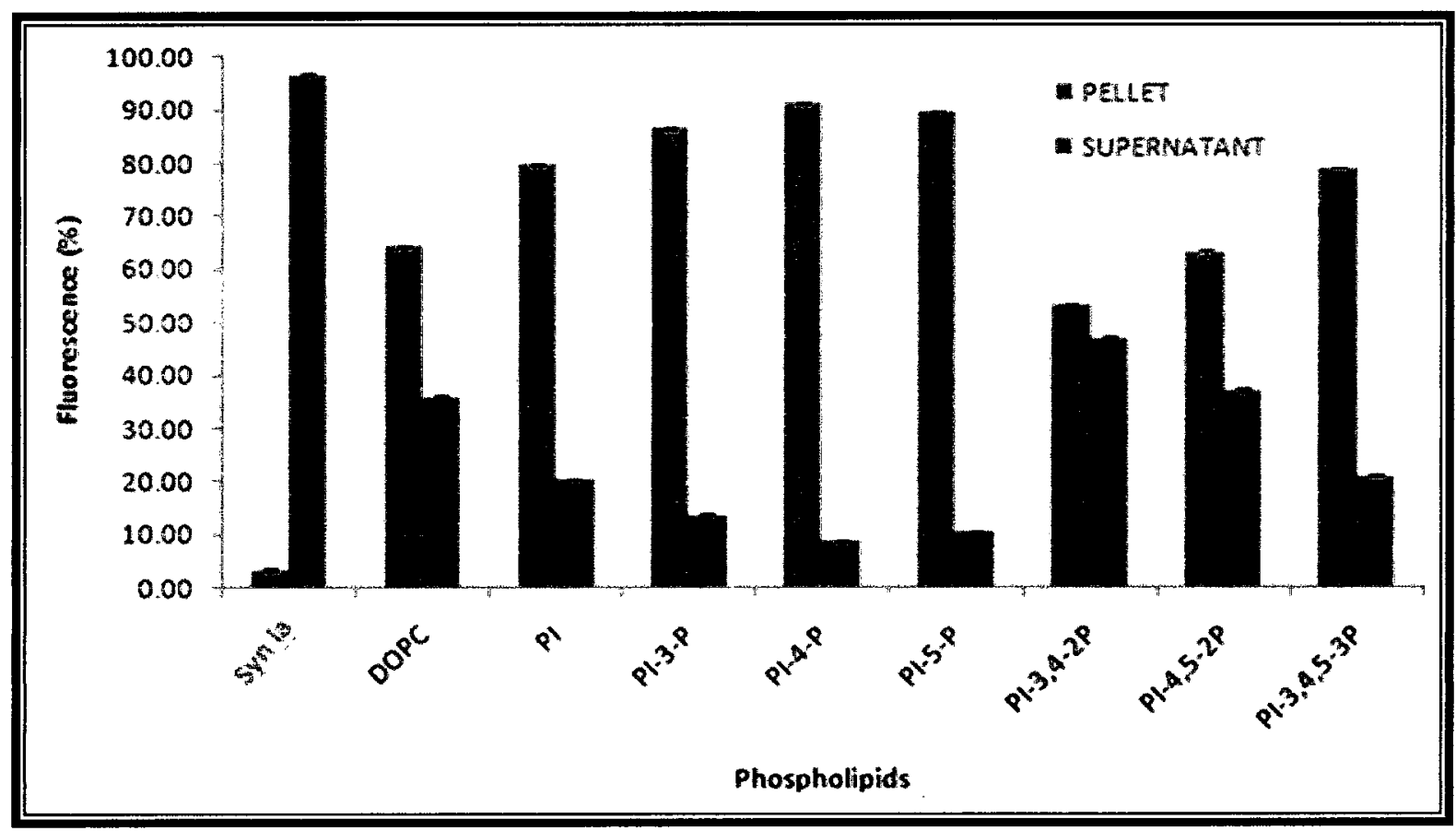

\section{Erig- 3.3.}




\subsection{Discussion}

Lipid composition controls the microenvironment in the membrane. For example, local proton and cation concentrations are increased when there is the presence of charged lipids in the membrane but decreased by the heightened cholesterol and lipid oxidation in aging membranes (Jacob and Manson 2005). The differences between soluble and membrane bound protein are most likely due to these and similar changes occurring at the membrane interface. Here, we aimed to better understand how membrane lipid composition can regulate the activity of membrane associated proteins by investigating syn Ia binding to charged membranes.

To this aim, we prepared LUVs by extrusion from lipid mixtures containing PI or specific PI derivatives. Charged lipids are known not to favor the formation of unilamellar vesicles. This is especially problematic for one working with PI lipids because they are also known to form micelles in solution (Carvalho et al. 2008). In this study, DLS was used to confirm the size of LUV solutions. Gel filtration, phosphate assay and TLC were then used to confirm that our unilamellar vesicles did contain PIs. Our results indicate that PI-4,5-2P incorporation into the membrane saturated at approximately $6.3 \mathrm{~mol} \%$ whereas any further increase in concentration leads to micelle formation. This result agrees well with the DLS results in which the size of the distribution varies as a function of the lipid composition.

PI containing LUVs were used to determine syn Ia binding affinity for specific PI isomers. Our results indicate that the phosphorylated state of phospholipid directly affects binding affinity of the protein. Syn Ia had high binding affinity for unphosphorylated PI and monophosphorylated derivatives (PI-3-P, PI-4-P, PI-5-P) and moderate and low binding affinity for triphosphorylated (PI-2,4,5-3P) and diphosphorylated (PI-3,4-2P and PI-4,5-2P) derivatives respectively. This result further supports the evidence that PI synthesis and depletion provides a 
mechanism by which changes in neurotransmitter release can occur (Hammond and Schiavo, 2006).

Syn Ia also displayed significant binding to un-charged lipids. This result is not surprising as non-specific binding has been shown to mediate some of the binding of synapsin to SVs (Murray et al. 2004). What is surprising however is the extent with which this binding occurs. Syn Ia binds to un-charged liposomes with greater affinity then liposomes containing di-or triphosphorylated PIs and almost to the same extent as liposomes containing un- or monophosphorylated derivatives.

Although we do not wish to disregard the possible significance of this result, we cannot help to wonder if some of this binding is artifactual. High-speed centrifugation provides a simple way to analyze protein-membrane interactions. However, protein aggregates or semi-soluble proteins in solution can easily be precipitated by high centrifugal forces (Zhan 1999). Synapsins are known to form dimers in solution. Hosaka and Südhof, 1999, demonstrated that synapsins form homo- and heterodimers with variable efficiency. The contact surface between the two subunits in the dimer is very large, leading to a strong interaction. This suggests that the synapsins coat the vesicle surface as dimers. Experimental errors can arise from not being able to distinguish between pelleted membrane bound proteins or pelleted protein aggregates. Furthermore, membrane surface accessibility can be compromised when pelleting at high speed for prolonged times as vesicles tend to compact (Zhan 1999). Thus, we cannot get a clear insight into protein association forces or membrane dynamics. High-resolution techniques capable of making real-time measurements of single-molecule behavior have, on the other hand, been shown to provide tremendous insight into the protein-lipid dynamics (Weerachatyanukul et al. 2007; Ira and Johnston 2007; Ira et al. 2009). For example, atomic force microscopy (AFM) has 
proven to be a useful method to examine the specific interaction of proteins with mixtures of zwitterionic and charged liposomes. Proteins such as annexin, saposin, myelin, and cytochrome C were all studied using this method and were all shown to interact through electrostatic interactions with charged lipids (Muller et al. 2000; Reviakine et al. 2001; Janshoff et al. 2001; You et al. 2003). Further direction for our study would be to provide further insight into the role of electrostatic and non-specific interactions on the absorption of syn Ia to lipid membranes using high-resolution imaging tools. 


\section{HYPOTHESIS III}

\section{QUANTIFICATION OF SYNAPSIN IA-LUV BINDING BY ATOMIC FORCE MICROSCOPY AND TOTAL INTERNAL REFLECTION FLUORESCENCE MICROSCOPY}

Protein binding to cell surfaces is a complex process involving different kinds of interactions. In hypothesis 1 and 2 of this thesis, measurements of syn Ia-membrane affinity based on separating bound protein from free protein in solution provided a way to determine the binding behavior of syn Ia and lipid vesicles. Although this technique allowed us to determine that both protein phosphorylation and vesicle lipid composition play intrinsic roles in syn Iavesicle binding, many questions still remain unanswered. Questions such as what roles specific lipids play in protein recognition, which interaction dominates the adhesion process and how strong are these interactions. Due to the complex nature of this problem, we focused on the development of model systems that are able to facilitate the investigation of protein-membrane interactions.

We used atomic force microscopy (AFM) and fluorescence imaging to directly visualize and quantify syn Ia-LUV interactions. Since individual biomolecules are often below the diffraction limit of optical microscopes, other approaches are required to study them complementarily. AFM has shown its advantages for obtaining three-dimensional images of such structures at atomic resolution (Dufrene and Lee 2000; Weerachatyanukul et al. 2007). The high sensitivity of the surface scanning probe is what allows direct detection at nanometer-scale through the measure of cantilever deflection as a result of fluctuation of forces between its tip and the sample surface (Park et al. 2006; Weerachatyanukul et al. 2007). A key aspect of monitoring single-molecule behavior using this technique is the immobilization of the molecules 
to a solid supported surface in a controlled fashion. Systems such as LUVs are useful as they can be designed to incorporate lipids with ligand functionalized headgroups for vesicle adsorption by means of specific molecular recognition. In our study specific tethering of the vesicles was mediated by the strong $\left(\mathrm{K}_{\mathrm{D}} \approx 10^{-15} \mathrm{M}\right)$ biotin-streptavidin interaction (Nidumolu et al. 2006). A high-density streptavidin monolayer was first immobilized onto a monolayer of biotin-terminated bovine serum albumin (BBSA) adsorbed to a glass cover slip. LUVs containing $1 \%$ phosphoethanolamine with biotin-functionalized headgroups (biotin-DHPE) were then bound to the streptavidin monolayer in order to generate a well separated, planar layer of individual intact vesicles (Figure 4.1). Monitoring of the multilayer construction was carried out using AFM as surface topography images provided insight into protein surface coverage, protein morphology, and more importantly, vesicle distribution.

Specific binding of the LUVs to the streptavidin layer was also measured by fluorescence imaging as both proteins and liposomes were labeled with fluorescent molecules, Fluorescein (FITC-strept) and Texas Red® (TR-LUVs), respectively (Figure 4.2). In our system biotinylated LUVs are either specifically tethered to the FITC-strept + BBSA treated glass cover slips or remain floating in solution. Since all of the LUVs were TR labeled, fluorophores that are close to the surface and those in the vesicles floating above the substrate interface are both excited and detected when using conventional fluorescence microscopy. Here, total internal reflection fluorescence (TIRF) microscopy is used to solve this problem as the total reflection of the incident light creates an evanescent wave that selectively illuminates a restricted region of the cover slip at the glass-water interface. By penetrating to a depth of only approximately $100 \mathrm{~nm}$ into the sample medium, only the fluorescence signal of surface bound material is detected and 
visualized (Jaiswal and Simon 2007). Correlating AFM/fluorescence images provided detailed monitoring of our multilayer structure with high spatial resolution.

Monitoring the absolute amount of syn Ia binding to the immobilized LUVs was also achieved by TIRF imaging as the protein is functionalized with a fluorescent marker, Alexa 488 . Varying the concentration of both labeled protein and vesicles allowed us to generate a kinetic binding plot, the fit to the data giving the relative binding constant. 
Figure 4.1 Illustration of a biotinylated large unilamellar vesicle specifically tethered to a FITCstrept layer by biotin-streptavidin interactions. BBSA serves as a cushion for the subsequent FITC-strept layer. 


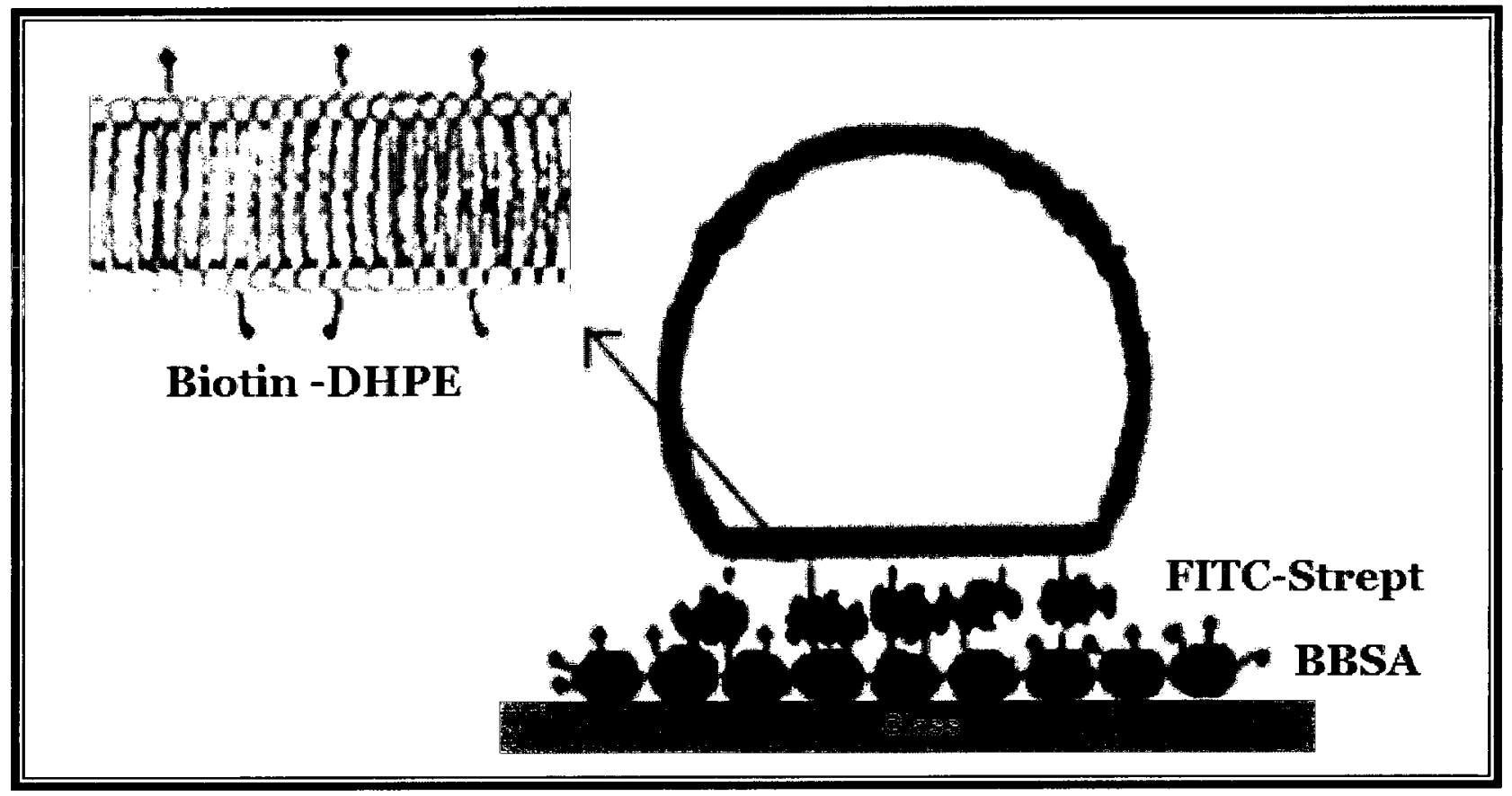


Figure 4.2 Chemical structures of Texas Red® 1,2-dihexadecanoyl-sn-glycero-3phosphoethanolamine, triethylammonium salt (TR-DHPE) and Fluorescein (FITC). 

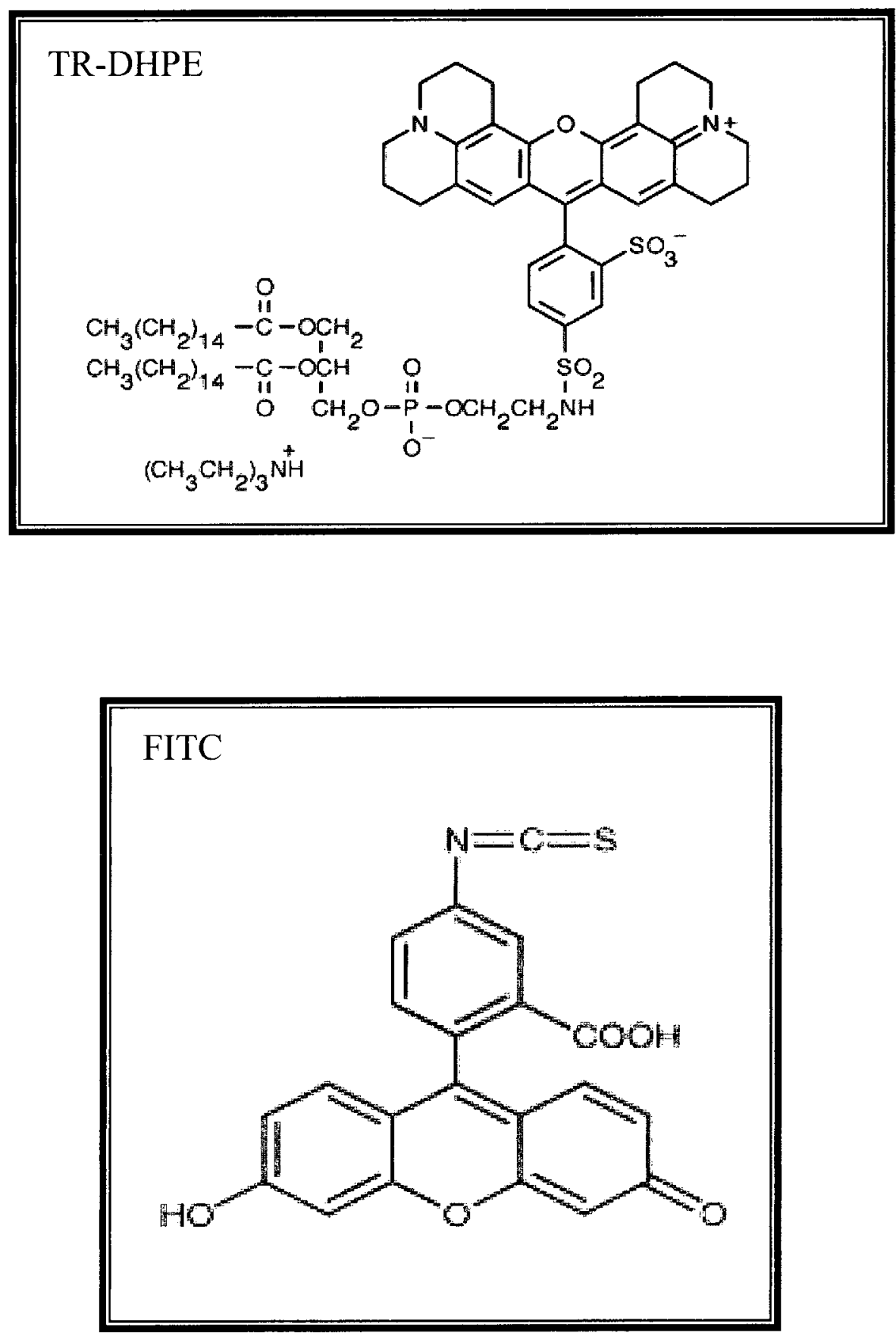


\subsection{MATERIALS AND METHODS}

\subsubsection{MATERIALS}

Dioleoylphosphatidylcholine (DOPC), cholesterol (chol), phosphatidylinositol (4,5)bisphosphate (PI-4,5-2P) and 1,2-dioleoyl-sn-glycero-3-phosphoethanolamine-N-(biotinyl) (biotin-DHPE) were obtained from Avanti Polar Lipids and were used as received. Texas Red® 1,2-dihexadecanoyl-sn-glycero-3-phosphoethanolamine, triethylammonium salt (TR-DHPE) was from Invitrogen. Biotin labeled Bovine Serum Albumin (BBSA), streptavidin and FITC labeled Streptavidin (FITC-strept) from Streptomyces avidinii were from Sigma Aldrich. Alexa 488 protein labeling kit was from Molecular Probes and the BCA Protein Assay kit was from Pierce. ACS grade methanol and HPLC grade chloroform were used in the experiments. All aqueous solutions where prepared with $18.2 \mathrm{M} \Omega \cdot \mathrm{cm}$ Milli-Q water. Ten $\mathrm{mM}$ Tris- $\mathrm{HCl}, 20 \mathrm{mM} \mathrm{NaCl}, \mathrm{pH}$ 7.4 (Tris-HCl) buffer was used for both AFM and TIRF experiments.

\subsubsection{ProteIn Preparation}

Syn Ia was previously purified from bovine brain under non denaturing conditions (Murray et al. 2003). Proper protein folding was confirmed using circular dichroism and actin polymerization assays (Cheetham et al., unpublished). Purity was checked by SDS-PAGE (data not shown) and the protein was stored in buffer ( $100 \mathrm{mM} \mathrm{NaCl}, 25 \mathrm{mM}$ Tris- $\mathrm{HCl}, \mathrm{pH} 7.4)$ at $80^{\circ} \mathrm{C}$. 
The protein was labeled with Alexa 488 (Alexa 488-syn Ia) by using Alexa 488 conjugate labeling kit following manufacturer's directions. Protein concentration was determined using the BCA Protein Assay kit.

\subsubsection{PREPARATION OF LUVS}

DOPC, chol, PI-4,5-2P and Biotin-DH-PE were dissolved in chloroform/methanol (2:1, v/v), TR-DHPE was dissolved in methanol. Lipid films i) DOPC, chol, PI-4,5-2P, biotin-DHPE, TR-DHPE (73.7:15.0:10.0:1.0:0.3 mol\%, TR-LUVs), ii) DOPC, chol, PI-4,5-2P , TR-DHPE (74.7:15:10:0.3 mol\%), iii) DOPC, chol, PI-4,5-2P, biotin-DHPE (74:15:10:1 mol\%), and iv) DOPC, chol, biotin-DHPE (84:15:1 mol\%) were obtained after drying the solvent and hydrated in water to obtain multilamellar vesicles. Each sample was then extruded 9 times through two 400, two 200 and two $100 \mathrm{~nm}$ pore diameter polycarbonate membranes, to clarity to form LUVs. Vesicle sizes were confirmed by Dynamic Light Scattering (DLS). Vesicle solutions were either used immediately or stored at $4^{\circ} \mathrm{C}$ for up to a week prior to use.

\subsubsection{SURFACE FUNCTIONALIZATION}

Piranha $\left(3: 1 \quad \mathrm{H}_{2} \mathrm{SO}_{4}: \mathrm{H}_{2} \mathrm{O}_{2}\right)$ cleaned glass cover slips were incubated with a $0.1 \mathrm{mg} / \mathrm{mL}$ BBSA (carrying 8 biotins per protein) for $20 \mathrm{~min}$ at RT. After rinsing with buffer (Tris- $\mathrm{HCl}, 5$ min), the pretreated surfaces were incubated with initial concentrations of FITC-strept of 0.0001 (substrate-4), 0.001 (substrate-3), 0.01 (substrate-2), or 0.1 (substrate-1) $\mathrm{mg} / \mathrm{mL}$ for $5 \mathrm{~min}$ in Tris- $\mathrm{HCl}$. The substrates were thoroughly rinsed with buffer, (Tris- $\mathrm{HCl}, 5 \mathrm{~min}$ ) and subsequently incubated with $0.05 \mathrm{mg} / \mathrm{mL}$ TR-vesicle suspension for $5 \mathrm{~min}$ followed by a buffer rinse (Tris$\mathrm{HCl}, 8 \mathrm{~min})$. 


\subsubsection{ATOMIC FORCE MICROSCOPY}

AFM images were obtained on a PicoSPM atomic force microscope (Molecular Imaging) in MAC mode using magnetic coated silicon tips with spring constants of $\sim 0.5 \mathrm{~N} / \mathrm{m}$ and resonance frequencies between 25 to $40 \mathrm{kHz}$ in aqueous solutions. Either a $30 \times 30 \mu \mathrm{m}^{2}$ or $7 \times 7$ $\mu \mathrm{m}^{2}$ scanner was used with a scan rate between $0.7-1.3 \mathrm{~Hz}$. Two or three independently prepared samples were imaged for BBSA, BBSA + FITC-strept (substrate-1) and substrate-1+ LUVs, respectively. Several areas were scanned for each sample.

\subsubsection{TOTAL INTERNAL FLUORESCENCE MICROSCOPY}

Fluorescence images were taken on an Olympus 1X81 total internal reflection fluorescence (TIRF) microscope equipped with a high resolution CCD camera (CoolSNAP, Photometrics, US) and a 63x/1.45 NA Plan Apochromat objective. FITC-strept and Alexa 488syn Ia were respectively excited with $488 \mathrm{~nm}$ Argon Ion laser and emission was collected using FITC emission filter. TR-LUVs were excited using $543 \mathrm{~nm}$ HeNe laser and emission collected using TR emission filter.

Binding of TR-LUVs on substrate-1, $-2,-3$ and -4 was studied by imaging the same area before and after addition of vesicles using both 488 and $543 \mathrm{~nm}$ lasers. Binding of Alexa 488-syn Ia to vesicles was studied by using unlabeled LUVs. Alexa 488-syn Ia was excited at $488 \mathrm{~nm}$ and emission was monitored in the FITC channel. 


\subsubsection{DATA ANALYSIS}

FITC-strept, TR-LUVs and Alexa 488-syn Ia images are normalized and displayed on fixed intensity scale unless otherwise noted. Intensity scales were determined by first determining background signals using the area function of the ImagePro software. Background signals plus three time standard deviation (Std Dev) were then used to set specific thresholds. Macros were designed to rapidly analyse and compare each image pixel $\left(266 \mathrm{~nm}^{2} /\right.$ pixel $)$ to a set threshold. For FITC-strept and TR-LUVs, surface coverage was determined by the sum of $60 \times$ 60 pixels that are above threshold value divided by the total number of pixels.

The total binding behavior of Alexa 488-syn Ia (S) to vesicles (V) was measured by monitoring the intensity changes while increasing the protein concentration. The total intensities measured at different protein concentrations is directly proportional to the total number of syn Ia molecules tethered (specifically or non-specifically) to vesicles within a given area. After normalizing the sum intensities of Alexa 488-syn Ia at different concentrations, a binding constant was obtained from fitting the plot using a Hill equation, as previously described by Martinez et al. (2003).

Briefly, data was fitted according to the chemical equilibrium $V+S \leftrightarrows V S$, neglecting nonspecific binding and depletion.

$$
V S^{*}=\frac{\mathrm{S} \tau}{\mathrm{K}_{\mathrm{d}}+\mathrm{S} \tau}
$$

$V S^{*}$ is the normalized measured fluorescence intensity of $S$ bound to $\mathrm{V}$, and is proportional to the concentration of VS. $\mathrm{S}_{\tau}$ is the concentration of Alexa 488-syn Ia added, $K_{d}$ is the apparent dissociation constant of the complex. 


\subsection{RESULTS}

\subsubsection{IMAGING OF BBSA + FITC-STREPT}

Surface-sensitive imaging techniques require the immobilization of the molecules under investigation. Apart from chemical-cross linking of the molecules to the surface, several surface immobilization strategies have been used based on high affinity interactions. Here, biotinstreptavidin interaction is used to immobilize biotinylated LUVs on a streptavidin (FITC-strept) coated glass surface. As illustrated in Figure 4.1, however, the streptavidin layer is not directly immobilized on the glass slides, but deposited on a BBSA monolayer. The use of a BBSA cushion over direct immobilization of FITC-strept to the glass surface allows streptavidin functionality to be maintained as it's not directly in contact with the potentially denaturing glass surface and allows for a better control of streptavidin surface coverage (Fitzpatrick et al. 1992; Pignataro et al. 2000).

Monitoring the protein multilayer was first achieved by AFM in Mac mode in buffer. Surface topography images before BBSA incubation (Figure $4.3 \mathrm{~A}$ ) and after a $20 \mathrm{~min}$ incubation period with BBSA $(0.1 \mathrm{mg} / \mathrm{mL}$, Figure $4.3 \mathrm{~B})$ revealed increased feature heights to $3.2 \mathrm{~nm}$ and an increase in surface roughness. The height difference between the protein layer and the glass surface is consistent with that of a BBSA monolayer (Pignataro et al. 2000). Subsequent incubation of the BBSA treated surface with a FITC-strept solution of $0.1 \mathrm{mg} / \mathrm{mL}$ initial concentration for $5 \mathrm{~min}$ followed by rinsing (substrate-1) resulted in a height increase of the protein layer $(5-7 \mathrm{~nm})$ and an increase in surface coverage due to protein absorption (Figure $4.3 \mathrm{C})$. 
Adsorption of streptavidin on BBSA monolayer was also monitored by fluorescence microscopy. We employed TIRF microscopy in order to only detect fluorescence signals of bound FITC-strept molecules. These signals were determined by using $488 \mathrm{~nm}$ exciting laser and FITC emission filter. From both TIRF image (Figure 4.4 B) and the AFM image of substrate-1 (Figure $4.4 \mathrm{~A}$ ), it is clear that streptavidins are homogeneously distributed across the sample surface. Because of their small size $(4.5 \times 4.5 \mathrm{~nm})$ FITC-strept molecules are represented by only one pixel in the TIRF images as the combined CCD camera and 60x Plan Apochromat objective generate images in which each pixel size is about $266 \mathrm{~nm}^{2}$. Pixel by pixel analysis of TIRF images revealed that $98 \%$ of the sample surface of substrate- 1 has been covered by FITC-strept. Surface coverage was not reduced by extensive washing as the adsorbed layer could not be removed. 
Figure 4.3 Topographic AFM images (using Mac mode) of (A) a clean glass cover slip; (B) a BBSA covered coverslip in buffer; (C) substrate-1 (BBSA-covered surface in (B) subsequently incubated with $0.1 \mathrm{mg} / \mathrm{mL}$ FITC-strept solution for $5 \mathrm{~min}$ followed by extensive rinsing). The image sizes are $2 \times 2 \mu \mathrm{m}^{2}$. Cross sections profiles are shown in (a), (b) and (c), respectively. 


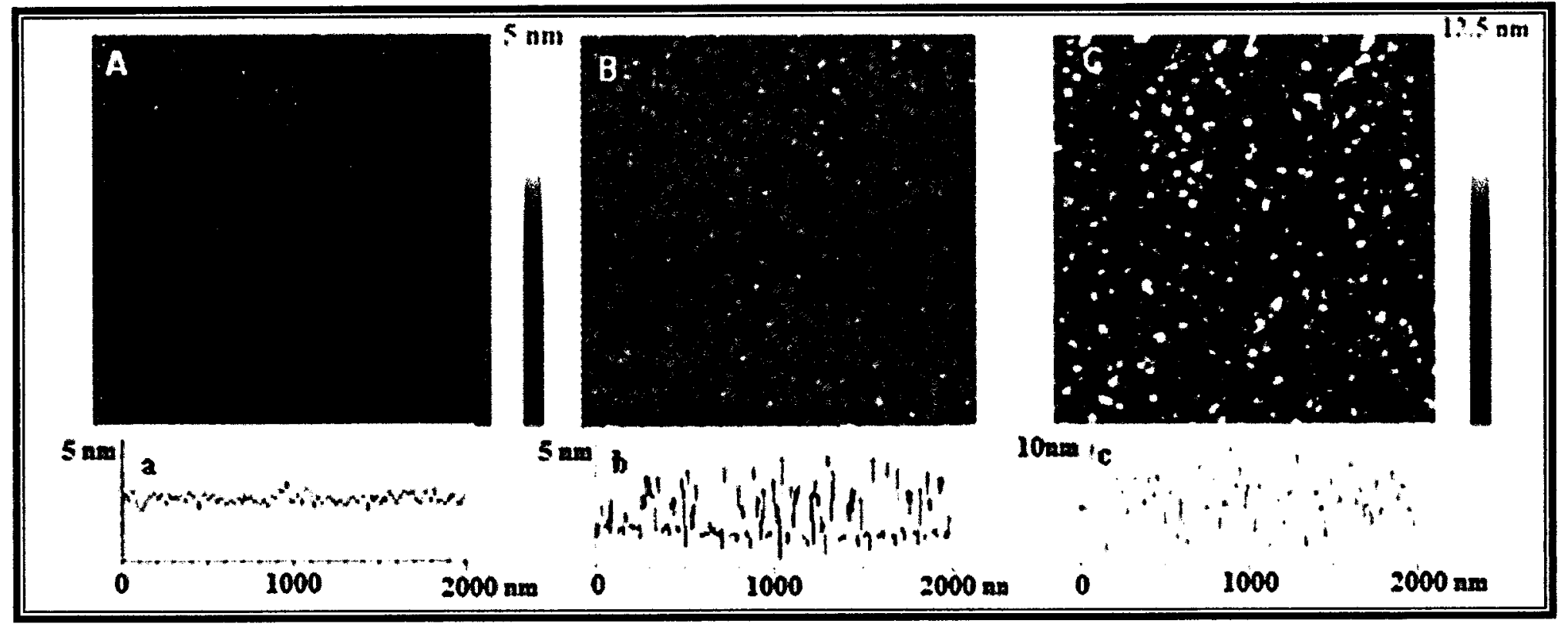

\section{$\left[\begin{array}{ll}0.3 & 3\end{array}\right.$}


Figure 4.4 Topographic AFM image (Mac mode) (A), and TIRF image (B) of substrate-1. Pixel by pixel analysis reveals that $98 \%$ of the sample surface is covered by FITC-strept. AFM image sizes is $2 \times 2 \mu \mathrm{m}^{2}$ and TIRF image is $16 \times 16 \mu \mathrm{m}^{2}$. 


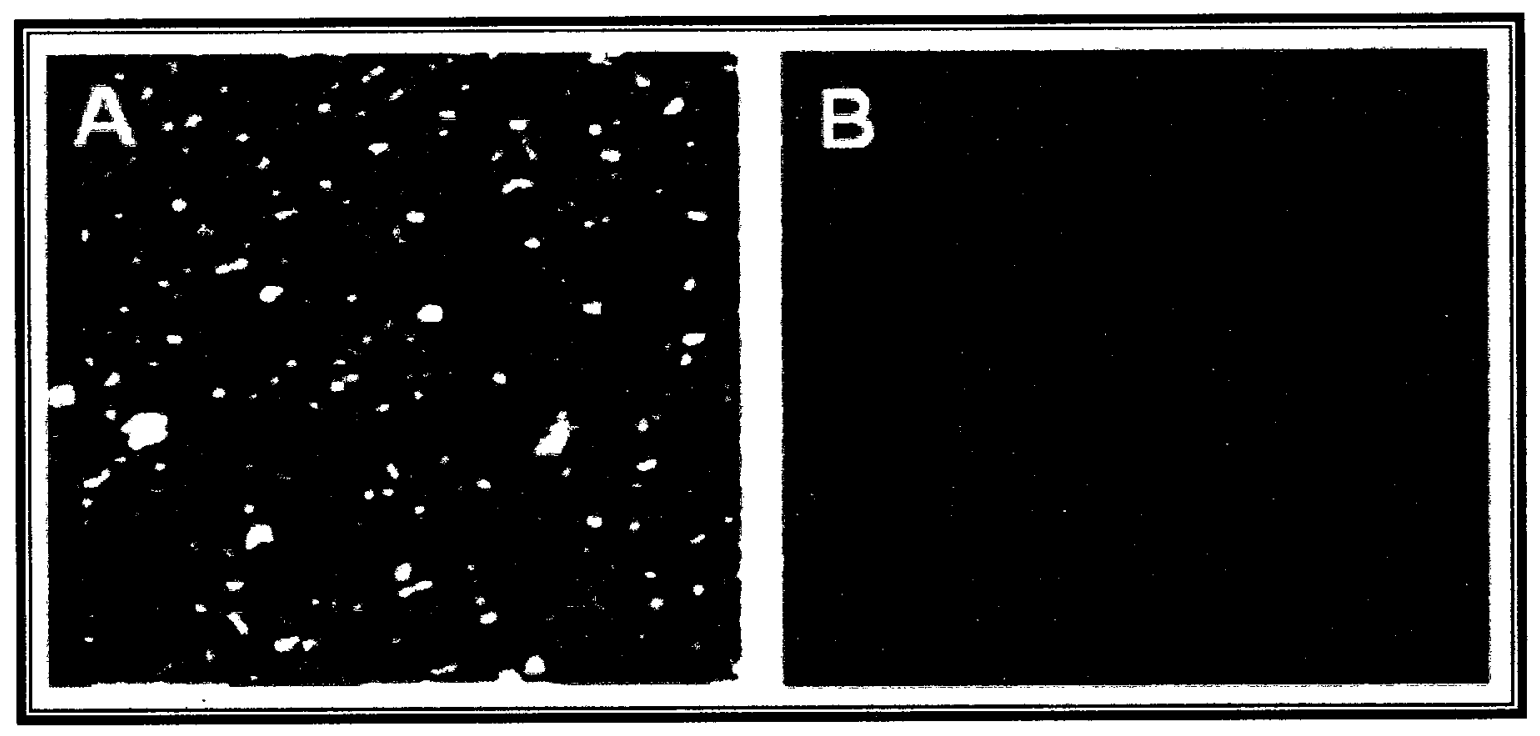

[fig 4.4] 


\subsubsection{IMAGING OF ADHERENT LUVS}

Biotin-DHPE has an alkyl chain that can be readily incorporated with vesicle lipids. As a consequence, DOPC, chol, PI-4,5-2P (73.7:15.0:10.0 mol\%) LUVs were functionalized with 1 mol\% biotin-DHPE. LUVs were immobilized on substrate-1 by incubating $0.05 \mathrm{mg} / \mathrm{mL} \mathrm{LUV}$ solution for $5 \mathrm{~min}$. The sample surface was then extensively washed to remove non-specifically bound vesicles. Monitoring of vesicle immobilization was achieved by TIRF microscopy as LUVs were also functionalized with $0.3 \mathrm{~mol} \%$ TR-DHPE. TR-DHPE was selected because of its high lipophilicity. Vesicle diameters of $110 \pm 31 \mathrm{~nm}$, as determined by dynamic DLS, are represented by one-to-four pixels in TIRF images. The surface coverage of tethered LUVs is calculated by the sum of pixels above threshold value divided by the sum of $60 \times 60$ pixels. $48 \%$ of substrate-1 was calculated to be covered by the functionalized LUVs (Figure 4.5 B).

Different areas in different samples showed vesicles that are more than one-to-four pixels. This can be explained by either surface induced aggregation due to high molecular recognition events between substrate and liposomes, or solution induced aggregation of liposomes due to the instability of stored vesicle solutions. DLS was performed to determine if the age of the liposome solution had an effect on vesicle aggregation. Vesicle solutions showed minimal aggregation after 4 days, average vesicle diameter was increased to $140 \pm 55 \mathrm{~nm}$ and a significant increase after 8 days, diameter increased to $212 \pm 49 \mathrm{~nm}$. Thus all vesicle solutions were used for experimentation for no more than 4 days.

AFM was used to obtain topographic images of the LUVs adhered to substrate-1. Comparing the vesicle TIRF image (Figure $4.5 \mathrm{~B}$ ) to the AFM image of a similar sample (Figure $4.5 \mathrm{~A})$ a decrease in vesicle surface coverage was observed. Similar results were obtained when imaging different samples and areas. Reasons for the reduced coverage can be attributed to 
difficulties encountered when imaging liposomes by AFM. At high load forces of 1-2 $\mathrm{nN}$ lateral forces may cause vesicle indentation/rupture and dragging of vesicles off the substrate surface. At low load forces (100 pN - $500 \mathrm{pN})$, adhesion may influence vesicle shape. These observations are in accordance with similar work done by Pignataro et al. 2000, who also demonstrate limitations of imaging tethered liposomes by AFM. Here, attempts to image LUVs were done using AFM in both Contact and Mac mode with tips of higher and lower spring constants. Figure 4.5 A was obtained in Mac Mode using a low spring constant cantilever $(0.06 \mathrm{~N} / \mathrm{m})$ with low load force $(500 \mathrm{pN})$. Although surface coverage was lower than expected, LUVs that were imaged using this method had average heights of 10-30 nm. Heights of 30-70 nm have been reported for LUVs of similar compositions when imaged at even lower spring constant $(\sim 100$ $\mathrm{pN}$. 
Figure 4.5 Topographic AFM image (Mac mode) (A) and TIRF image (B) of $0.5 \mathrm{mg} / \mathrm{ml} \mathrm{TR-}$ LUV solution containing $1 \mathrm{~mol} \%$ of biotin-DHPE were incubated on substrate-1 for $5 \mathrm{~min}$ followed by rinsing. The AFM image size is $10 \times 10 \mu \mathrm{m}^{2}$ and cross section profile is shown in (a). Pixel by pixel analysis on (B) reveals that $48 \%$ of the surface of substrate- 1 is covered by TR-LUVs. TIRF image size is $16 \times 16 \mu \mathrm{m}^{2}$. 


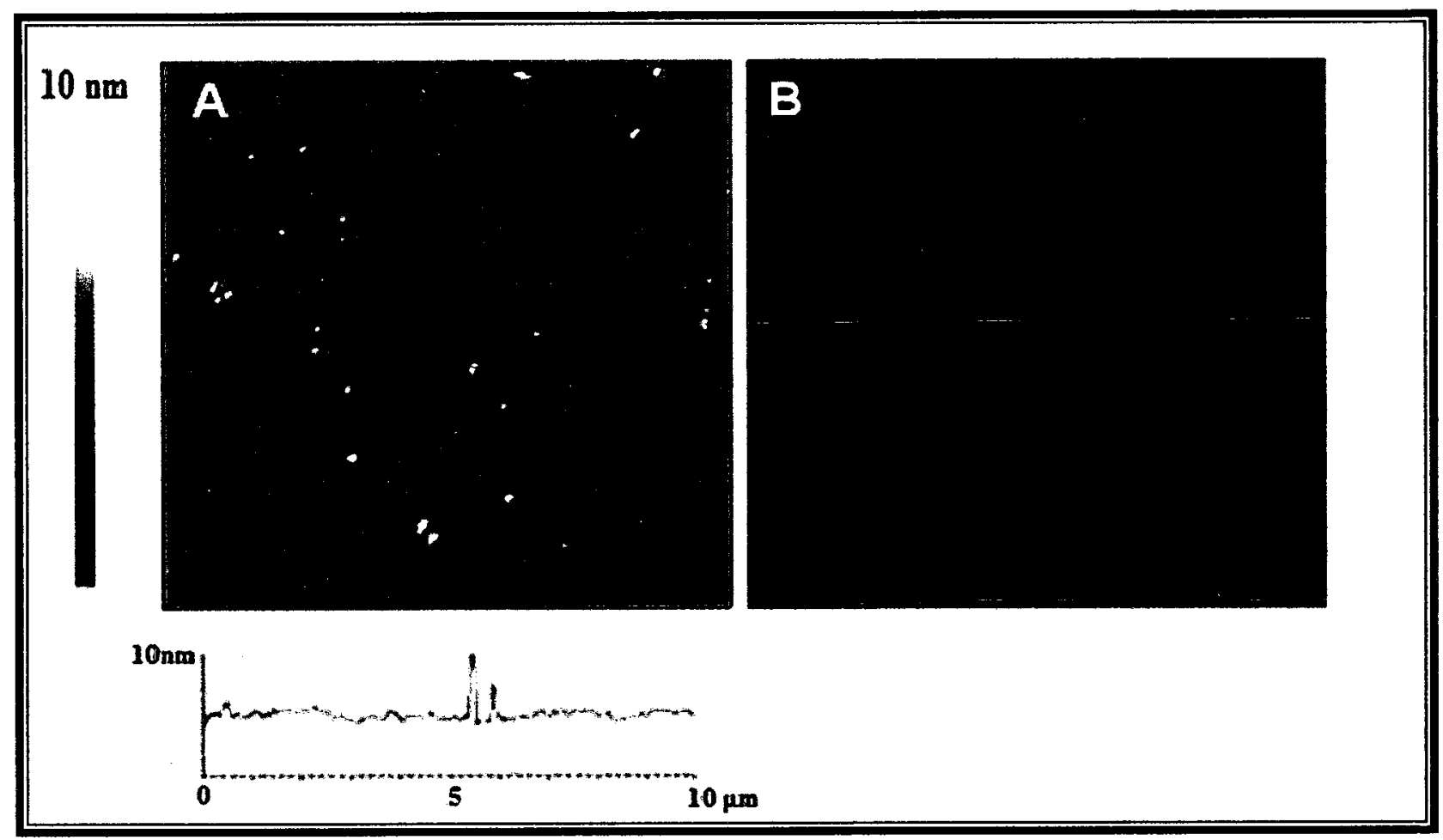

$[$ fig. 4.5] 


\subsubsection{INFLUENCE OF STREPTAVIDIN CONCENTRATION ON LUV BINDING}

Upon incubating the BBSA monolayer with increasing FITC-strept concentrations, (Figure 4.6 A-D) an increase in surface coverage was observed. At the lowest concentration studied $(0.0001 \mathrm{mg} / \mathrm{mL}), 2 \%$ of the surface was covered (substrate- 4$)$. This value was increased to 67,88 and $98 \%$ when initial FITC-strept concentrations of $0.001 \mathrm{mg} / \mathrm{mL}$ (substrate-3), 0.01 $\mathrm{mg} / \mathrm{mL}$ (substrate-2) and $0.1 \mathrm{mg} / \mathrm{mL}$ (substrate-1) were used, respectively. Plotting the surface coverage as a function of streptavidin concentrations (Figure 4.6 E) shows the presence of a plateau at $0.1 \mathrm{mg} / \mathrm{mL}$ indicating complete surface saturation. Further increasing the streptavidin concentration did not lead to increased surface coverage but did however lead to increased surface aggregation (data not shown).

The effect of streptavidin concentration on vesicle surface coverage was investigated by subsequent incubation of substrates-4, $-3,-2$ and -1 with $0.05 \mathrm{mg} / \mathrm{mL}$ LUV solution for $5 \mathrm{~min}$ followed by extensive rinsing (Figure 4.7 A-D). Plotting the surface coverage of tethered LUVs as a function of streptavidin concentration reveals a linear increase of vesicle coverage from 1 to $48 \%$ upon increasing the FITC-strep surface coverage from 2 to $98 \%$ (substrates-4, $-3,-2$ and -1 ;

Figure 4.7 E). The absence of a plateau in the vesicle binding plot indicates that increasing the vesicle concentration and/or incubation time would lead to increased surface coverage. 
Figure 4.6 TIRF images of substrates-4 (A), $0.0001 \mathrm{mg} / \mathrm{ml}$ initial FITC-strept concentration (5 min + rinsing) on BBSA treated glass substrate. Initial FITC-strept concentrations are increased in substrate-3 $(0.001 \mathrm{mg} / \mathrm{ml},(\mathbf{B}))$, substrate-2 $(0.01 \mathrm{mg} / \mathrm{ml},(\mathbf{C}))$ substrate-1 $(0.1 \mathrm{mg} / \mathrm{ml},(\mathbf{D})$. The surface coverage in function of the FITC-strept concentration is plotted in (E). TIRF images are $16 \times 16 \mu \mathrm{m}^{2}$. 

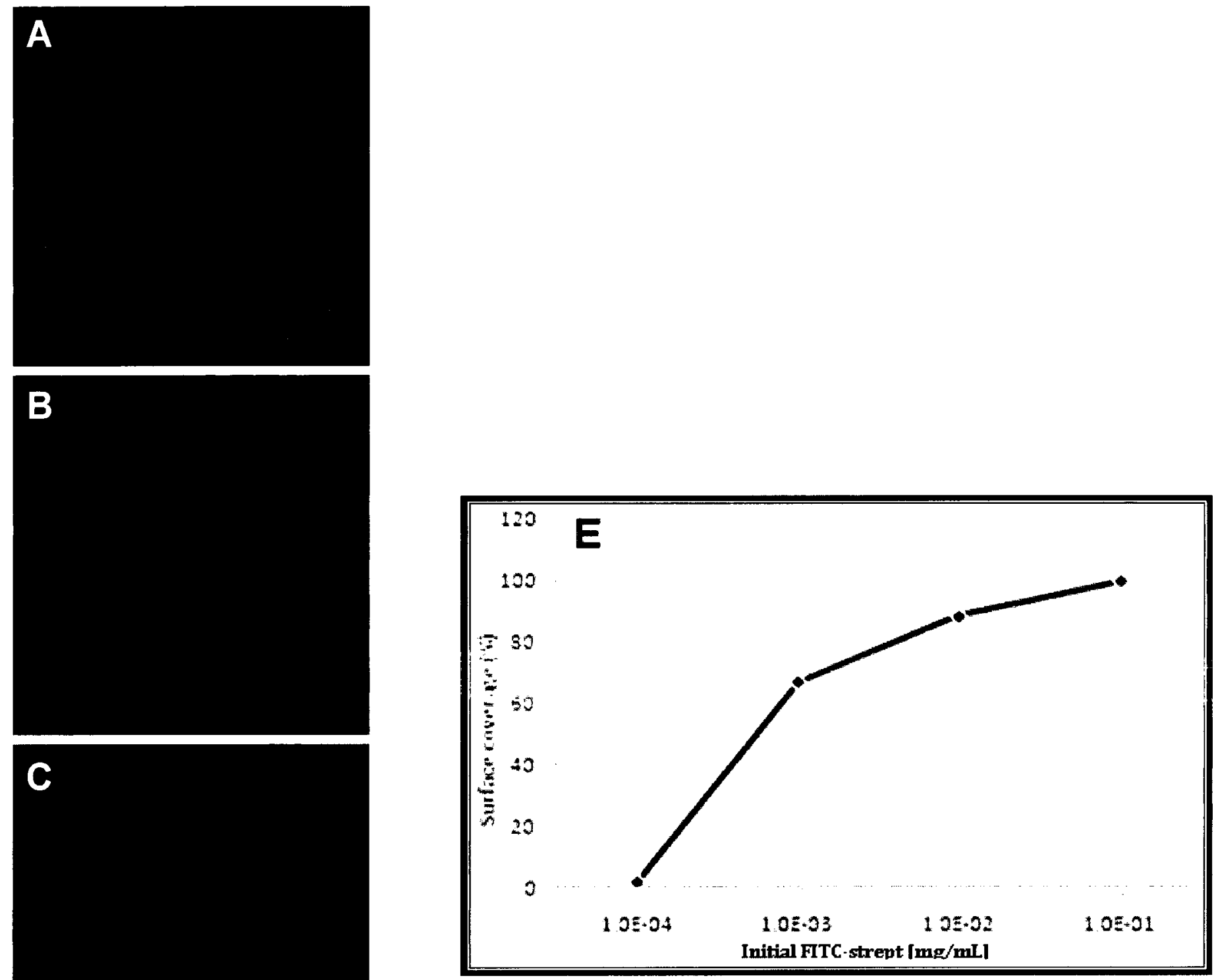

D 
Figure 4.7 TIRF images of TR-LUVs $(0.05 \mathrm{mg} / \mathrm{ml}, 20 \mathrm{~min})$ incubated on substrates-4 (A), -3 (B), -2 (C) and -1 (D) followed by rinsing. The percent surface coverage of the vesicles in function of the increasing FITC-strept concentration (E). TIRF images are $16 \times 16 \mu \mathrm{m}^{2}$. 

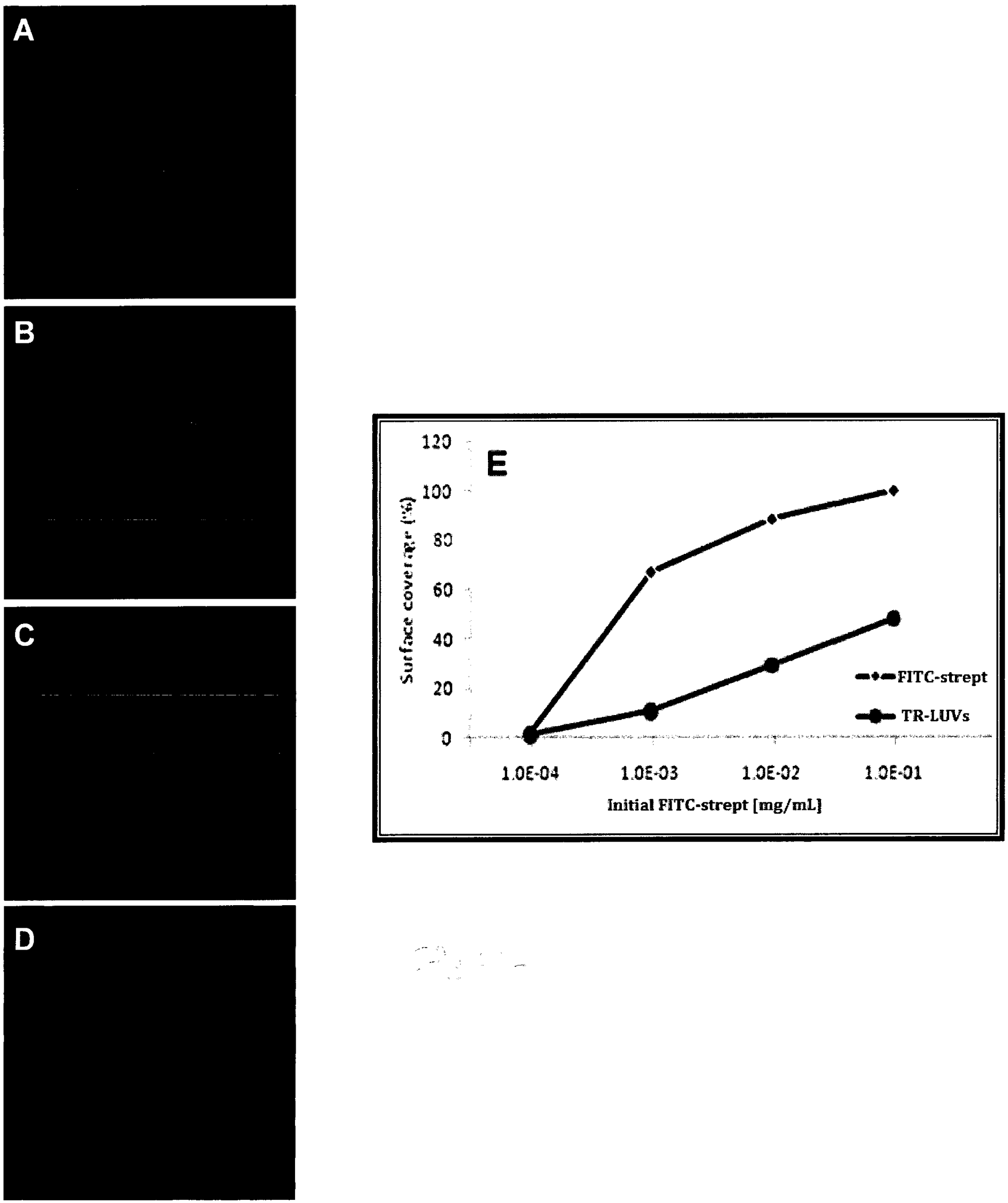


\subsubsection{TWO-COLOUR TIRF IMAGING TO MONITOR SPECIFIC TETHERING OF LUVS}

By simultaneously labeling streptavidin and LUVs with fluorophores having separate excitation and emission spectra, we can examine the proximity of the labeled molecules within a single sample simply by using different fluorescence filter combinations. Here, fluorescence signals of FITC-strept in substrate-1 are colored in green (Figure $4.8 \mathrm{~A} \mathrm{I}$ ), whereas fluorescence signals of TR-LUVs ( $48 \%$ surface coverage) in the same area are colored in red (Figure $4.8 \mathrm{~A}$ II). Upon overlaying the two images (Figure 4.8 A III) two features that are colocalized are consequently represented in yellow (the combined effect of green and red pixels). Surprisingly, analysis of composite images of substrate-1 + TR-LUVs (Figure 4.8 A III) and of all subsequent FITC-strept concentrations tested (Figure 4.8 B III, C III and D III) reveal that little to no FITCstrept and TR-LUVs pixels correspond to each other. LUVs of $\sim 100 \mathrm{~nm}$ diameter contain roughly 50,000 lipid molecules (calculated on the basis that a single phospholipid molecule occupies approximately $0.65 \mathrm{~nm}^{2}$ (Takamori et al. 2006). Thus, with $1 \mathrm{~mol} \%$ of biotin-DHPE, our LUVs should contain $\sim 500$ molecules of biotin. Given the strong interaction between streptavidin and biotin, $2 \times 10^{10} \mathrm{M}^{-1}$ for streptavidin interacting with surface bound biotin (lower than in solution $10^{15} \mathrm{M}^{-1}$, because of steric hindrance) and the fact that immobilization of biotinylated liposomes on streptavidin layers have been well studied and documented (Pignataro et al. 2000; Martinez et al. 2003), we have no reason to believe that our vesicles are not specifically binding to the streptavidin layer. With this in mind, a sample containing DOPC, DOPE, chol, PI-4,5-2P, TR-DHPE (74.7:15:10:0.3 mol\%) without biotin-DHPE was used as a negative control and incubated on substrate-1. Although some nonspecific binding can be 
observed ( $\sim 1 \%$ surface coverage, image not shown) it does not account for the lack of colocalization observed in the composite images.

The FITC dye is known to be very susceptible to photobleaching. We therefore initially hypothesized that lack of co-localization could be due to the repeat excitation of the FITC molecules. Analysis of FITC-strept TIRF images before and after TR-LUV addition (Figure 4.9) revealed that the FITC-fluorescence signal is in fact being reduced. Surface coverage of 67,88 and $98 \%$ for substrates-3, -2 and -1 before vesicle addition is reduced to 51,57 and $52 \%$ respectively after vesicle tethering (Figure 4.9). A control experiment in which subsequent imaging of substrate-1 in the absence of vesicles was undertaken and revealed that photobleaching only accounts for $0.1 \%$ reduction of fluorescence intensity, thus is not sufficient to account for the observed $\sim 46 \%$ reduction in surface coverage. Literature revealed that due to their overlap of emission and adsorption, FITC fluorophores can be quenched by TR. This energy transfer can only happen when the two fluorophores are in close proximity $(\leq 10 \mathrm{~nm})$, thus only taking place upon specific binding of biotinylated vesicles to streptavidin on the substrate.

Attempts to eliminate quenching of FITC were undertaken by substituting TR-DHPE with cholesterol labeled Dansyl. Monitoring tethering of Dansyl-labeled-LUVs is achieved by exciting at $355 \mathrm{~nm}$ and monitoring the emission at $535 \pm 35 \mathrm{~nm}$. Although Dansyl molecules can be quenched when in close proximity to FITC, making vesicles that contain $\sim 1500(1 \mathrm{~mol} \%)$ Dansyl molecules, insures that not all molecules are being quenched as only part of the vesicle is in contact with the FITC-strept layer. Working with Dansyl however presented another problem as the TIRF microscope does not allow incident light from the UV lamp to be reflected at the 
glass-water interface. In compromising the resolution in such a way, we were not able to visualize surface tethered vesicles or to differentiate between bound and unbound vesicles. 
Figure 4.8 TIRF images of substrates-1 (AI), -2 (BI), -3 (CI) and -4 (DI) and TR-LUVs $(0.5$ $\mathrm{mg} / \mathrm{mL}$ ) incubated on substrates-1 (AII), -2 (BII), -3 (CII) and -4 (DII), respectively. Composite images are in column III. Any co-localized pixels are represented in yellow. TIRF images are 16 $\times 16 \mu \mathrm{m}^{2}$. 


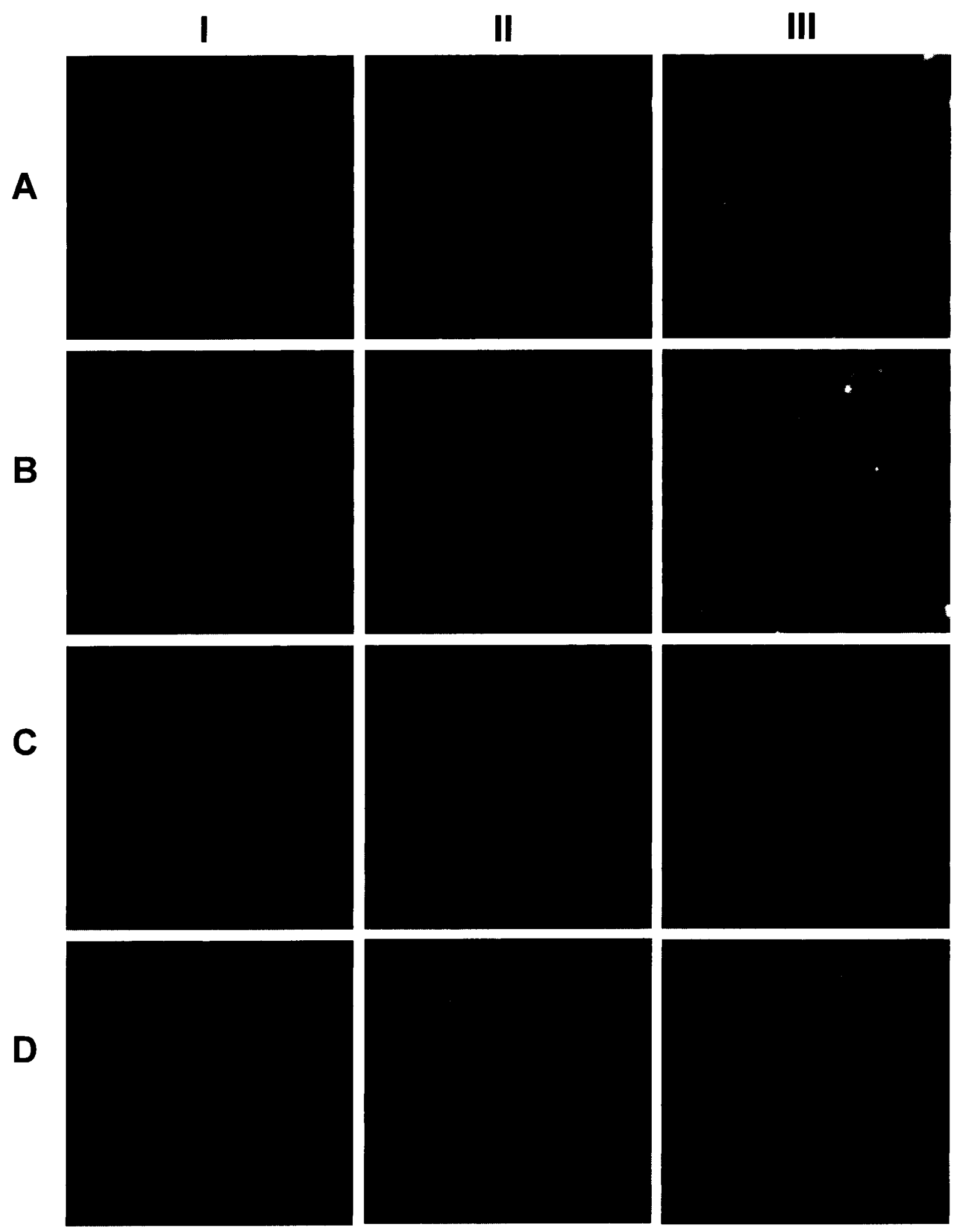


Figure 4.9 TIRF images of FITC-strept obtained before (A) and after (B) $0.05 \mathrm{mg} / \mathrm{mL}$ TR-LUVs incubated on substrates-1 (I), -2 (II), -3 (III) and -4 (IV). Plotting the percent surface coverage as a function of FITC-strept concentration (C) reveals that streptavidin signal is reduced upon vesicle addition possibly due to quenching by TR. TIRF images are $16 \times 16 \mu \mathrm{m}^{2}$. 

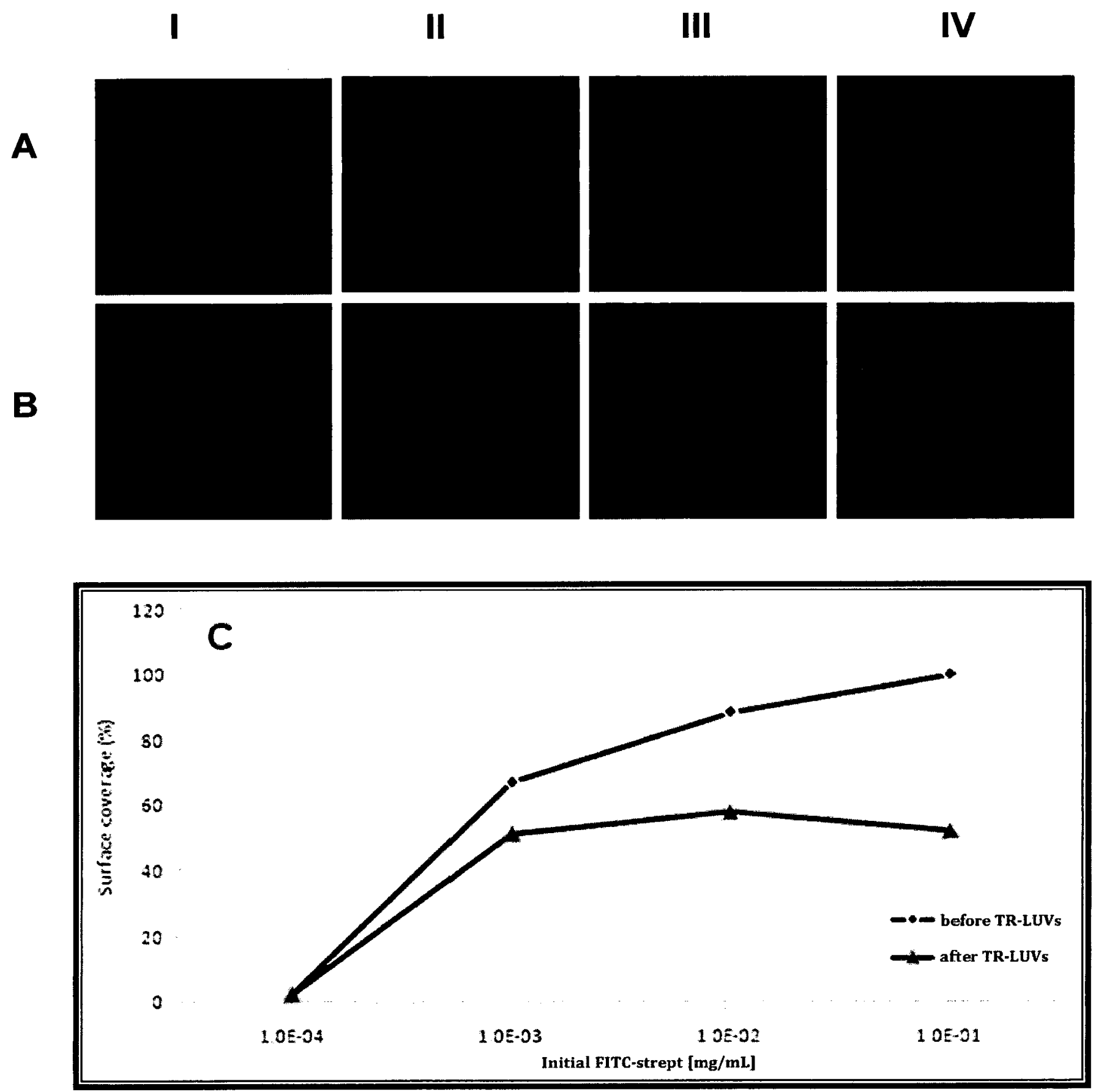


\subsubsection{BINDING OF SYNAPSIN IA TO LUVS}

In order to observe and quantify syn Ia binding to anionic vesicles, tethered TR-LUVs containing PI-4,5-2P were subsequently incubated with varying concentrations of syn Ia. Syn Ia being labeled with Alexa 488 presented a problem as its emission overlaps with the TR adsorption spectra, therefore would be quenched upon binding to TR-LUVs. To avoid any loss of protein fluorescence signal due to quenching, LUVs without any fluorescent probes were used.

Dye free LUVs were immobilized on substrates- 2 and -3 to cover 27 and $11 \%$ of the sample surface (as determined previously by fluorescence signals when using TR-LUVs Figure 4.7). Alexa-488 labeled syn Ia proteins in a series of concentrations ranging from $1 \times 10^{-6}$ to 1 $\mathrm{mg} / \mathrm{mL}$ were then added to the vesicle treated substrates for a 30 min incubation at $4^{\circ} \mathrm{C}$. Unbound proteins were subsequently removed by extensive buffer rinsing. Alexa-488 fluorophore intensity was monitored by exciting the sample at $488 \mathrm{~nm}$ and collecting fluorescence signal using the FITC emission filter. Figures 4.10 A and B show the fluorescence signals obtained with increasing Alexa 488 -syn Ia concentration. When, $27 \%$ of the sample is covered by LUVs (Figure 4.10 A) fluorescence signal can be determined for protein concentrations as low as $1 \times 10^{-6} \mathrm{mg} / \mathrm{mL}$ compared to concentrations of $1 \times 10^{-3} \mathrm{mg} / \mathrm{mL}$ when $11 \%$ of the surface is covered by vesicles. Thus upon reduction of LUV concentration by $\sim 40 \%$, the fluorescence signal from syn Ia is reduced.

Binding is quantified through the summation of TIRF signals of bound Alexa 488-syn Ia. When $27 \%$ of the surface is covered by anionic vesicles, syn Ia binding is saturated at $1 \mu \mathrm{g} / \mathrm{mL}$ compared to $1 \times 10^{-2} \mathrm{mg} / \mathrm{mL}$ when $11 \%$ of the surface is covered by vesicles (Figure $4.11 \mathrm{~A}$ ). 1 $\mathrm{mg} / \mathrm{mL}$ of synapsin was also incubated on substrates- 2 and -3 in the absence of vesicles to serve as negative controls. Little to no fluorescence signal from Alexa 488 fluorophores could be 
detected (Figure 4.10 A and B, strept). Plotting the normalized intensity as a function of varying Alexa 488- syn Ia concentrations (Figure $4.11 \mathrm{~B}$ ) and fitting the data with a Hill equation results in a $\mathrm{K}_{\mathrm{d}}$ of $12.5 \mathrm{nM}$.

Binding to anionic vesicles involves both electrostatic and nonspecific interactions. Here, $1 \mathrm{mg} / \mathrm{mL}$ of Alexa 488-syn Ia was also incubated on substrate-2 with LUVs (27\% surface coverage) containing DOPC, chol, Biotin-DHPE with and without PI-4,5-2P to determine the degree of nonspecific binding. A total intensity signal of 179980 A.U. was obtained for Alexa 488-syn Ia bound to anionic vesicles (Figure $4.12 \mathrm{~A}$ ). This signal was reduced to 24508 A.U. upon protein binding to uncharged liposomes (Figure $4.12 \mathrm{~B}$ ). Thus, electrostatic binding accounts for $\sim 86 \%$ of the synapsin-vesicle interaction. 
Figure 4.10 TIRF images of TR-free LUVs incubated on substrate-2 (A) and -3 (B), respectively. Samples were further incubated with increasing concentrations of syn Ia protein labeled with Alexa 488. Fluorescence intensity increases with increasing the synapsin/vesicle molar ratio. Images are $27 \times 27 \mu \mathrm{m}^{2}$. 


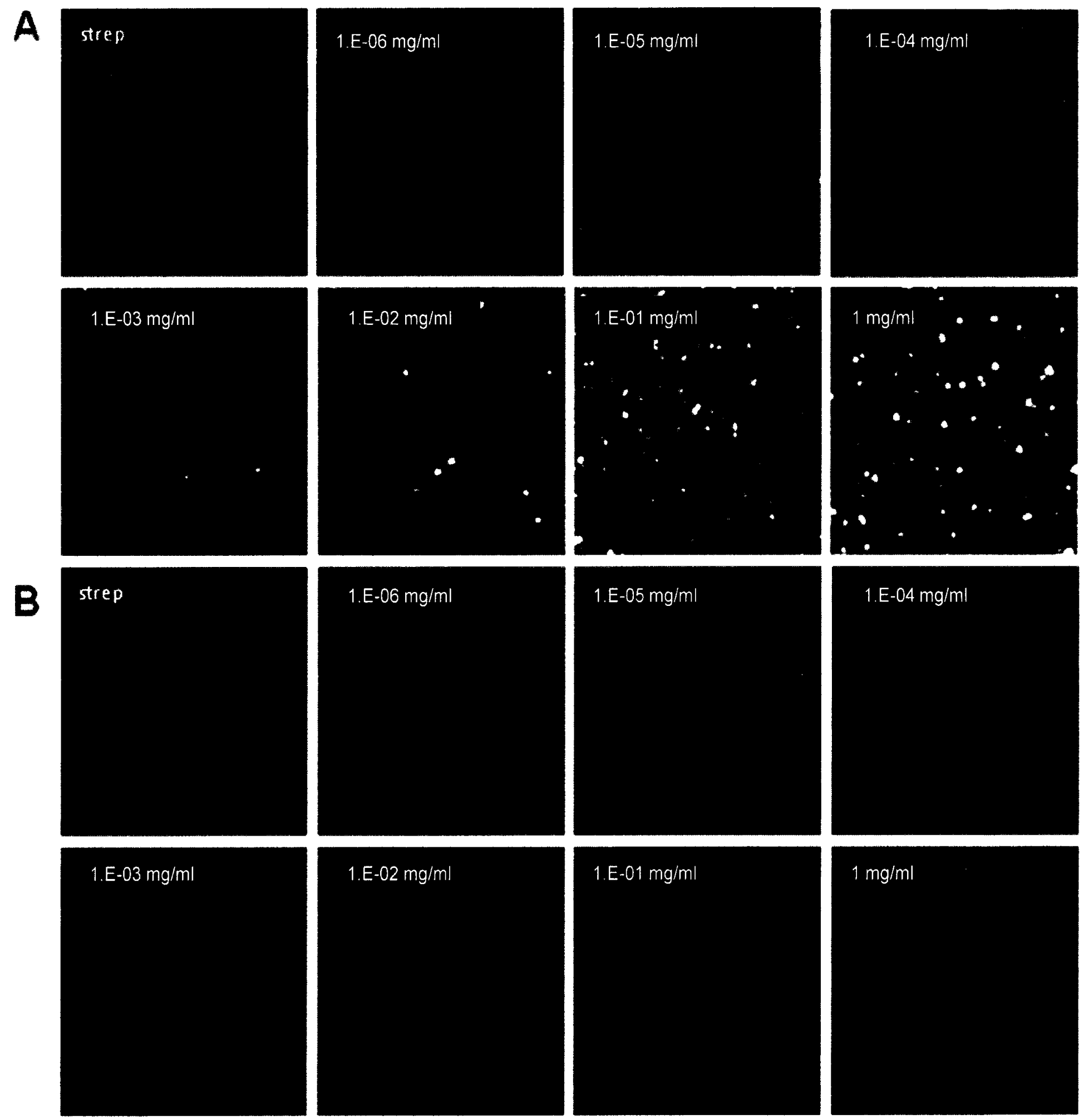


Figure 4.11 Sum intensity signals of Alexa 488-syn Ia incubated with TR-free LUVs immobilized on substrate- 2 and -3 . Intensities are plotted as a function of increasing protein concentration (A) and have been normalized in (B) in order to determine a synapsin I-anionic vesicle binding constant. A binding constant of $12.5 \mathrm{nM}$ was obtained from fitting the data a Hill equation. 

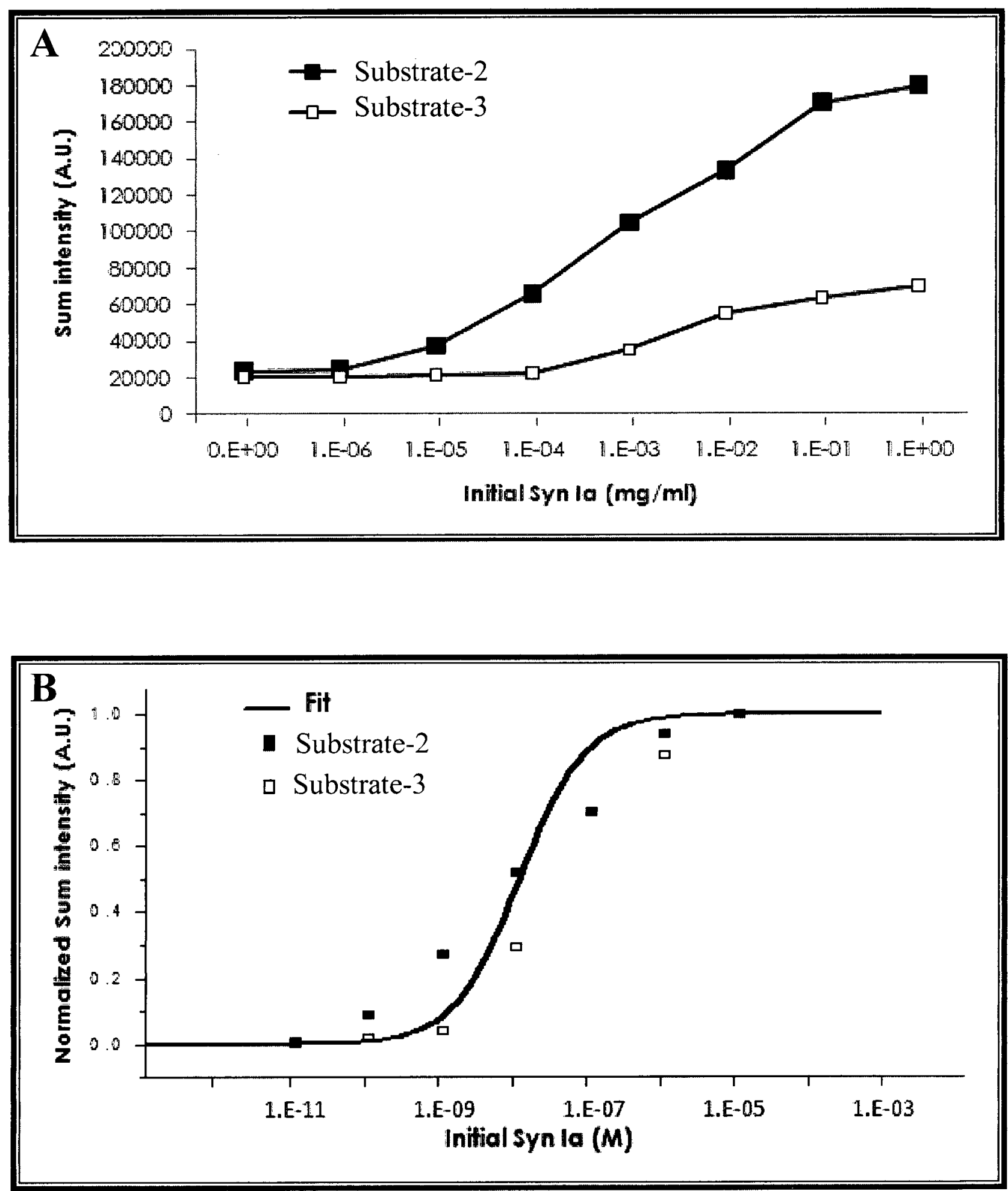
Figure 4.12 TIRF images of samples prepared with $1 \mathrm{mg} / \mathrm{mL}$ Alexa 488-syn Ia incubated on TRfree vesicles containing $10 \%$ PI-4,5-2P (A) and without (B) on substrate-2. Images are $27 \times$ $27 \mu \mathrm{m}^{2}$. 

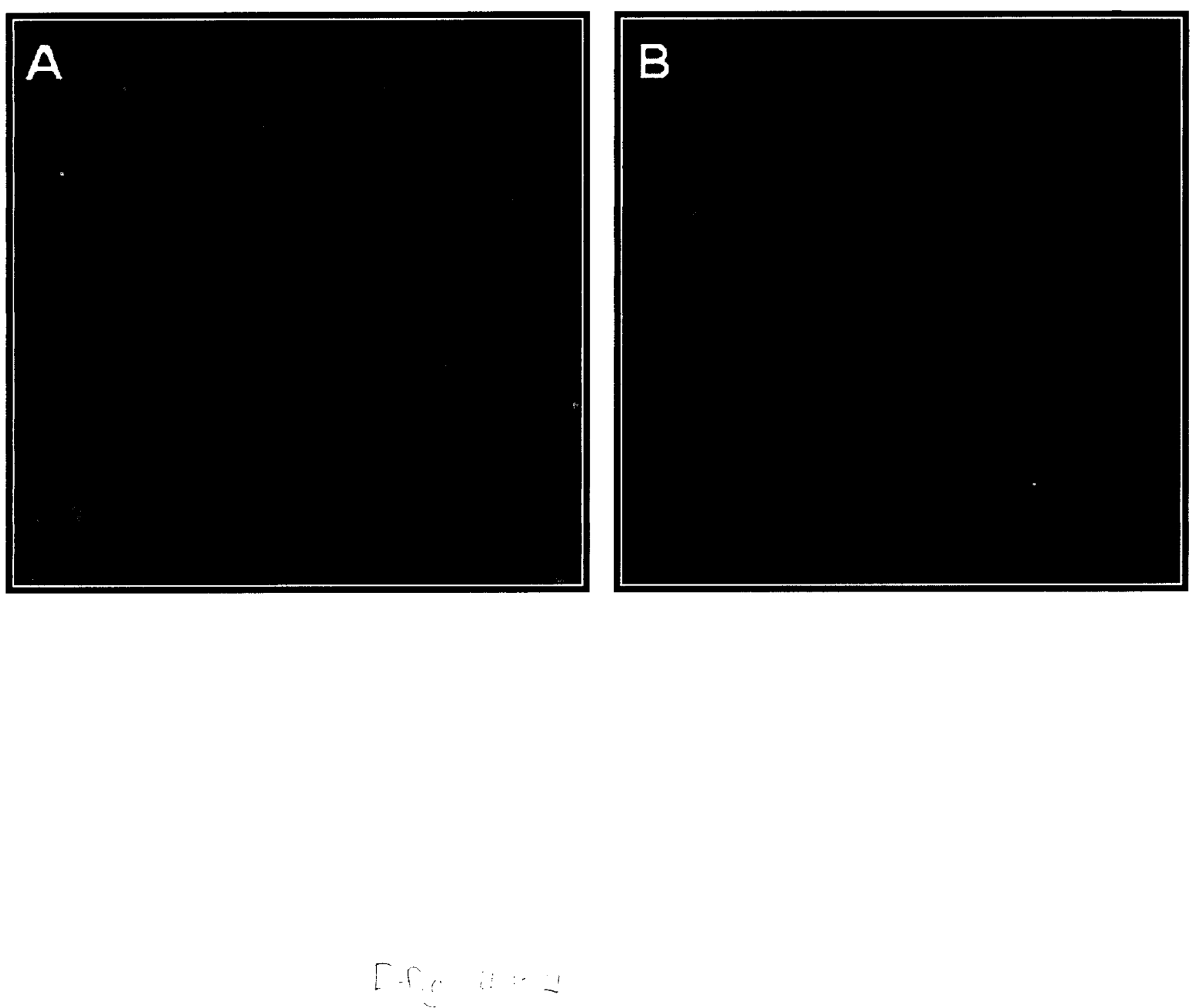


\subsection{DISCUSSION}

LUVs more closely resemble in vivo SVs due to their small size $(\sim 100 \mathrm{~nm})$ and surface curvature. Here, AFM was to be used to study the interaction of syn Ia with LUVs. LUVs containing both charged and uncharged lipids were functionalized with biotin molecules and immobilized on streptavidin treated glass substrates. Monitoring this multilayer construction, which also included addition of a BBSA monolayer prior to FITC-strept adhesion, was achieved by AFM. Results indicate increased surface roughness and coverage upon subsequent incubation of BBSA treated glass coverslips with streptavidin. Imaging vesicles however presented a problem. Because individual liposomes are more susceptible to lateral forces (Pignataro et al. 2000), scanning was unstable due to dragging and disruption of surface bound liposomes. Consequently, few liposomes were detected and those would often later disappear upon imaging the same area several times. To decrease the effect of lateral forces, one could image at reduced force using softer cantilever with small spring constant. Also, increasing vesicle-surface interactions by increasing the biotin-DHPE concentrations in our LUVs would render vesicles less susceptible to lateral forces.

In order to be able to directly detect the interaction of syn Ia with anionic LUVs, we utilized total internal reflective fluorescence microscopy. FITC-strept, LUVs and syn Ia were all functionalised with fluorescent probes, FITC, TR and Alexa 488, respectively. We first observed the binding of TR-LUVs to FITC-strept by monitoring the intensity of FITC and TR emission signals, respectively. This technique proved useful to demonstrate that i) streptavidin surface coverage is increased upon increasing the initial FITC-strept concentrations but saturates at 0.1 $\mathrm{mg} / \mathrm{mL}$, and ii) vesicle surface coverage increases linearly with the increasing streptavidin concentration. This technique did not however, allow us to directly visualize the specific binding 
vesicles to streptavidin based on co-localization because FITC fluorescence signal was being quenched by TR. Thus, upon merging TRIF images of FITC-strept and TR-vesicle for the same area, little to no pixels were coinciding. This also proved problematic for the study of syn Ia binding to LUVs because similar to FITC, Alexa 488 would also be quenched by TR. Nevertheless, the decreased fluorescence after LUV adsorption indirectly provides the evidence of specific binding of TR-vesicles to FITC-strept. Using unlabeled vesicles, we were able to estimate a dissociation constant $\left(\mathrm{K}_{\mathrm{d}}\right)$ of $12.5 \mathrm{nM}$ for the syn Ia interaction with anionic $(10 \% \mathrm{PI}-$ 4,5-2P ) vesicles. Hunter et al. 1983, showed that purified dephosphorylated syn Ia bound to syn I-depleted SVs with an affinity slightly higher $\left(\mathrm{K}_{d}=10 \mathrm{nM}\right)$ than observed here. Differences between these two values could be attributed to lipid composition, vesicle curvature ( $50 \mathrm{~nm}$ vs $100 \mathrm{~nm}$ ) or binding accessibility (our vesicles being tethered to the surface, syn Ia accessibility is reduced). Furthermore synapsins have been shown to have one or more binding partners on the vesicle that specifically target them to the membrane. Syn Ia was shown to interact to a vesicleassociated form of CaM kinase II (Benfenati et al. 1992) as well as a vesicle-associated form of c-src (Onofri et al. 2000). Absence of these binding partners in our system could lead to reduced syn Ia binding.

Syn Ia binding to SVs has exhibited the absolute requirement of acidic phospholipids (Benfenati et al. 1989b). To test this hypothesis, we also incubated Alexa 488-labeled syn Ia on LUVs without PI-4,5-2P. Our results indicate that the binding of synapsin is reduced but not completely eliminated upon incubation with neutral LUVs. Electrostatic interactions between the A-domain and anionic-phospholipids would account for $86 \%$ of the synapsin-vesicle interaction. Thus specific targeting of syn Ia to vesicles cannot merely be explained by the presence of the net surface negative charges but is likely to be mediated by membrane involved hydrophobic and 
non-specific interactions. PC liposomes negatively charged by inclusion of $10 \mathrm{wt} \%$ diacetyl phosphate were shown to bind syn Ia to a low extent and with low affinity (Benfenati et al. 1989a and b). This further indicates that synapsin-vesicle interactions are not merely because of the net surface negative charges, but also highly dependent on vesicle composition. Future direction of this study would also include determining the dissociation constant of the synapsinPC interaction, as well as syn Ia with different PI isomers. 


\section{GENERAL CONCLUSION}

Specific targeting of syn Ia to SVs was shown to be initiated by a somewhat specific surface electrostatic attraction between synapsin A-domain and charged vesicles lipids (Benfenati et al. 1989a). Scheibler and co-workers partially characterized the association of synapsin to SVs by demonstrating that purified dephosphorylated syn Ia bound to syn Iadepleted SVs with high affinity $\left(\mathrm{K}_{\mathrm{d}}=10 \mathrm{nM}\right)$ and saturability $(\mathrm{Bmax}=800 \mathrm{fmol} / \mu \mathrm{g}$ protein) (Hunter et al. 1983). This interaction was eliminated upon either increasing the ionic strength of the medium, or phosphorylating synapsin A-domain at Ser-9. In our study, investigation of the role of Ser-9 phosphorylation in the modulatory action of synapsins revealed that pseudophosphorylation of wildtype syn Ia did not result in the complete elimination of synapsinvesicle interaction (Figure 2.4). Furthermore, our combined AFM/fluorescence studies revealed that electrostatic interactions account for $86 \%$ of synapsin-vesicle interaction (Figure 4.12). These results suggest that the specific targeting of syn la to LUVs cannot be fully explained by syn Ia-A-domain interaction with the charged membrane surface and is likely to involve either other protein-lipid interactions or currently unidentified protein-protein interactions.

Of potential interest is the syn-Ia C-domain which has been shown to penetrate the hydrophobic core of SVs following the initial electrostatic interaction (Benfenati et al. 1989a; Cheetham et al. 2001) Amino acid sequence analyses revealed over $50 \%$ identity between vertebrate and invertebrate syn Ia C-domains, implying a crucial role for this domain in many of the conserved functions of synapsins (Hilfiker et al. 1999; Kao et al. 1999). We believe that the C-domain does more than simply anchor synapsins to the vesicle surface by working with the Adomain for vesicle recognition. Consequently, the fact that our wildtype syn Ia was found to bind preferentially to unphosphorylated PI and monophosphorylated derivatives (PI-3-P, PI-4-P, 
PI-5-P) versus other PI isomers can no longer only be attributed to A-domain electrostatic interactions. We conclude that (A) in our study, as well as others, synapsins are targeted to neutral vesicles (Murray et al. 2004) and (B) the C-domain is likely to be a PI binding domain as the C-domain binds ATP which share similar structural properties to PIP head groups (Hosaka and Südhof 1998).

It is of further interest to us to determine the importance of the syn Ia C-domain in vesicle recognition. AFM lends itself well to such a study as this technique has been used to measure binding forces of biomolecular interactions (Yoshimura et al. 2006; Park et al. 2006; Liu et al. 2007). In our study we have developed an efficient method to tether SVs to the scanning surface in a controlled fashion, one now only has to concentrate on coupling either full-length synapsin or synapsin peptides to the silicon nitride cantilever in order to obtain single molecule force measurements of the binding force between syn Ia-LUVs.

Of further interest would be to study the effect of lipid-peptide interactions on changes in synapsin domain structures. Our working hypothesis is that upon the arrival of action potential synapsins will undergo fast changes presumably to allow rapid release of the SV from the reserve pool, followed by slower structural changes over time. To date, only Benfenati et al. (1993a) were able elucidate syn I conformational changes upon vesicle binding noted by an increase in the alpha-helix content. To this aim, Raman spectrometry can be used to identify structural changes in synapsin vesicle binding domains upon (A) lipid-protein interactions and (B) A-domain phosphorylation. 


\section{SIGNIFICANCE OF THIS RESEARCH}

This research helps us to understand protein behaviour at the membrane interface and the factors regulating the activity of membrane-associated proteins. For example, membrane changes that occur in aging, such as increased cholesterol content, or increased lipid oxidation, may facilitate changes in the activities of peripheral membrane proteins such as synapsin. Changes in PI and PI isomer levels are important in modulating the SV cycle, and this research helps to clarify how these changes will affect synapsin binding to SVs.

This research also helps us to understand, at a molecular level, how proteins can selectively bind to different PI lipids, and how this binding is regulated. These findings help to clarify the roles of syn I in the presynaptic regulation of neurotransmitter release. 


\section{REFERENCES}

Bacia, K., C. G. Schuette, N. Kahya, R. Jahn and P. Schwille (2004). "SNAREs prefer liquiddisordered over "raft" (liquid-ordered) domains when reconstituted into giant unilamellar vesicles". J Biol Chem. 279:37951-5.

Bahler, M. and P. Greengard (1987). "Synapsin I bundles F-actin in a phosphorylationdependent manner." Nature 326:704-7.

Bahler, M., F. Benfenati, F. Valtorta, A. J. Czemik and P. Greengard (1989). "Characterization of synapsin I fragments produced by cysteine-specific cleavage: a study of their interactions with F-actin." J. Cell Biol. 108: 1841-9.

Bahler, M., F. Benfenati, F. Valtorta and P. Greengard (1990). "The synapsins and the regulation of synaptic function." Bioassays 12:259-63.

Baines, A. J. and V. Bennett (1985). "Synapsin I is a spectrin-binding protein immunologic ally related to erythrocyte protein 4.1." Nature 315: 410-3.

Baines, A. J. and V. Bennett (1986). "Synapsin I is a microtubule-bundling protein." Nature 319:145-7.

Benfenati, F., M. Bahler, R. Jahn and P. Greengard (1989a). "Interactions of synapsin I with small synaptic vesicles: distinct sites in synapsin I bind to vesicle phospholipids and vesicle proteins." J. Cell Biol. 108:1863-72.

Benfenati, F., P. Greengard, J. Brunner and M. Bahler (1989b). "Electrostatic and hydrophobic interactions of synapsin I and synapsin I fragments with phospholipid bilayers." J Cell Biol. 108:1851-62.

Benfenati, F., F. Valtorta, M. Bahler and P. Greengard (1989c). "Synapsin I, a neuronspecific phosphoprotein interacting with small synaptic vesicles and F-actin." Cell Biol. Int Rep 13:1007-21.

Benfenati, F., F. Valtorta, J. L. Rubenstein, F. S. Gorelick, P. Greengard and A. J. Czernik (1992). "Synaptic vesicle-associated Caz-s/calmodulin-dependent protein kinase 11 is a binding protein for synapsin 1." Nature 359:417-20.

Benfenati, F., F. Valtorta, P. Neyroz and P. Greengard (1993a). "Binding of synapsin I to synaptic vesicles: clues from the study of its interactions with liposomes." Liposome Res. 3:599-609.

Benfenati, F., F. Valtorta, M. C. Rossi, F. Onofri, T. Sihra and P. Greengard (1993b). "Interactions of synapsin I with phospholipids: possible role in synaptic vesicle clustering and in the maintenance of bilayer structures." J. Cell Biol. 123:1845-55. 
Carvalho, K., L. Ramos, C. Roy and C. Picart (2008). "Giant unilamellar vesicles containing phosphatidylinositol $(4,5)$ bisphosphate: characterization and functionality". Biophys. J. 95:4348-60.

Cheetham, J. J., S. Hilfiker, T. Weber, F. Benfenati, P. Greengard and A. J. Czernik (2001). "Identification of synapsin I peptide sequences that insert into lipid membranes." Biochem. J. 354:57-66.

Chin, L. S., L. Li and P. Greengard (1994). "Neuron-specific expression of the synapsin I gene is directed by a specific core promoter and upstream regulatory elements." J. Biochem. 269:18507-13.

Chin, L. S., L. Li, A. Ferreira, K. S. Kosik and P. Greengard (1995). "Impairment of axonal development and of synaptogenesis in hippocampal neurons of synapsin 1- deficient mice." Proc. Natl. Acad. Sci. USA 92:9230-34.

Chi, P., P. Greengard and T.A. Ryan (2003). "Synaptic vesicle mobilization is regulated by distinct synapsin I phosphorylation pathways at different frequencies". Neuron. 38:69-78.

Cole, R. N. and G. W. Hart (1999). "Glycosylation sites flank phosphorylation sites on synapsin 1: O-linked $\mathrm{N}$-acetylglucosamine residues are localized within domains mediating synapsin I interactions." J. Neurochem. 73:418-28.

Czernik, A. J., D. T Pang. and P. Greengard (1987). "Amino acid sequences surrounding the cAMP-dependent and calciumlcalmodulin-dependent phosphorylation sites in rat and bovine synapsin I." Proc. Natl. Acad. Sci. USA 84:7518-22.

De Camilli, P., R. Cameron and P. Greengard (1983a). "Synapsin I (protein I), a nerve terminalspecific phosphoprotein. I. Its general distribution in synapses of the central and peripheral nervous system demonstrated by immunofluorescence in frozen and plastic sections." J. Cell Biol. 96:1337-54.

De Camilli, P., S. M. Harris, W. B. Huttner and P. Greengard (1983b). "Synapsin I (Protein I), a nerve terminal-specific phosphoprotein. " J. Cell Biol. 96:1355-73.

De Camilli, P., F. Benfenati, F. Valtorta and P. Greengard (1990). "The Synapsins." Annu. Rev. Cell Biol. 6:433-60.

Deisenhofer, J., L. A. Chad, A. Brautigam and Y. Chelliah (2004). "Tetramerization and ATP Binding by a Protein Comprising the A, B, and C Domains of Rat Synapsin I" J. Cell Biol. 279:11948-56.

Dufrene Y. F. and G. U. Lee (2000). "Advances in the characterization of supported lipid films with the atomic force microscope." Biochim. Biophys. Acta. 1509:14-41. 
Esser, L., C. R. Wang, M. Hosaka, C. S. Smagula, T. C. Südhof and J. Deisenhofer (1998). "Synapsin I is structurally similar to ATP-utilizing enzymes." EMBO 17:977-84.

Ferreira, A., H. Q. Han, P. Greengard and K. S. Kosik (1995). "Suppression of synapsin 11 inhibits the formation and maintenance of synapses in hippocampal culture." Proc. Natl. Acad. Sci. USA 92:9225-9.

Ferreira, A., L. S. Chin, L. Li, L. M. Lanier, K. S. Kosik and P. Greengard (1998). "Distinct roles of synapsin I and synapsin 11during neuronal development." Mol. Med. 4:22-8.

Ferreira, A., H. T. Kao, J. Feng, M. Rapoport and P. Greengard (2000). "Synapsin III: developmental expression, subcellular localization, and role in axon formation." Neurosci. 20:3736-44.

Fiumara, F, S. Giovedì, A. Menegon, C. Milanese, D. Merlo, PG. Montarolo, F. Valtorta, F. Benfenati and M. Ghirardi (2004). "Phosphorylation by cAMP-dependent protein kinase is essential for synapsin-induced enhancement of neurotransmitter release in invertebrate neurons". J. Cell Sci. 117:5145-54.

Fiumara, F., C. Milanese, A. Corradi, S. Giovedì, G. Leitinger, A. Menegon, P.G. Montarolo, F. Benfenati and M. Ghirardi (2007)."Phosphorylation of synapsin domain A is required for post-tetanic potentiation." J. Cell Sci. 120:3228-37.

Fitzpatrick, H., P. F. Luckham, S. Eriksen and K. Hammond (1992). "Bovine serum albumin adsorption to mica surfaces" Collo. and Sur. 65:43-49.

Forstner, M. B., C. K. Yee, A.N. Parikh and J.T. Groves (2006). "Lipid lateral mobility and membrane phase structure modulation by protein binding." J. Am. Chem. Soc. 128:152217.

Greengard, P., F. Valtorta, A. J. Czernik and F. Benfenati (1993). "Synaptic vesicle phosphoproteins and regulation of synaptic function." Science 259:780-5.

Groves, J. T., R. Parthasarathy and M. B. Forstner (2008). " Fluorescence Imaging of Membrane Dynamics" Ann. Rev. Biom. Eng. 110: 890-5.

Hall, F. L., J. P. Mitchell and P. R. Vulliet (1990). "Phosphorylation of synapsin I at a novel site by proline-directed protein kinase." J. Biol. Chem. 265:6944-8.

Hammond, G. R. and G. Schiavo (2006). "Polyphosphoinositol lipids: under-PPInning synaptic function in health and disease". Dev. Neurobiol. 67:1232-47.

Han, H. Q. and P. Greengard (1994). "Remodeling of cytoskeletal architecture of nonneuronal cells induced by synapsin." Proc. Natl. Acad. Sci. USA 91(18): 8557- 61. 
Han, S. J., S. H. Hong, C. G. Kim, J. B. Lee, D. K. Choi, K. R. Kim and C. G.Kim (2004). "Synapsin IIb interacts with the C-terminal SH2 and SH3 domains of PLC gamma and inhibits its enzymatic activity". Cell Biol Int. 28:943-8.

Heuser, J. E. and T. S. Reese (1973). "Evidence for recycling of synaptic vesicle membrane during transmitter release at the frog neuromuscular junction." J. Cell Biol. 57:315-44.

Hilfiker, S., F. E. Schweizer, H. T. Kao, A. J. Czernik, P. Greengard and G. J. Augustine (1998). "Two sites of action for synapsin domain $\mathrm{E}$ in regulating neurotransmitter release." Nat Neurosci. 1:29-35.

Hilfiker, S., V. A. Pieribone, A. J. Czernik, H. T. Kao, G. J. Augustine and P. Greengard (1999). "Synapsins as regulators of neurotransmitter release." Biol. Sci. 354:269-79.

Hirokawa, N., K. Sobue, K. Kanda, A. Harada and H. Yorifuji (1989). "The cytoskeletal architecture of the presynaptic terminal and molecular structure of synapsin I." Cell Biol. 108:111-26.

Ho, M. F., M. Bahler, A. J. Czernik, W. Schiebler, F. J. Kezdy, E. T. Kaiser and P. Greengard (1991). "Synapsin I is a highly surface-active molecule." J. Biol. Chem 266: 5600-7.

Horton, M. R., J. Rädler and A. P. Gast. (2006). "Phase behavior and the partitioning of caveolin1 scaffolding domain peptides in model lipid bilayers". J Coll. Inter. Sci. 304:67-76.

Hosaka, M. and T. C. Südhof (1998). "Synapsins I and II are ATP-binding proteins with differential Ca2+ regulation." J. Biol. Chem 273:1425-9.

Hosaka, M. and T. C. Südhof (1998). "Synapsin Ill, a novel synapsin with an unusual regulation by Ca2+." J Biol. Chem. 273:13371-4.

Hosaka, M., R. E. Hammer and T. C. Südhof (1999). "A phospho-switch controls the dynamic association of synapsins with synaptic vesicles." J. Neuro. 24:377-87.

Hosaka, M. and T. C. Südhof (1999). "Homo- and heterodimerization of synapsins." J. Biol. Chem 274:16747-53.

Ira and L. J. Johnston (2008). "Sphingomyelinase generation of ceramide promotes clustering of nanoscale domains in supported bilayer membranes". Biochim. Biophys. Acta. 1778:18597.

Ira, S. Zou, D. M. Ramirez, S. Vanderlip, W. Ogilvie, Z. J. Jakubek and L. J. Johnston (2009). "Enzymatic generation of ceramide induces membrane restructuring: Correlated AFM and fluorescence imaging of supported bilayers". J. Struct. Biol. 168:78-89.

Jacob, R. F. and R. P. Mason (2005). "Lipid peroxidation induces cholesterol domain formation in model membranes. " J. Biol. Chem. 280:39380-7.. 
Johnson, E. M., H. Maeno and P. Greengard (1971). "Phosphorylation of endogenous protein of rat brain by cyclic adenosine 3',5'-monophosphate-dependent protein kinase." J. Biol. Chem. 246:7731-9.

Kao, H. T., B. Porton, A. J. Czernik, J. Feng, G. Yiu, M. Haring, F. Benfenati and P. Greengard (1998). "A third member of the synapsin gene family." Proc. Natl. Acad. Sci. USA 95:4667-72.

Kao, H. T., B. Porton, S. Hilfiker, G. Stefani, V. A. Pieribone, R. DeSalle and P. Greengard (1999). "Molecular evolution of the synapsin gene family." J. Exp. Zool. 285:360-77.

Klagges, B. R., G. Heimbeck, T. A. Godenschwege, A. Hofbauer, G. O. Pflugfelder, R. Reifegerste, D. Reisch, M. Schaupp, S. Buchner and E. Buchner (1996). "Invertebrate synapsins: a single gene codes for several isoforms in Drosophila." J. Neurosci. 16: 315465.

Li, L., L. S. Chin, P. Greengard, N. G. Copeland, D. J. Gilbert and N. A. Jenkins (1995). "Localization of the synapsin II (SYN2) gene to human chromosome 3 and mouse chromosome 6." J. Geno. 28:365-6.

Li, X., T. W. Rosahl, T. C. Südhof and U. Francke (1995). "Mapping of synapsin II (SYN2) genes to human chromosome $3 \mathrm{p}$ and mouse chromosome 6 band F." Cytogenet Cell Genet. 71:301-5.

Llinas, R., T. L. McGuinness, C. S. Leonard, M. Sugimori and P. Greengard (1985). "Intraterminal injection of synapsin I or calcium/calmodulin-dependent protein kinase IT alters neurotransmitter release at the squid giant synapse." Proc. Natl. Acad. Sci. USA 82:3035-9.

Liu, D., L. Ge, F. Wang, H. Takahashi, D. Wang, Z. Guo, S. H. Yoshimura, T. Ward, X. Ding, $\mathrm{K}$. Takeyasu and X. Yao (2007). "Single-molecule detection of phosphorylation-induced plasticity changes during ezrin activation". FEBS Lett. 581:3563-71.

Lu, B., A. J. Czernik, S. Popov, T. Wang, M. M. Poo and P. Greengard. (1996) "Expression of synapsin I correlates with maturation of the neuromuscular synapse" Neuroscience 74:1087.

Martinez, K. L., B. H. Meyer, H. Ruud, L. Kenneth and V. Horst (2003). "Ligand binding to G protein-coupled receptors in tethered cell membranes." Langmuir 19:10925-29.

Matsubara, M., M. Kusubata, K. Ishiguro, T. Uchida, K. Titani and H. Taniguchi (1996). "Sitespecific phosphorylation of synapsin I by mitogen-activated protein kinase and CdkS and its effects on physiological functions." J. Biol. Chem 271:21108-13. 
Monaldi, I., M. Vassalli, A. Bachi, S. Giovedì , E. Millo, F. Valtorta, R. Raiteri, F. Benfenati and A. Fassio (2010). "The highly conserved synapsin domain $\mathrm{E}$ mediates synapsin dimerization and phospholipid vesicle clustering. " Biochem. J. 426:55-64.

Murray, J., L. Cuccia, A. Ianoul, J. J. Cheetham and L. J. Johnston (2004). "Imaging the selective binding of synapsin to anionic membrane domains". J. Biol. Chem. 5:1489-94.

Navone, F., P. Greengard and P. De Camilli (1984). "Synapsin I in nerve terminals: selective association with small synaptic vesicles." Science 226: 1209-11.

Nidumolu, B. G., M. C. Urbina, J. Hormes, C. S. Kumar, W. T. Monroe (2006). "Functionalization of gold and glass surfaces with magnetic nanoparticles using biomolecular interactions". Biotechnol. Prog. 22:91-5.

Onofri, F., S. Giovedi, P. Vaccaro, A. J. Czernik, F. Valtorta, P. De Camilli, P. Greengard and F. Benfenati (1997). "Synapsin I interacts with c-Src and stimulates its tyrosine kinase activity." Proc. Natl. Acad. Sci. USA 94:12168-73.

Onofri, F., S. Giovedi, H. T. Kao, F. Valtorta, L. B. Borbone, P. De Camilli, P. Greengard and F. Benfenati (2000). "Specificity of the binding of synapsin I to Src homology-3 domains." J. Biol. Chem. 3: 1270-76.

Osborne, S., P. J. Wen and F. A. Meunier (2006). "Phosphoinositide regulation of neuroexocytosis: adding to the complexity" J. Neurochem. 98:336-42.

Park, J. H., E. Y. Kwon, H. I. Jung and D. E. Kim (2006). "Direct force measurement of the interaction between liposome and the $\mathrm{C} 2 \mathrm{~A}$ domain of synaptotagmin I using atomic force microscopy". Biotechnol. Lett. 28:505-9.

Pieribone, V. A., O. Shupliakov, L. Brodin, S. Hilfiker-Rothenfluh, A. J. Czernik and P. Greengard (1995). "Distinct pools of synaptic vesicles in neurotransmitter release" Nature 375(6531): 493-7.

Pignataro, B., C. Steinem, H. J. Galla, H. Fuchs and A. Janshoff (2000). " Specific adhesion of vesicles monitored by scanning force microscopy and quartz crystal microbalance". Biophys. J. 78:487-98.

Porton, B., H. T. Kao and P. Greengard (1999). "Characterization of transcripts from the synapsin III gene locus." J Neurochem. 73: 2266-71.

Pramanik, A., P. Thyberg and R. Rigler (2000). "Molecular interactions of peptides with phospholipid vesicle membranes as studied by fluorescence correlation spectroscopy". Chem. Phys. Lipids. 104:35-47.

Reinhard, J., W. Schiebler and P. Greengard (1984). "A quantitative dot-immunobinding assay for proteins using nitrocellulose membrane filters. " Proc. Natl. Acad. Sci. USA 81:1684-7. 
Rhoades, E., T. F. Ramlall, W. W. Webb and D. Eliezer (2006). "Quantification of alphasynuclein binding to lipid vesicles using fluorescence correlation spectroscopy". Biophys. J. 90:4692-700.

Rohrbough, J. and K. Broadie (2005). "Lipid regulation of the synaptic vesicle cycle" Nat. Rev. Neurosci. 6:139-50.

Rosahl, T. W., D. Spillane, M. Missler, J. Herz, D. K. Selig, J. R. Wolff, R. E. Hammer, R. C. Malenka and T. C. Südhof (1995). "Essential functions of synapsins I and Il in synaptic vesicle regulation [see comments]." Nature 375:488-93.

Rusu, L., A. Gambhir, S. McLaughlin and J. Rädler (2004). "Fluorescence Correlation Spectroscopy Studies of Peptide and Protein Binding to Phospholipid Vesicles" Biophys. J. 87:1044-53.

Schaeffer, E., J. Alder, P. Greengard and M. M. Poo (1994). "Synapsin Ha accelerates functional development of neuromuscular synapses." Proc. Natl. Acad. Sci. USA 91:3882-6.

Schiebler, W., R. Jahn, J. P. Doucet, J. Rothlein and P. Greengard (1986). "Characterization of synapsin Ibinding to small synaptic vesicles" J. Biol. Chem. 261:8383-90.

Sieghart, W., J. Fom, R. Schwarcz, J. T. Coyle and P. Greengard (1978). "Neuronal localization of specific brain phosphoproteins." Brain Res 156: 345-50.

Sihra, T. S., J. K. Wang, F S. Gorelick and P. Greengard (1989). "Translocation of synapsin lin response to depolarization of isolated nerve terminals." Proc. Natl. Acad. Sci. USA 86: 8108-12.

Südhof, T. C., A. J. Czernik, H. T. Kao, K. Takei, P. A. Johnston, A. Horiuchi, S. D. Kanazir, M. A. Wagner, M. S. Perin and P. De Camilli (1989). "Synapsins: mosaics of shared and individual domains in a family of synaptic vesicle phosphoproteins." Science 245: 147480 .

Südhof, T. C. (1990). "The structure of the human synapsin I gene and protein." J. Biol. Chem. 265:7849-52.

Südhof, T. C., M. Hosaka and R. E. Hammer, (1999). "A phospho-switch controls the dynamic association of synapsins with synaptic vesicles". Neuron. 24:377-87.

Takamori S, M. Holt, K. Stenius, E. A. Lemke, M. Grønborg, D. Riedel, H. Urlaub, S. Schenck, B. Brügger, P. Ringler, S.A. Müller, B. Rammner, F. Gräter, J. S. Hub, B. L. De Groot, G. Mieskes, Y. Moriyama, J. Klingauf, H. Grubmüller, J. Heuser, F. Wieland and R. Jahn (2006). "Molecular anatomy of a trafficking organelle". Cell. 127:831-46. 
Takei, Y., A. Harada, S. Takeda, K. Kobayashi, S. Terada, T. Noda, T. Takahashi and N. Hirokawa (1995). "Synapsin I deficiency results in the structural change in the presynaptic terminals in the murine nervous system." J. Cell Biol. 131:1789-800.

Valtorta, F, F. Benfenati and P. Greengard (1992a). "Structure and function of the synapsins." J. Biol. Chem. 267:7195-8.

Valtorta, F., P. Greengard, R. Fesce, E. Chieregatti, and F. Benfenati (1992b). "Effects of the neuronal phosphoprotein synapsin I on actin polymerization. I. Evidence for a phosphorylation-dependent nucleating effect". J. Biol Chem. 267:11281-8.

Yang-Feng, T. L., L. J. DeGennaro and U. Francke (1986). "Genes for synapsin I, a neuronal phosphoprotein, map to conserved regions of human and murine X chromosomes." Proc. Natl. Acad. Sci. USA 83:8679-83.

Yoshimura, S. H., H. Takahashi, S. Otsuka and K. Takeyasu (2006). "Development of glutathione-coupled cantilever for the single-molecule force measurement by scanning force microscopy". FEBS Lett. 580:3961-5.

Weerachatyanukul, W., I. Probodh, K. Kongmanas, N. Tanphaichitr and L. J. Johnston (2007). "Visualizing the localization of sulfoglycolipids in lipid raft domains in model membranes and sperm membrane extracts". Biochim. Biophys, Acta. 1768 :299-310.

Zhan, H. (1999). "A method for quick measurement of protein binding to unilamellar vesicles." J. Biochem. Biophys. Methods 41:13-9. 